Establishing a 200-Mile Fisheries Zone

June 1977

NTIS order \#PB-273578

\section{Establishing a 200-Mile Fisheries Zone}

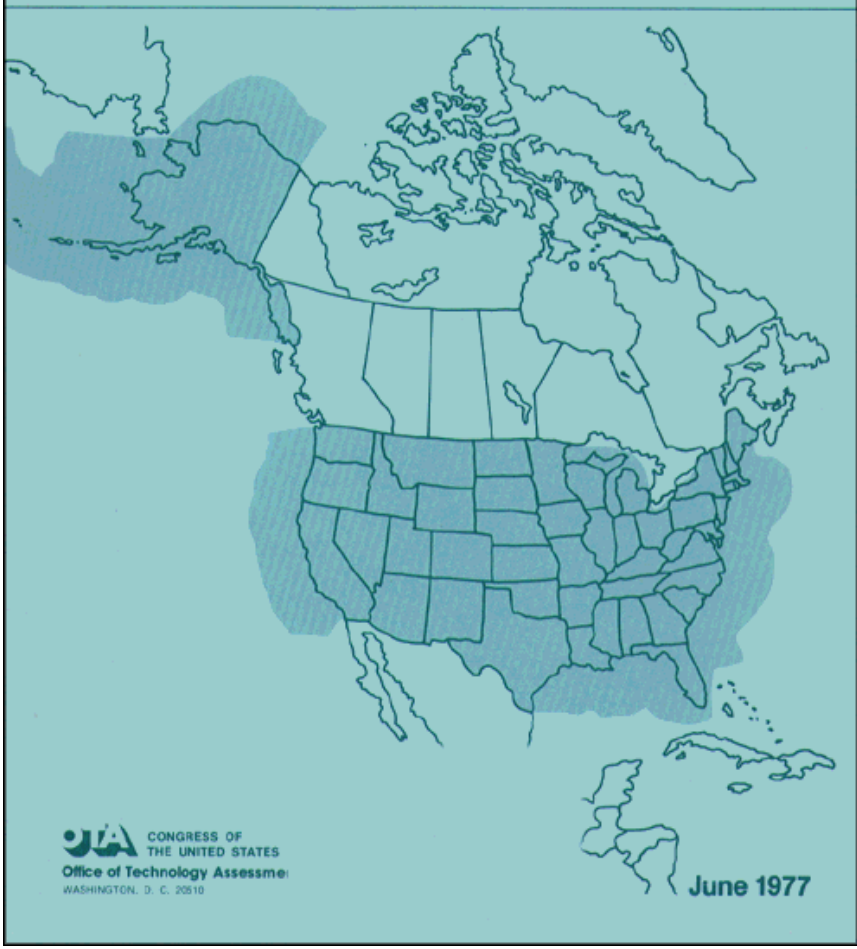




\section{Establishing a 200-Mile" Fisheries Zone}

OTA OCEANS PROGRAM STAFF

Robert W. Niblock, Program Manager

Peter A. Johnson, Project Director

Prudence S. Adler

Kathleen A. Beil

Thomas A. Cotton

Renee M. Crawford
Emilia L. Govan

Richard C. Raymond

Judith M. Roales

Bennett L. Silverstein

\section{- I'.) CONGRESS OF \\ THE UNITED STATES \\ Office of Technology Assessment \\ WASHINGTON, D. C. 20510}

Library of Congress Catalog Card Number 77-600021

For sale by the Superintendent of Documents, U.S. Government Printing Office

Washington, D.C, 20402 
The Honorable Ernest F. Hollings

Chairman

National Ocean Policy Study

United States Senate

Washington, D. C. 20510

The Honorable John P. Murphy

Chairman

Merchant Marine and Fisheries Committee

U.S. House of Representatives

Washington, D.C. 20515

Dear Mr. Chairmen:

On behalf of the Board of the Office of Technology Assessment, we are forwarding to you the report, Establishing a 200-Mile Fisheries Zone.

This report concludes OTA's assessment of important problems and opportunities which result from implementation of the Fishery Conservation and Management Act of 1976, which became effective March 1 of this year.

The assessment was conducted in accord with a request from the Senate National Ocean Policy Study in January 1974, and a subsequent request by the House Merchant Marine and Fisheries Committee.

A draft of this report was made available to the committees in March 1977, and the final report was approved by the Technology Assepment Board on April 19, 1977.

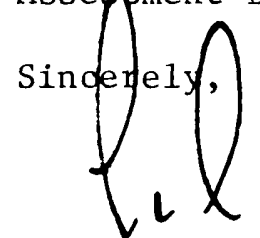

Edward M. Kennedy Chairman

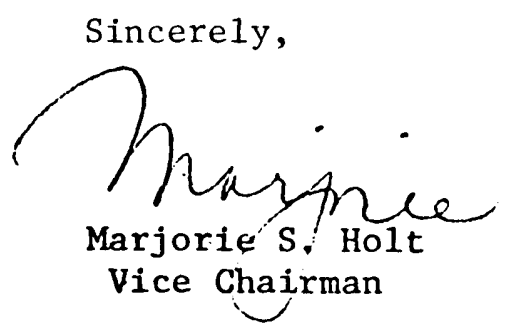


The Honorable Edward M. Kennedy

Chairman of the Board

Office of Technology Assessment

U.S. Congress

Washington, D. C. 20510

Dear Mr. Chairman:

The enclosed report, Establishing a 200-Mile Fisheries Zone, presents OTA's analysis of important problems and opportunities which result from implementing the Fishery Conservation and Management Act of 1976.

The assessment which led to this report was requested by the Chairmen of the Senate National Ocean Policy Study and the House Merchant Marine and Fisheries Committee. The assessment was conducted by the Oceans Program staff of OTA with input from representatives of the fishing industry and government agencies which are involved in carrying out provisions of the legislation which extended U.S. jurisdiction over commercial fisheries out to the 200-mile limit.

The report analyzes four major aspects of the new fisheries law: 1) enforcement of fisheries regulations and U.S. jurisdiction over the fishery zone; 2) management of the new fishery zone; 3) information which will be needed for implementation of the law; and 4) opportunities for expanding and revitalizing the U.S. fishing industry as a result of implementation of the law. Among the conclusions of the report are suggestions for four pilot projects which could aid Federal agencies in determining the most successful and cost-effective means of implementing certain aspects of the law.

This transmittal includes two volumes: the assessment report and working papers which provide back-up material for discussions in the report.

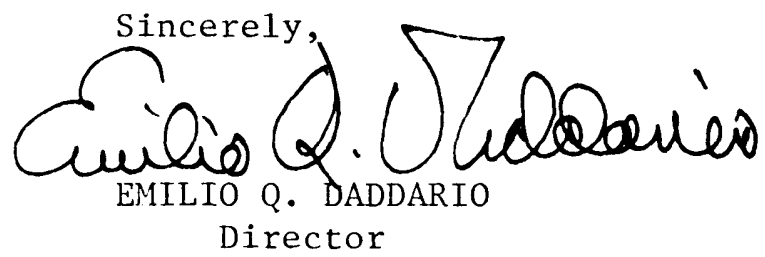




\section{Acknowledgements}

The staff wishes to acknowledge the assistance and cooperation of the following contractors and consultants in the gathering and formulation of the background data:

James M. Acheson, University of Maine Frederick W. Bell, Florida State University Development Sciences Inc., East Sandwich, Massachusetts

Douglas Campbell

Eastland Resolution Fisheries Survey, Atlantic, Pacific, and Gulf State Marine Fisheries Commissions

John M. Gates, University of Rhode Island
William Jensen, Willamette University, Oregon

Stanford Research Institute, Menlo Park, California

Synergy Inc., Washington, D.C.

Robert M. Snyder, Jupiter, Florida

Robert E. Taber, University of Rhode Island

John Vernberg, University of South Carolina

The staff further wishes to acknowledge the assistance of former OTA staff member Cynthia Mercing, who worked on the early development of this study, and those other people and organizations, both public and private, which reviewed and commented on various draft documents circulated by OTA or provided other types of assistance:

William T. Burke, University of Washington

Francis T. Christy, Resources for the Future

Patrick J. Doody, Zapata-Haynie Corp.

David J. Etzold, Univeristy of Southern Mississippi

Wade L. Griffin, Texas $A$ \& $M$ University

Sig Jaeger, North Pacific Fishing Vessel Owners Assn.

Lauriston R. King, National Science Foundation

J.L. McHugh, State University of New York

William G. Mustard, Atlantic States Fishcries Commission

Virgil Norton, University of Rhode Island

Susan B. Peterson, Woods Hole Oceanographic Institution
Gilbert C. Radonski, Sport Fishing Institute

Courtland L. Smith, Oregon State University

Richard Stroud, Sport Fishing Institute

U.S. Department of Commerce, National Marine Fisheries Service

U.S. Department of Defense, Office of the Oceanographer of the Navy

U.S. Department of State, Oceans and Fisheries Affairs

U.S. Department of Transportation, Coast Guard

Lee Weddig, National Fisheries Institute

Walt V. Yonker, Association of Pacific Fisheries 


\section{Preface}

This report, "Establishing a 200-Mile Fishery Zone," is the result of a study of the major problems and opportunities which may occur because of the Fishery Conservation and Management Act of 1976. The study was requested by Senator Ernest F. Hollings on behalf of the Senate National Ocean Policy Study in January 1974, and by former Representative Lenore K. Sullivan of the House Merchant Marine and Fisheries Committee in April 1974. Upon retirement, Mrs. Sullivan was replaced by Representative John Murphy as Chairman of that Committee. These requests were endorsed by Senator Edward M. Kennedy in September 1975, and subsequently approved for execution by the Technology Assessment Board.

The report was prepared by the Oceans Program staff of OTA with the assistance of advisors from the fishing industry, Government, and academia who reviewed draft materials and provided guidance.

The work undertaken by the Office of Technology Assessment, and reported in this document, was confined to evaluation of techniques which will be used for enforcing regulations in the 200-mile fishery zone, problems which may be encountered in the management of fisheries, and information which will be needed in order to implement the Fishery Conservation and Management Act of 1976. This limited scope made it possible for OTA to offer specific criticism of existing systems and specific suggestions for congressional action to further improve fisheries conservation and management.

The Technology Assessment Board, governing body of OTA, approves the release of this report, which identifies a range of viewpoints on a significant issue facing the U.S. Congress. The views expressed in this report are not necessarily those of the Board, the OTA Advisory Council, or of individual members thereof. 


\section{Table of Contents}

PAGE

LIST OF WORKING PAPERS .......................... ix

LIST OF FIGURES . . . . . . . . .

Chapter 1

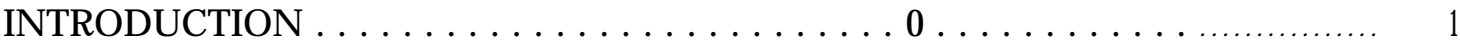

Chapter 11

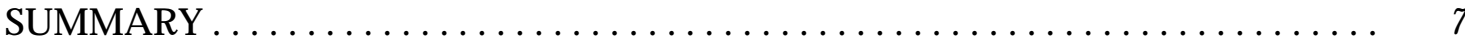

Chapter III

ENFORCEMENT. . . . . . . . . . . . . . . . . . . . . . . . . . . . . . . . 19

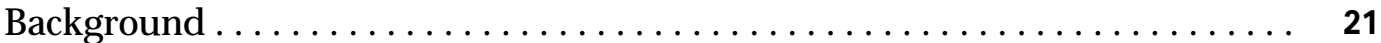

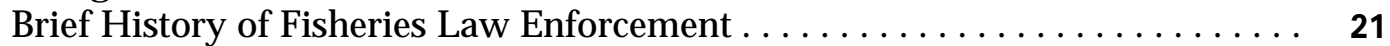

Requirements of the Law ............................ 23

Present Plans for Near-Term Enforcement . . . . . . . . . . . . . . . . . . . . . 24

Level of Enforcement, . . . . . . . . . . . . . . . . . . . . . . . . 27

Existing Capabilities............................. 29

Other Possibilities for Near-Term Enforcement. . . . . . . . . . . . . . . . . 38

Recommended Pilot Project ....................... 42

Possibilities for Long-Range Enforcement. . . . . . . . . . . . . . . . . 43

Recommended Pilot Project ...................... 43

New Technologies.................................. 45

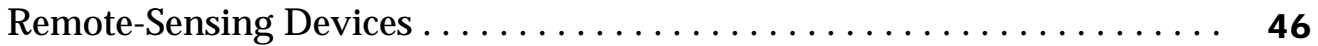

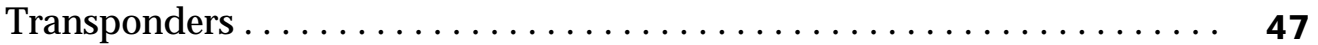

Microwave Radar ............................ 50

Over-the-Horizon Radar . . . . . . . . . . . . . . . . . . . . . . . . . . . . . . . 52

Microwave Radiometry, ......................... 53

Optical and Electro-Optical Techniques . . . . . . . . . . . . . . . 55

Electromagnetic Intercept Techniques . . . . . . . . . . . . . . . . . . . 57

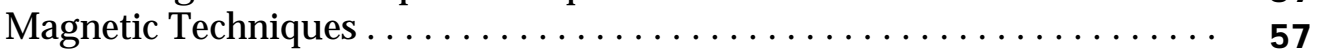

Acoustic Techniques. ........................... 58 
Chapter IV

MANAGEMENT OF NEW U.S. FISHERIES ZONE ., . . . . . . . . . . . . . . . . . 59

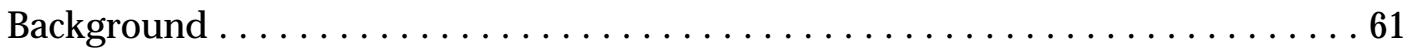

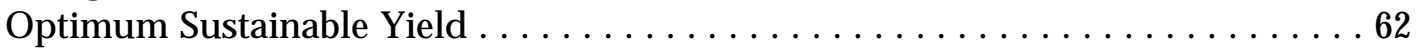

Regional Fishery Management Councils . . . . . . . . . . . . . . . . 63

Preliminary Management Plans for Foreign Fisheries . . . . . . . . . . . . . . . 69

Final Management Plans for Domestic Fisheries. . . . . . . . . . . . . . . 73

Evaluation of Management Effectiveness. ........ . . . . . . . . . . 74

Chapter $\mathrm{V}$

INFORMATION NEEDS FOR IMPLEMENTATION OF PUBLIC LAW 94-265... 75

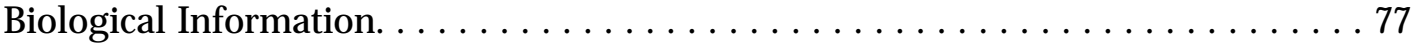

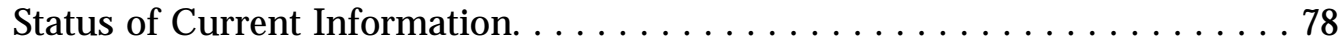

Methods of Improving Information Base..... . . . . . . . . . . . . . . . . . 79

Economic Information. . . . . . . . . . . . . . . . . . 81

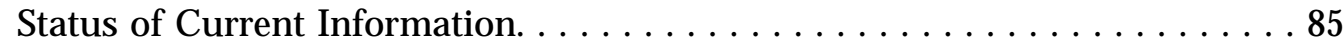

Methods of Improving Information Base,$\ldots \ldots \ldots \ldots \ldots \ldots$

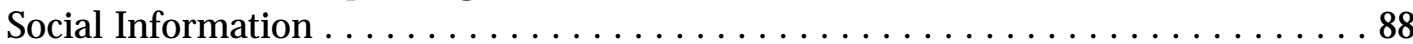

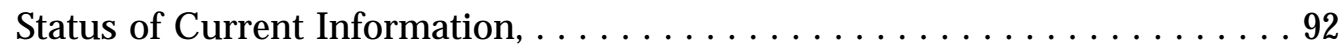

Methods of Improving Information Base.... . . . . . . . . . . . . . . . . . 92

Chapter VI

FUTURE DEVELOPMENTS IN THE FISHING INDUSTRY. . . . . . . . . . . 93

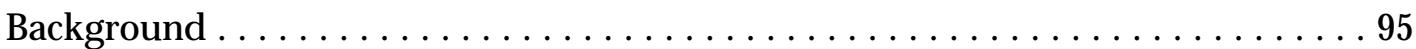

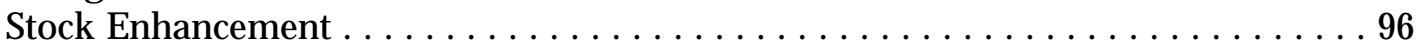

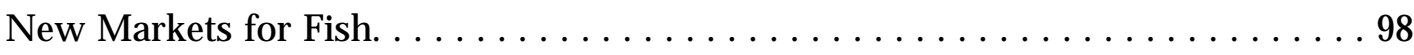

Revitalization of Fishing Industry . . . . . . . . . . . . . . 99

Chapter VII

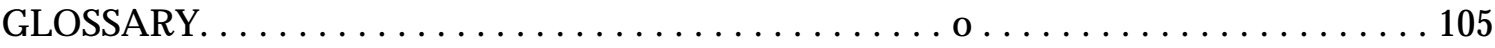

Chapter VIII

FOOTNOTES . . . . . . . . . . . . . . . . . . . . . . . . . . 109

Chapter IX

FISHERY CONSERVATION AND MANAGEMENT ACT . . . . . . . . . . . . . . . 115 


\section{List of Working Papers}

Working Paper No. 1: Economic Data Needs in Fisheries Management Under Extended Jurisdiction by John M. Gates

Working Paper No. 2: Social Data Needs in Fisheries Management Under Extended Jurisdiction by James M. Acheson, University of Maine

Working Paper No. 3: Marine Fisheries Stock Assessment: Issues and Needs by Development Sciences Inc.

Working Paper No. 4: A Short Analysis of Stock Enhancement Possibilities for Certain Commercially Important Marine Species by John Vernberg, University of South Carolina

Working Paper No. 5: Survey of the Potential of Remote Sensing Technology to Support Enforcement of the 200-Mile Fishing Zone by Stanford Research Institute 


\section{List of Figures}

Figure No.

1 U.S. Landings, Imports, and Consumption of Edible Fishery Products. . . . .

2 Overfished Species of Importance to U.S. Fisheries as of August 1975 . . . . .

3 Historic World and U.S. Landings of Fish and Shellfish. . . . . . . . . . . . .

4 Summary of Fisheries Regulations, Where Proposed, Effectiveness of Selected Surveillance Techniques. ............................

5 Expected Number of Undetected Violations by Month Under "No Effort," FY 75 Level, and Planned Enforcement. . . . . . . . . . . . . . . . . . . . . . . .

6 Planned Coast Guard Aircraft Patrols - New England. . . . . . . . . . . . . . . . . . .

7 Planned Coast Guard Aircraft Patrols - Mid Atlantic . . . . . . . . . . . . . . . . . . .

8 Planned Coast Guard Aircraft Patrols - Gulf of Mexico . . . . . . . . . . . . . . . . .

9 Planned Coast Guard Aircraft Patrols - West Coast. . . . . . . . . . . . . . . . . . . . . .

10 Planned Coast Guard Aircraft Patrols - Alaska. . . . . . . . . . . . . . . . . .

11 Possible Flow of Surveillance Data. . . . . . . . . . . . . . . . . . .

12 Summary of the Potential of Remote-Sensing Technology To Support Enforcement of the 200-nmi Fishing Zone . . . . . . . . . . . . . . . .

13 Useful Surveillance Coverage by a State-of-the-Art Microwave Radar . . . . .

14 Over-the-Horizon Radar . . . . . . . . . . . . . . . . . . . . . . . . . . . . . . . . . .

15 Over-the-Horizon Radar Coverage From Hypothetical Stations. . . . . . . . . . . .

16 Airborne Scanning Microwave Radiometer ....................

17 Regional Council Jurisdictions and National Marine Fisheries Service

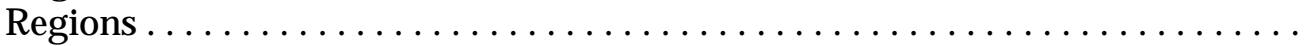

18 Appointed Voting Members of Regional Councils . . . . . . . . . . . . . . . . . . .

19 Duties of Regional Council and National Marine Fisheries Service . . . . . . . .

20 Fishery Management Plans, as of February $1977 \ldots$. . . . . . . . . . . . . . . . . . .

21 Preliminary Management Plan Allocations . . . . . . . . . . . . . . .

221977 Northeast Stock Assessment and U.S. and Foreign Quotas . . . . . . . . . . .

23 Summary of Projected Program Costs for Economic Data Collection . . . . . .

24 Nature and Effect of Canadian Government Subsidies at Each Level of Canadian Groundfish Industry. . . . . . . . . . . . . . . . . . . . . . 100

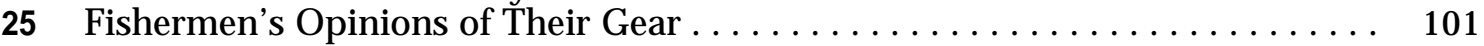

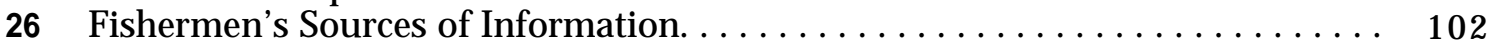




\section{Introduction}


Fish are an important part of man's pattern of survival.

Directly-that is, fish and shellfish consumed by man-fish provide about 14 percent of the world's supply of animal protein. The Food and Agricultural Organization (FAO) of the United Nations has estimated that every man, woman, and child in the world consumes an average of 26 pounds of fish each year. ${ }^{1}$ However, that figure varies greatly from country to country, ranging from only a small fraction-of-a-pound per person per year in Afghanistan to more than 86 pounds per person per year in Iceland, In the United States, the average consumption per person is about 12 pounds of fish annually. $\mathrm{z}$ According to FAO the consumption of fish is likely to increase through 1990 at a growth rate higher than that of beef, pork, vegetables, cereal, or milks This suggests increasing pressure on already heavily utilized ocean resources worldwide in the next 10 years,

Indirectly-in the form of meal and oil fed to pigs and chickens which are in turn eaten by man-fish provide another 10 or 11 percent of the world's animal protein. ${ }^{4}$

Twenty years ago, the United States was the world's second largest fishing nations But by 1974 American fisherman were fifth, catching only 4 percent of the world's supply of fish. In that time, the U.S. catch had dropped only about 8 percent, but the catch of some foreign nations had increased by as much as 250 percent. In 1974, the world catch was nearly 70million metric tons. $s$ Much of that was coming from waters off the United States where, within 200 miles of the coasts, about one-fifth of the world's fishery resources are located. Worldwide, the National Oceanic and Atmospheric Administration has projected that the oceans can sustain an annual catch of only 100-million metric tons, a catch figure they expect to be reached by $1980 .{ }^{10}$ Already, increased fishing has caused acute pressure on some stocks, depleting the supply and threatening their existence. For example, off the coast of the United States about 20 species of fish and shellfish are believed to be seriously depleted ${ }^{11}$ (see figures 1 and 2 ).

\section{Figure 1}

\section{U.S. Landings, Imports, and Consumption of Edible Fishery Products}

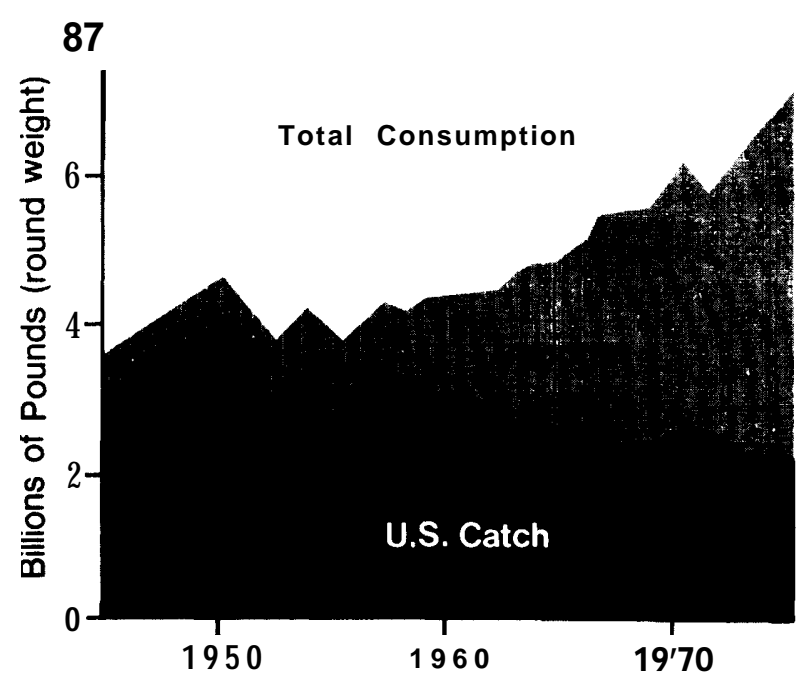

Source: U.S. Department of Commerce, National Oceanic and Atmospheric Administration 

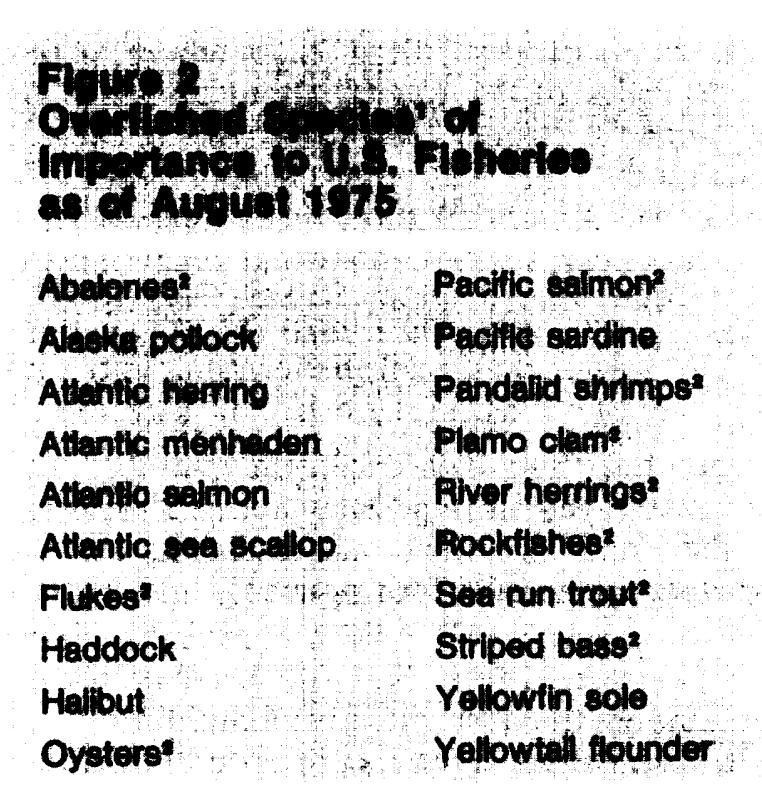

'Soma atoeks haya been go roduced throuch overfishing or wy of ing ind tosd or natural cause, that a subs with reduction in flahing effort must be achieved so that stocks can replenish themselves to produce optimum yleld.

${ }^{2}$ Not all stocks depleted.

Source: U.S. Department of Commerce, National Oceanic and Atmospheric Administration

Historically, access to fishing grounds has been uncontrolled. Fish have been a commonproperty resource, available to any and all nations and individuals who seek to hunt them and harvest them. This common-property nature has prevented any one nation from assuming management control and has made regulation of the catch difficult. Conservation of stocks has not been successful in spite of international agreements and treaties with other fishing nations.

As a result, technically sophisticated foreign fishing fleets have taken a heavy toll in traditional U.S. fisheries, particularly off the northeast and northwest coasts where there are several species of prime interest to U.S. com- mercial fishermen and consumers. The decline of the New England haddock fishery which was reduced from a major commercial enterprise in 1950 to a relatively small activity today, is a principal example of the effects of overfishing within 200 miles of the U.S. coasts. The U.S. haddock catch in 1950 was 20 times larger than it was in $1974 .^{12}$ Total catch of other important commercial species, such as flounder and ocean perch, also declined as overfishing reduced the amount of stock available (see figure 3 ).

In response to widespread public concern about overfishing, the U.S. Congress moved to adopt a 200-mile fishery zone to give the United States power to limit or exclude foreign fishing off its coasts and impose on both foreign and U.S. fishermen responsibilities for conservation and utilization of the fishery resources within the zone.

In passing the Fishery Conservation and Management Act of 1976 (P.L. 94-265), Congress officially noted that certain stocks of fish off the coasts of this country "have been overfished to the point where their survival is threatened and other such stocks have been so substantially reduced in number that they could become similarly threatened." ${ }^{13}$

The law made it the policy of the United States to establish a "workable and effective" fisheries management and conservation program based on the best scientific information available, involving interested States and citizens, and drawing on Federal, State, and academic capabilities to carry out research, administration, management, and enforcement. ${ }^{14}$

On March 1, 1977, the law went into effect. A beginning was made toward reaching the difficult goals of conserving, managing, and developing the fisheries off U.S. coasts. To accomplish these goals, the law establishes Regional Councils--groups which reflect the expertise and interests of the States along each 


\section{Figure 3 \\ Historic Worid and \\ U.S. Landings of \\ Fish and Shellfish}

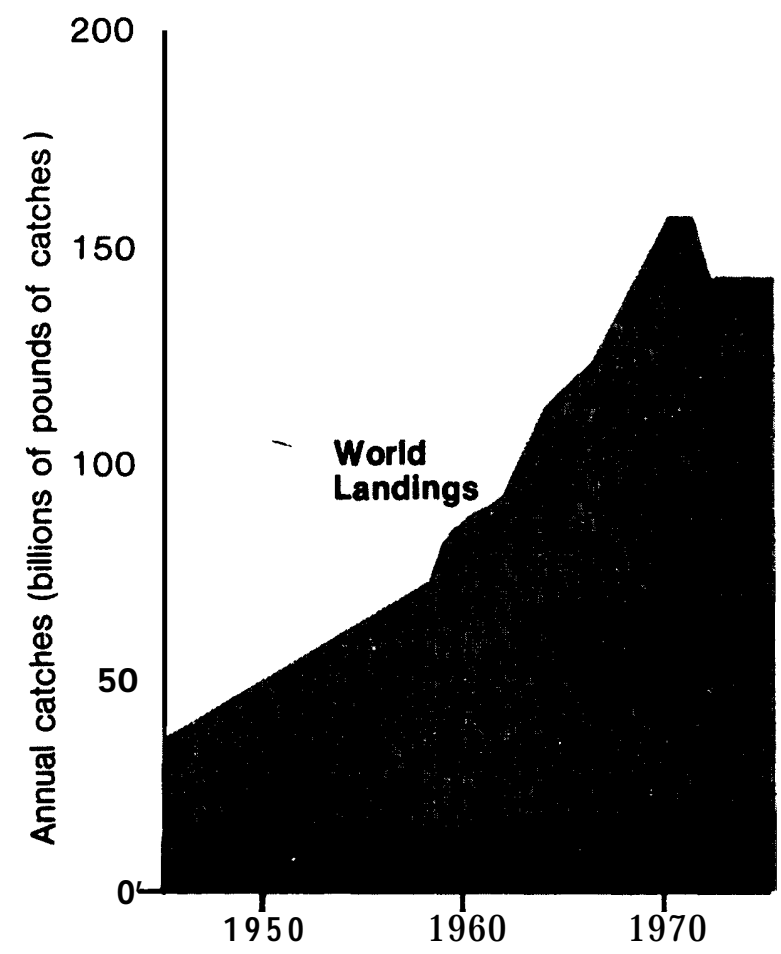

Source: U.S. Department of Commerce, National Oceanic and Atmospheric Administration

fishery - to oversee implementation of the law and become managers of the fish and shellfish resources off their coast. Already these councils have been involved to some extent in the National Marine Fisheries Service work to set some 1977 catch limitations and draw up preliminary regulations.

But this is just the outline of a system which must be developed in future years as the councils, Government, fishermen, and the Nation gain better information and understanding for their job.
The task of husbanding the U.S. fishery resources is a major one. At stake is not only a major supply of animal protein, but also an American industry which provides employment for more than a quarter-of-a-million people ${ }^{15}$ and has a $\$ 6.5$ billion impact on the U.S. economy. ${ }^{16}$ It is a resource used by foreign fishermen from more than 17 nations, ${ }^{17}$ U.S. commercial fishermen, and an estimated 30 million $^{18}$ recreational fishermen, whose catch is roughly equal in size and value to the catch of edible fish by U.S. commercial fishermen. ${ }^{19}$

Managing such a resource will involve scientific, social, and political problems for many years to come. Not the least of these problems is the fact that implementation of the law will require the use of much information about all phases of the fishing industryinformation which has not been consistently collected and analyzed in the past. But if the principles established by the Fishery Conservation and Management Act are pursued, there is substantial promise of a rational system for resolving conflicts between the needs of foreign, domestic, and recreational fishermen and the need for conservation.

The major problems relate to how the United States will determine and enforce new management regulations, how it will build the information base necessary for reaching management decisions and laying conservation strategies, and how it will revitalize the existing fishing industry and develop new opportunities. This report addresses some of those problems which are amenable to possible solution by actions of the U.S. Congress. Some potential actions for Congress and appropriate Federal agencies are identified.

Neither the Fishery Conservation and Management Act or this report cover all problem areas or possible solutions. For example, many species of inshore and migratory high seas fisheries are still unregulated and 
may be subject to increasing fishing pressures if stronger controls are placed on stocks in the 200-mile zone. Tuna is the major commercial stock which is excluded from U.S. jurisdiction as a highly migratory species. The Act does, however, raise considerable hope for restoring stocks and encouraging the American fishing industry to expand. Some of the potential new opportunities which may result are also discussed in this report.

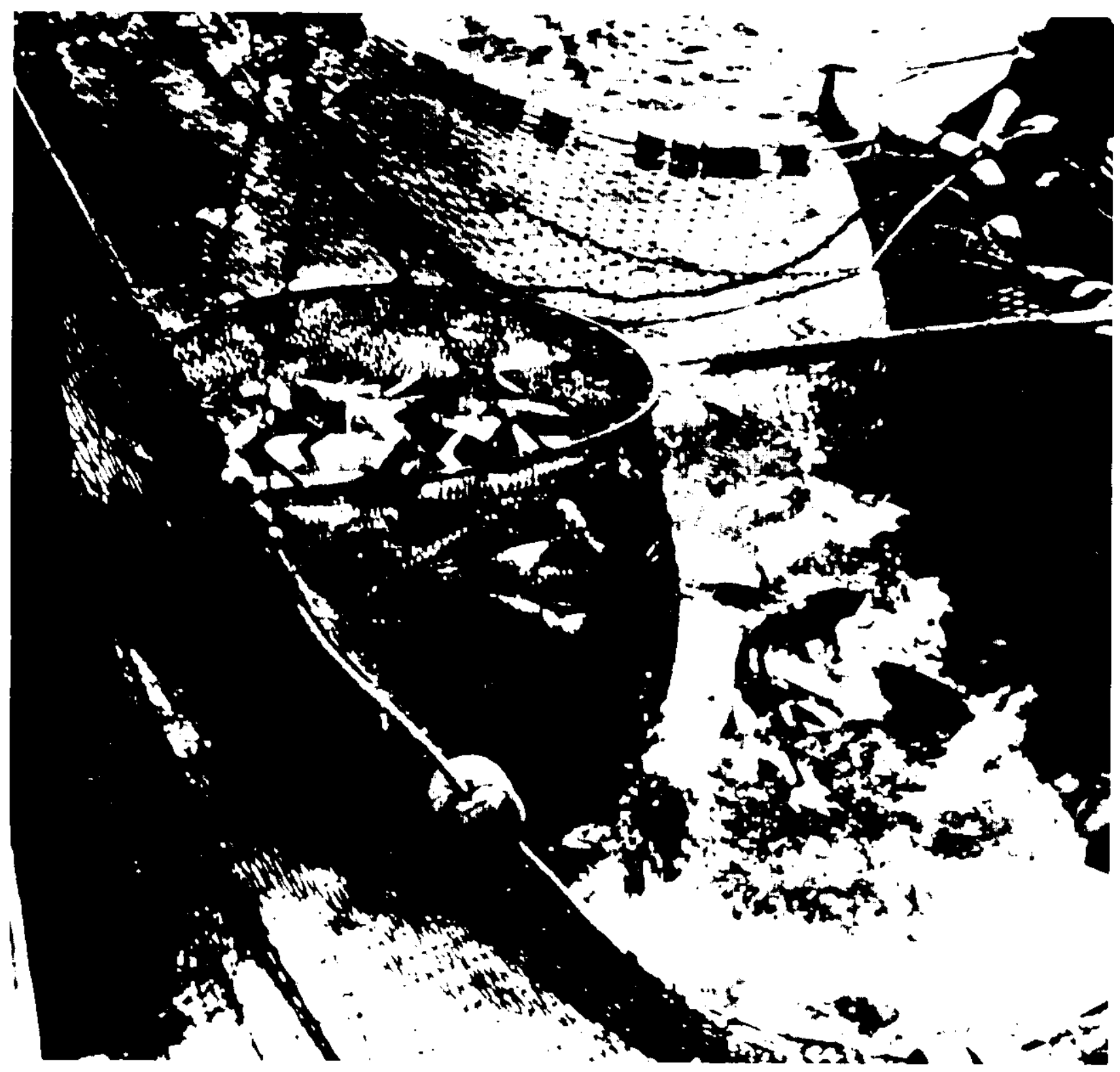

National Oceanic and Atmospheric Administration Photo

Fishermen bail their catch from a purse seine into the hold of the boat, 
2 Summary 
In March 1977, the Fishery Conservation and Management Act of 1976 became effective, extending U.S. jurisdiction over offshore fisheries within 200 miles of its coast and possessions, and making it the policy of the land to use some of the most advanced ideas available about ways to mange marine fisheries.

Implementation of the law will require a level of understanding about the fishing resources and industry that has never before been attempted by the U.S. Government. It will require development of methods of balancing biological, economic, and social factors relating to fisheries in order to best serve the national needs. Most of the information necessary for this process does not yet exist.

The law establishes Regional Councils to work with the National Marine Fisheries Service of the Department of Commerce in managing fishery resources and setting out regulations, including allocation of the catch of commercial species between domestic and foreign fishermen. Preliminary regulations and catch allocations have been drawn up, but better working relationships between all interested parties are needed and many changes will be necessary in early management activities as experience is gained.

Management of the 200-mile fishery zone will, of necessity, have enforcement of regulations as an integral part if it is to accomplish restoration and conservation of fish stocks and provide the domestic fishing industry with incentive to grow. The U.S. Coast Guard will be primarily responsible for enforcing regulation of foreign fishermen and the National Marine Fisheries Service will oversee domestic fishing. Both enforcement groups are beginning their tasks by increasing existing activities. This appears appropriate for the time being, but it is likely new enforcement techniques and advanced equipment will be needed in the future. Improvements are needed in long-term evaluation of enforcement needs, costs and benefits, and attention should be given to coordinating some military information and equipment with Coast Guard requirements for fisheries.

The Office of Technology Assessment's analysis of implementation of the new 200mile fisheries zone can be expressed in terms of the conclusions reached during the assessment, the practical and organizational problems which were discovered, and the OTA suggestions for resolving those problems.

The overall conclusions of the assessment are given here for each of the major subject areas of the report. These conclusions are grouped as they relate to:

- enforcement of the U.S. fisheries regulations and jurisdiction;

- management of the new fisheries zone;

- data which will be needed for implementation of the law; and

- opportunities for expanding and revitalizing the U.S. fishing industry which may result from implementation of the law.

These overall conclusions include four pilot projects, which are OTA's major suggestions for determining the most successful and costeffective means of enforcing U.S. jurisdiction in the 200-mile fisheries zone. 


\section{Enforcement}

Also included in this Summary are some of the specific problems which stand in the way of full implementation of the Fishery Conservation and Management Act of 1976.

It is the practice of the Office of Technology Assessment to make an objective analysis of a subject and not to recommend specific policy actions to the US. Congress. Adhering to that practice, OTA has made no policy recommendations in this report. However, due to the practical nature of this report and the desires of the congressional committee which requested this study, it seemed appropriate in this case to make a number of specific suggestions for more effective implementation of the Fishery Conservation and Management Act of 1976. These recommendations are outlined in this section and discussed in more detail where appropriate in later sections.

Throughout this Summary, page numbers are noted after individual conclusions in order to simplify reference to fuller discussion in the main text of the report.

\section{Need for Enforcement}

Adequate management and strict enforcement offer the opportunity for future increase in fish stocks and yields due to tighter controls to prevent overfishing, less pressure on stocks which are normally taken as bycatch, less conflict among fishermen for certain grounds, less conflict between different types of equipment, and assurance of workable allocation of catch quotas among foreign and U.S. fishermen. (See pages 27 to 29.)

The Existing Coast Guard Enforcement Plan for Foreign Fisheries

The Coast Guard plan of increasing its present fishery enforcement capabilities is a reasonable first step in enforcement. It is flexible in that resources can be added at a reasonable first cost and the program can be curtailed or accelerated as assumptions and need are proven or disproven by experience. (See pages 29 to 31.)

Enforcement of Domestic Fisheries by NMFS and USCG

The National Marine Fisheries Service's present approach to enforcing regulations in domestic fisheries by means of dockside inspections may be sufficient under the new law if it is combined with a program of random at-sea inspections, However, if regulations for domestic fisheries duplicate the kinds of gear restrictions and operational controls used in foreign fisheries, more atsea enforcement capability will be needed. (See pages 29 to 31.)

In the event that an at-sea enforcement capability is needed in domestic fisheries, the Coast Guard could use the same types of equipment and techniques which are planned for enforcement activities in 
foreign fisheries. However, additional facilities would be needed to cover the different areas used by domestic fishermen and the additional fishing vessels. (See pages 29 to 31 .)

Techniques To Improve Near-Term Enforcement Effectiveness

Several fairly simple strategies which could be activated almost immediately for enforcement have not been given favorable consideration by the Coast Guard and the National Marine Fisheries Service. Three of these are:

1) establishment of an efficient reporting system which would allow domestic fishermen to aid in observing foreign fishing vessels,

2) more extensive use of observers onboard foreign fishing vessels, and

3) creation of specific guidelines to be followed in granting annual fishing permits and renewing Governing International Fishery Agreements. (See pages 38 to 42 .)

Extensive use should be made of observers in a dual role: to collect data needed for management of fisheries and to observe fishing operations for enforcement functions. A near-blanket program of observers may be necessary for a dependable, costeffective enforcement program. (See pages 38 to 43.$)$

Planning Needed for Long-Term Enforcement

It is likely that proposed near-term enforcement capabilities will not be adequate for long-range demands. Therefore, plans should be made for further improvements in enforcement by use of remote-sensing devices and other advanced technology. (See pages 43 to 45 .)
Remote-Sensing Systems for Future Enforcement Needs

The cost of most remote-sensing systems is high and it will probably be necessary to share the cost of such systems with other users. However, remote-sensing devices could be expected to improve enforcement by better coverage, better performance, and a reduction of the need for expanding conventional ship and aircraft patrols of fishing areas in the future. (See pages 46 to 47.)

Transponders have good future potential for use in fisheries enforcement. Particularly when combined with Loran-C, transponders can be used to detect, identify, and classify fishing vessels. (See pages 47 to 49.)

New microwave radar equipment has the technical potential to supplement or supplant existing airborne radar for fisheries enforcement within the next 10 years, but the cost would be very high. (See pages 50 to 52.)

Over-the-horizon radar techniques have good potential for use in fisheries enforcement. However, due to both the classified nature of most of the military work in the field and the high cost, use of this system will be contingent upon close cooperation between the Department of Defense and the Coast Guard. (See pages 52 to 53.) 


\section{Recommended Pilot Projects in Enforcement}

Recommendations on Enforcement Levels and Evaluation (see pages 24 to 29)

Problem 1: No desirable level of enforcement has been determined, based on a policy decision, as to what level of enforcement is most desirable.

Recommendation: In order to determine the type of effort and equipment necessary, there should be a specific definition of the desirable level of enforcement, followed by regular assessment of changing enforcement needs and the actual level of enforcement which has been achieved compared to the desired level. In addition, the Regional Councils should make a projection of desired enforcement actions in their areas, possible compliance inducements for fisheries in their areas, and potential domestic enforcement plans.

Problem 2: The existing Coast Guard analysis of the appropriate level of enforcement was made without benefit of an adequate method for assessing the benefits and the cost (in social, economic, political, and scientific terms) of various enforcement strategies, that is, the various combinations of aircraft, ships, electronic devices, and imposition of penalties.

Recommendation: A general analytical system is needed to provide quantitative estimates of the impacts of alternative management techniques and enforcement strategies on the quantities and prices of fish available, the state of recreational fishing, and other measures of the benefits of management.

Problem 3: Fisheries management-modeling efforts currently being supported by the National Oceanic and Atmospheric Administration, such as the one at Stanford University, do not include enforcement components.

Recommendation: The Coast Guard should develop the enforcement component, so that its model could be used in conjunction with one adopted by NOAA.
The cost of enforcing fishery regulations in the new 200-mile zone may escalate as experience is gained in managing the fisheries, and it may be learned that a higher level of enforcement is necessary than that which is now planned. Therefore, a reasonable approach to gaining experience with different enforcement techniques is desirable in order to determine which are the most successful and cost-effective methods of achieving the goals of the Fishery Conservation and Management Act of 1976.

The research conducted during this study suggests that such experience might be most efficiently gained through a series of pilot programs in various areas of enforcement. The following four projects are an outline of the types of work which may be useful. These projects are suggested with the assumption that in the long-run, the cost of gaining sufficient experience on which to make informed choices and trade-offs in enforcement activities would be less than the cost of possible erroneous decisions about the use of very expensive, electronic-surveillance systems, the cost of adding large numbers of new and possibly unnecessary air and sea craft, and the cost of possibly failing to protect the fishery resources by adequate enforcement of regulations.

Included in the project discussions are rough-cost estimates whenever such fiscal information was available to OTA. However, it should be pointed out that one of the primary reasons for conducting these projects would be to obtain information that will allow the appropriate agencies to make estimates of the costs of full-scale setup and operation of certain programs. Presently, such information does not exist. 
It is suggested that these projects should be conducted for at least a year, possibly more, in order to cover the entire fishing season and range of activities on any given area. At the end of the project, each should be evaluated with special attention to determining the completeness of coverage provided, the cost, the timeliness and usefulness of information obtained, and a comparison of each method with traditional enforcement activities, and other possible alternatives to the pilot method.

Shipboard Observers (for background discussion, see pages 38 to 42 )

OTA's analysis suggests that much could be learned from a pilot project in which a foreign fishery is nearly blanketed with shipboard observers who have both management and enforcement duties.

The New England region would be most suitable for such a pilot project because the fishing grounds are concentrated and foreignfishing practices are well known; many of the foreign vessels fish in groups which could simplify the arrangement of vessels with observers and control vessels without observers; and the stocks in that region are generally depleted and information for use in restoring stocks is badly needed.

About 150 foreign vessels, on the average, have traditionally fished within the 200-mile zone off New England. At this writing, the number of permit applications which had been received suggested that this number will probably go down because of the 1977 catch allocations. Therefore, it appears that a total of about 100 shipboard observers would be suitable for the pilot project. These observers should be selected on the basis of experience in fishing practice and knowledge of fishery matters. If they are given enforcement duties, they should be Coast Guard personnel, instead of NMFS personnel. However, they should receive some training from NMFS in observing, collecting, and reporting information of value. Some familiarity with the nation on whose vessel the observer serves would also be helpful.

Based on NMFS estimates for their existing limited-observer program the cost of a 100man pilot program would be roughly $\$ 2$ million plus funds for an accurate evaluation of the pilot.

Under the law, this cost is passed on to the foreign vessels. However, other fees and charges are also levied, under the law, to reimburse the United States for management and enforcement activities in the 200-mile zone. Since the observer program would presumably make some other expenditures covered by these levies unnecessary, the gross-tonnage fee or tax on ex-vessel value of the catch could be reduced accordingly.

Transfer of Military Data (for background discussion, see pages 43 to 44 )

OTA proposes a pilot program utilizing one of the existing military systems for the collection and transfer of available surveillance data for one specific region. Some precedent for such a project already exists at the Naval Ocean Surveillance Information Center where the Coast Guard has recently detailed one officer to work on data which are of interest to the Coast Guard and have not, in the past, been processed by Navy personnel.

OTA has not investigated the feasibility of using a specific system in any region, but it appears that the Navy's west coast network could be a likely pilot region. Any pilot project should begin with an indepth investigation of the Navy's existing system and its ability to 
provide information needed for fisheries enforcement.

Some funding would be necessary to add personnel who would coordinate the transfer of fisheries-related data from the Navy to the Coast Guard district in charge of fisheries enforcement in that zone.

On one hand, there may be difficulties in working with and protecting classified information and there may be a danger that this extra task might not receive adequate attention in a facility oriented to an existing military mission. However, such an information-sharing program could ultimately cut costs substantially by reducing duplication of effort and facilities. It could also provide cooperative experience which might lead to sharing of other services and resources needed for enforcement and the opportunity to evaluate new technology which may be of use in fisheries enforcement.

Joint Research (for background discussion, see pages 45 to 46 )

OTA suggests that a pilot project for cooperation and joint research could bring together the Coast Guard, Department of Defense, and the National Aeronautics and Space Administration to develop new systems and find efficient ways of using technology in a multimission context.

Such a pilot project could include joint preparation of long-range plans for determining the most appropriate research and development strategy for new technologies, identifying the needs of all potential users of such technology, and analyzing the costs and benefits of developing and utilizing new technology, especially remote-sensing devices.
Transponders with Loran-C (for background discussion, see pages 47 to 49 )

OTA suggests early implementation of a pilot program utilizing transponders in two specific regions-the Bering Sea off Alaska and the Georges Bank off New England. Since each of these areas are traditional fishing grounds, but with very different prevailing conditions, the usefulness of transponders could be evaluated for a broad range of applications by this pilot project.

The pilot programs would require the design and manufacture of Loran-C transponder equipment specifically for this purpose. The Loran-C network is already planned or in operation in the regions proposed. A licensing arrangement and installation technique for fitting transponders on each foreign fishing vessel entitled to fish in the region would need to be devised. Control stations and receivers on patrol ships or aircraft would need to be installed.

It is estimated that the transponder which would go on board each foreign vessel would cost less than $\$ 2,500$. Once the system were developed and installed, operational costs would be roughly equivalent to the operational cost of the aircraft carrying each control station, \$1 million to \$1.6 million annually. Funds for evaluating the pilot project would be in addition to these costs.

The Georges Bank pilot program would require about 150 transponder units and a control station most likely at a Coast Guard shore base in New England. Each vessel entering the 200-mile zone at Georges Bank for fishing would be required to activate its transponder which would automatically transmit identification and location to the shore base. The shore base would keep plots of all foreign fishing activity on the banks and give this to patrol craft. Regular patrols of the region would use this information to check on any 


\section{Management of New U.S. Fishery Zone}

fishing activity that was not reported by this system.

In the Bering Sea region a similar network of transponders could be required aboard foreign fishing vessels. In this region it may be desirable to combine the transponder network with microwave radar systems already used aboard Coast Guard patrol aircraft and receiving stations also aboard the patrol craft. In this way a specific region could be covered by regular overflight, all vessels operating in the region located by radar, each vessel interrogated to determine whether an approved transponder is aboard stating identification and location, and any vessels without transponders investigated. There are several advantages to a system thus described, especially in Alaska where long distances and large areas can best be covered by aircraft and where frequent cloud cover makes visual observation difficult or impossible.
New Management Concepts Needed

New research concepts need to be developed and much new data must be gathered in order to obtain an integrated view of all the fisheries of the United States and to determine the optimum yield of each fishery. Optimum yield is a judgmental decision on the size of fish catch which will achieve the most advantageous combination of biological, economic, and social results. However, there is presently no agreed-upon method of determining optimum yield. (See pages 62 to 63.)

Even when analytical methods and reliable data are generated, there will be uncertainty about stock assessments and other projections used for fishery management. Techniques for dealing with that uncertainty will be necessary. (See pages 62 to 63.)

Relationships Between Federal Agencies and Regional Councils

It is possible that better accountability for the existence and the reliability of data provided by the National Marine Fisheries Service (NMFS) to the Regional Councils could be achieved if the NMFS member on the councils were the head of the regional fisheries research center rather than, or in addition to, the Regional Director. (See pages 63 to 69 .)

Conflicts can probably be expected in the future between the Regional Councils and the NMFS laboratories over the division of research funds because of some local fishermen's mistrust of national NMFS operations and council desires to break out of the traditional NMFS research patterns. Conflicts may evolve over who does specific research tasks. Such conflicts may delay collection of much-needed information or cause duplication of research effort; 
however, there is no framework--other than informal negotiations between NMFS and the councils-for resolving such conflicts. (See pages 63 to 69.)

\section{NMFS Management Guidelines Needed}

No decisions have been made within NMFS as to who will be responsible for research, data collecting, and development of analytical methods. There is a division of opinions among NMFS staff as to whether recommendations on data and methods should be made by NMFS to the councils or by the councils to NMFS. (See pages 69 to 73.)

The preliminary management plans prepared by NMFS were not coordinated in content or format. Guidelines for presentation of management plans were not promulgated. This failure to standardize operations with NMFS before the initial plans were written may have complicated the councils' job of preparing succeeding plans by failing to give them a model after which to pattern their work. It may also perpetuate regional differences within NMFS and complicate the national review process. (See pages 69 to 73 .)

\section{Management Information Needed}

Much must be learned about the effectiveness of management techniques and presentation of plans. However, the most pressing need for improvement is in the area of developing and considering economic, social, and biological data to be used to modify the catch figures presented in the preliminary plans. (See pages 69 to 74.)
Recommendation for Management Planning (See pages 73 to 74.)

Problem: There is no deadline for preparation of domestic fishery-management plans and no priority listing of domestic fisheries for which management plans should be prepared.

Recommendation: NMFS should prepare a priority listing of domestic fisheries for which management plans are needed, delineating the needs and citing available data. 


\section{Information Needed To Implement Public Law 94-265}

New Evaluation of Fisheries Stock Information Needed

The new Regional Councils could make a substantial improvement in the old system of making estimates of fishery yields and advice about health of stocks available only to international governing bodies. The councils could interpret scientific data on stocks, publish it widely, and provide an opportunity for continual access to information and debate of the issues by interested parties. Input by and involvement of users and other public parties is crucial to the success of fishery management. (See pages 77 to 79 .)

\section{Status of Stock Information}

Present assessments of heavily utilized stocks are quite accurate. However, projections of sustainable yields in the future are subject to large uncertainties due to effects of interspecies relationships, environmental change, fishing effort, and other unknown natural variations. (See pages 77 to 79 .)

Presently no stock has adequate quantitative data on all items necessary to develop estimates of maximum potential yields that can be harvested without reducing the parent stock. (See page 78.)

\section{Stock Assessment Needs}

Since estimates about the condition of a stock are basically judgmental anyway, it may be far more cost-effective to agree upon a few key indicators of the health and size of the stock rather than to attempt to assess all possible indicators. (See pages 79 to 81.$)$

Because of pressures to expand existing stock assessment methodologies to provide data for near-term decisions, pressure to treat fishery information as a precise science, and the lack of validity for existing methods of research, a program should be undertaken to improve the stock assessment data which will be used and establish future research priorities. (See pages 79 to 81.)

Foreign Investment Information

Mandatory disclosure of the actual extent of foreign investment in U.S. fish processing and wholesale operations would be necessary in order to determine if foreign investment results in uncontrolled foreign fishing or if it has an adverse effect on the competitive position of U.S. firms. However, such disclosure is not presently required. (See pages 81 to 85 .)

\section{Economic Information Needs}

Economics and statistics staffs are being added to Regional Fisheries Research Centers, but these staffs are not likely to have the time or direction to address national problems. These staffs cannot be considered a substitute for a central economics research and planning capability in NMFS. (See pages 86 to 88 .)

Information Needed on Social Effects of Fisheries Management

The Regional Councils will need to know the major social effects of the decisions made under the new law in order to make sensible alterations in fisheries regulations as conditions continue to change. (See pages 88 to 92 .) 


\section{Future Developments in the Fishing Industry}

Recommendation for Improved Management Information (See pages 81 to 86 .)

Problem: Most of the regional economic studies which have been done and the economic and social data generated by NMFS would be of limited use to the Regional Councils in their management work because it is outdated or not maintained in a format applicable to fisheries managers.

Recommendation: The National Marine Fisheries Service consulting with the Regional Councils could evaluate the economic and social-data needs and the suggestions for improvement which are outlined in this report and develop a comprehensive management information system.
Information Needed To Evaluate Opportunities

In order to make decisions on how to improve an existing fishery or develop a new fishery by enhancement techniques, new information is necessary. This includes an intensive and integrated examination of all facets of a fishery: resource assessment, harvest and processing technologies and costs; market potentials; and institutional factors including artificial barriers to trade. None of this information presently exists within the Federal agencies. (See pages 96 to 99.)

Sufficient data about various segments of the fishing industry are not now available for determining what, if any, actions should be taken by the Government to encourage growth in the fishing industry. (See pages 99 to 104.)

Underutilized Species Not Defined

In addition to the possible prices which presently underutilized species might bring, stock assessments and projections of yield from the species are needed in order to determine if the stocks can sustain a market. (See pages 98 to 99.)

Recommendations for Addressing New Opportunities (See pages 95 to 104.)

Recommendation: Data collected by the General Accounting Office, the Eastland Resolution group, the Office of Technology Assessment, and NMFS should be synthesized and analyzed by a committee of the Regional Councils which could identify missing information, fill the gaps itself or contract for research, and make recommendations for congressional action or administrative changes which would be helpful in revitalizing the fishing industry.

Recommendation: The Federal fishery information structure that exists in Sea Grant and NMFS should be expanded and improved to reach a larger segment of the industry with a variety of information from many sources. 
3. Enforcement 


\section{Background}

Management of the new 200-mile U.S. fishery zone will, of necessity, have enforcement of regulations as an integral part if it is to accomplish restoration and conservation of fish stocks and provide the domestic fishing industry with the potential and incentive to grow, as mandated by the Fishery Conservation and Management Act of 1976 (P.L. 94-265).

Management plans to be drawn-up under provisions of the Act will lay the groundwork for the types of regulations which will be required and which must be enforced. However, fish resources are already scarce enough and the demand for fish products high enough that it is logical to conclude that foreign nations can justify the risk of violating these regulations and the United States can justify the effort and expense of enforcing them. In fact, the U.S. Coast Guard, the agency primarily charged with the enforcement task, has concluded in a report on its preparations for increased fisheries duties that "the state of the fish stocks today is too critical to allow for any lapse in enforcement." ${ }^{20}$

A discussion of enforcement problems and opportunities is offered first in this report for two reasons:

1) Clear and timely indication of U.S. intentions to strictly enforce fishery regulations within the 200-mile zone is imperative for gaining foreign cooperation.

2) Even the best of management plans cannot succeed without effective enforcement of its provisions.

Later sections of this report deal with the problems and opportunities of managing the 200-mile fishing zone and with the need for much additional information as Federal agencies and Regional Councils seek to refine and improve management techniques.

\section{Brief History of Fisheries Law Enforcement}

The United States began to exercise control over its coastal fisheries soon after it became a country. Until the passage of the Bartlett Act, in the middle 1960's, however, enforcement was essentially confined to the "territorial sea", the area within 3-nautical miles offshore.

The early control activities were generally mild. It wasn't until the late 1800's and early 1900 's, that strong legislation was passed to resolve fishery and marine mammal problems in Alaska and the Pacific Northwest, In the early 1900's, foreign fishing vessels were seized and brought to American ports, and fines were successfully levied against the crews and vessels.

The Bartlett Act has been the primary fisheries law. Foreign fishing is not only prohibited within the territorial sea, but also is excluded within a contiguous 9-mile fisheries zone beyond the 3-mile territorial sea. In addition, foreign fishermen cannot retain creatures of the Continental Shelf (shellfish and crustacean). Violations of the Bartlett Act could result in fines, imprisonment, and forfeiture of the vessel, gear, and catch.

There are a number of treaties and international agreements in which the United States and other countries have agreed to manage fishery resources, outside the 12-mile zone. ICNAF (International Convention for the Northwest Atlantic Fisheries) is an example of one important treaty. Here, the 18 member governments prepare the regulations, which for the most part are concerned with quota 
allocations. Inspectors may stop, board, and examine member fishing vessels for violations of the regulations, but prosecution and punishment (if any) are carried out by the "flag state", the home country of the particular fishing vessel.

The United States was a member of ICNAF for more than 25 years. However, it withdrew from the convention after Congress passed the Fishery Management and Conservation Act of 1976, unilaterally assuming jurisdiction over most of the east coast waters in which American fishermen work.

The growth in breadth and strength of enforcement of fisheries laws can be traced to two primary interrelated occurrences:

- intense foreign fishing off our coasts, and -depletion of many fish species due to overfishing.

In 1975, there were 17 foreign nations fishing off our coasts. ${ }^{21}$ In June 1975, almost 1,000 foreign fishing vessels were sighted; the year's monthly average was more than 500. The foreign vessels caught about three-quarters of the 3 million metric tons of fish caught in the 200-mile zone that year.

From 1964 through September of 1976, nearly 100 foreign fishing vessels were cited for violation of U.S. fishing laws. The most frequent offenders have been Japan, Canada, Cuba, and the U.S.S.R. Fishermen from these nations account for more than 70 percent of the violations of U.S. law. In addition, approximately 100 treaty violations are documented each year. $^{23}$

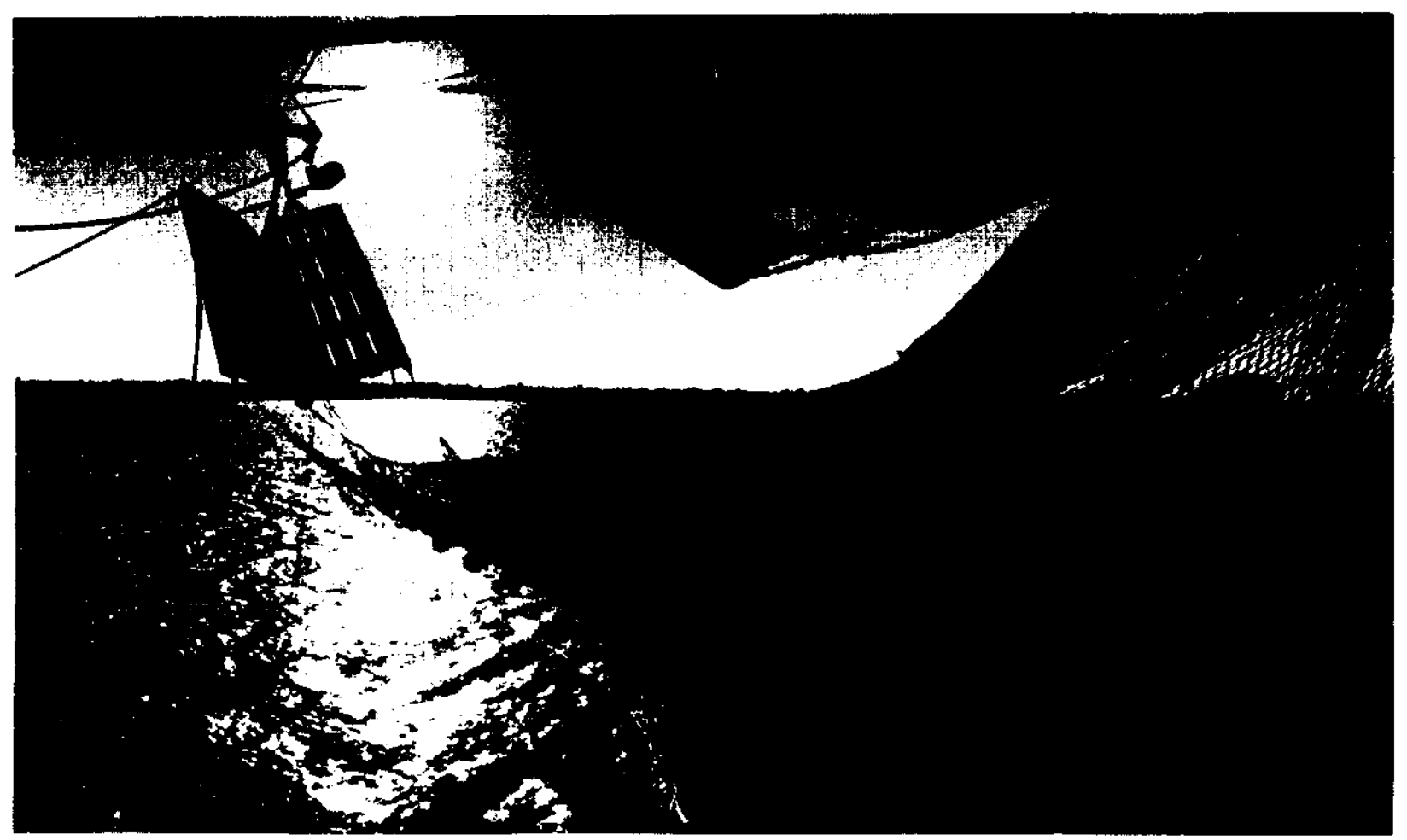

OTAI Photo 


\section{Requirements of the Law}

Violations of U.S. law can be classified as:

- geographical intrusion, that is entrance into forbidden areas, such as territorial waters or closed areas; and

- catch and illegal retention of creatures from the continental shelf, such as lobsters and crabs.

Treaty violations take the form of:

- improper fishing gear, which is prohibited in certain areas by regulation;

- illegal retainment of bycatch, that is, catching and keeping prohibited species;

- overfishing of quotas; and

- violating administrative regulations, such as improper keeping of log books or not reporting required scientific data.

In the past, fisheries enforcement responsibility has been vested primarily in the U.S. Coast Guard. The Coast Guard has provided the ships and aircraft and much of the manpower to staff the vehicles, the sensing equipment and the command and control function of operations. The National Marine Fisheries Service, which is primarily concerned with gathering management and scientific data, assisted in enforcement. NMFS provided personnel with expertise on fishing gear, fishing techniques, and fish identification and catch rates. There was close cooperation between the two groups, with personnel from both agencies frequently onboard the same vessels,

The State Department has also played an important role in fisheries law enforcement. The State Department negotiated the various treaties and international agreements, and in the past, any foreign fishing vessel was seized only after coordination with the Secretary of State. A close liaison between the State Department and the Coast Guard was needed since any interference with foreign shipping, warranted or not, could certainly affect U.S. relations with the foreign country.
The purpose and policies set out in Public Law 94-265 have important effects on enforcement. The law vests the responsibility for enforcement in the Secretary of Commerce (NMFS) and in the Secretary of Transportation (Coast Guard). Authorization is given to arrest violators, to seize vessels and cargo, and to issue citations.

In addition a number of specific instructions, which have a major effect on enforcement, are spelled out in the law:

1. No foreign fishing is permitted in the fishery conservation zone except:

a. under agreements or treaties (new and renegotiated), and

b. with a permit.

2. In every international agreement:

a. The foreign country agrees to abide by all U.S. regulations.

b. The foreign country allows a U.S. officer to:

(1) board the vessel,

(2) make arrests and seizures, and

(3) examine the permit,

c. The permit must be prominently displayed.

d. Appropriate position-fixing and identification equipment, such as transponders, if required by the Coast Guard, are to be installed and maintained on each vessel.

e. U.S. observers will be allowed to board any vessel, the cost to be reimbursed to the United States.

f. Foreign agents are to be sited in the United States to deal with any legal process.

$\mathrm{g}$ The foreign nation acts in behalf of its individual vessels. 


\section{Present Plans for Near-Term Enforcement}

3. An allocation of fishing level (fish quotas) will be made to specific foreign countries.

4. If a foreign vessel, with a permit, violates the regulations:

a. The permit of that vessel could be revoked.

b. The permit could be suspended.

c. Additional conditions could be imposed on the foreign nation and on any of its permits,

5. Civil penalties for violations could be as much as $\$ 25,000$ per violation, where every day may be considered as an additional violation.

6. Criminal penalties for violations could be as much as $\$ 100,000$ and 10 years in prison.

7. Any vessel, its fishing gear and cargo, could be forfeited to the United States.

Since the passage of the Fishery Management and Conservation Act of 1976, some concern has been voiced by Members of Congress, members of the Regional Councils, and others, that foreign investments in U.S. fishing operations and joint ventures between foreign and domestic fishing and processing companies may provide a means of circumventing controls on foreign fishing interests within the 200-mile zone. Such investments may guarantee foreign firms the almost unlimited access to fish stocks which is intended for domestic fishermen and allow them to operate outside certain regulations-such as gear restrictions-which may be in effect only for foreign fishermen. While such investments may pose problems in enforcing the intent of the Act, they are not, strictly speaking, an enforcement problem to be dealt with by the Coast Guard and NMFS operational divisions.

The problems and benefits of foreign investments are discussed as management concerns in other sections of this report.
Enforcement of regulations in the new 200mile fishery zone is complicated by the size of the area and the fact that fishing is to be regulated not prohibited. The area encompassed by the 200-mile-wide band surrounding the United States and its possessions adds up to almost 21/Q-million square miles of ocean. According to Coast Guard estimates, major fisheries cover approximately one-fourth of that area. These prime fishing grounds will require concentrated enforcement efforts during certain seasons, In addition, at least some level of enforcement may be required in all parts of the zone at some time during the year. A dense mixture of marine traffic, including merchant vessels, warships, tankers, recreational craft, and both domestic and foreign fishing vessels, is found within the 200-mile zone. From this mix of vessels, foreign fishing craft must be located and identified by nation. Further, in order to enforce any regulation in any fishing area at any given time, fishing vessels must be classified as fishing according to the provisions of their permits and existing regulations or in violation of these controls; violators must be apprehended; and some prosecutor action must be taken.

This detection, identification, and classification of foreign fishing activity must go on under any sea conditions that permit fishing itself. Experienced fishermen have indicated that this means enforcement activities may be 
necessary through at least sea state 7 (28- to 40-knot winds and 22- to 40-foot waves).

In addition, for each enforcement step, different vehicles and equipment are useful. For example, an aircraft flying at 200 knots, at 15,000 feet in clear weather will cover a greater area, using sight and radar, and detect more fishing vessels than will a cutter at sea doing 15 knots. On the other hand, the aircraft cannot put a boarding party on fishing vessels, while a cutter can accomplish this mission.
It is not now possible to project explicitly what enforcement will be necessary to detect and deter violations because the Regional Councils, which are charged with creating the regulations for fishery management, have not yet formalized final plans which will include the regulations which are to be enforced. Regulations which have been drawn-up by the National Marine Fisheries Service for implementation as of March 1, 1977, are merely interim rules which will be supplanted once the councils formulate regulations specific to

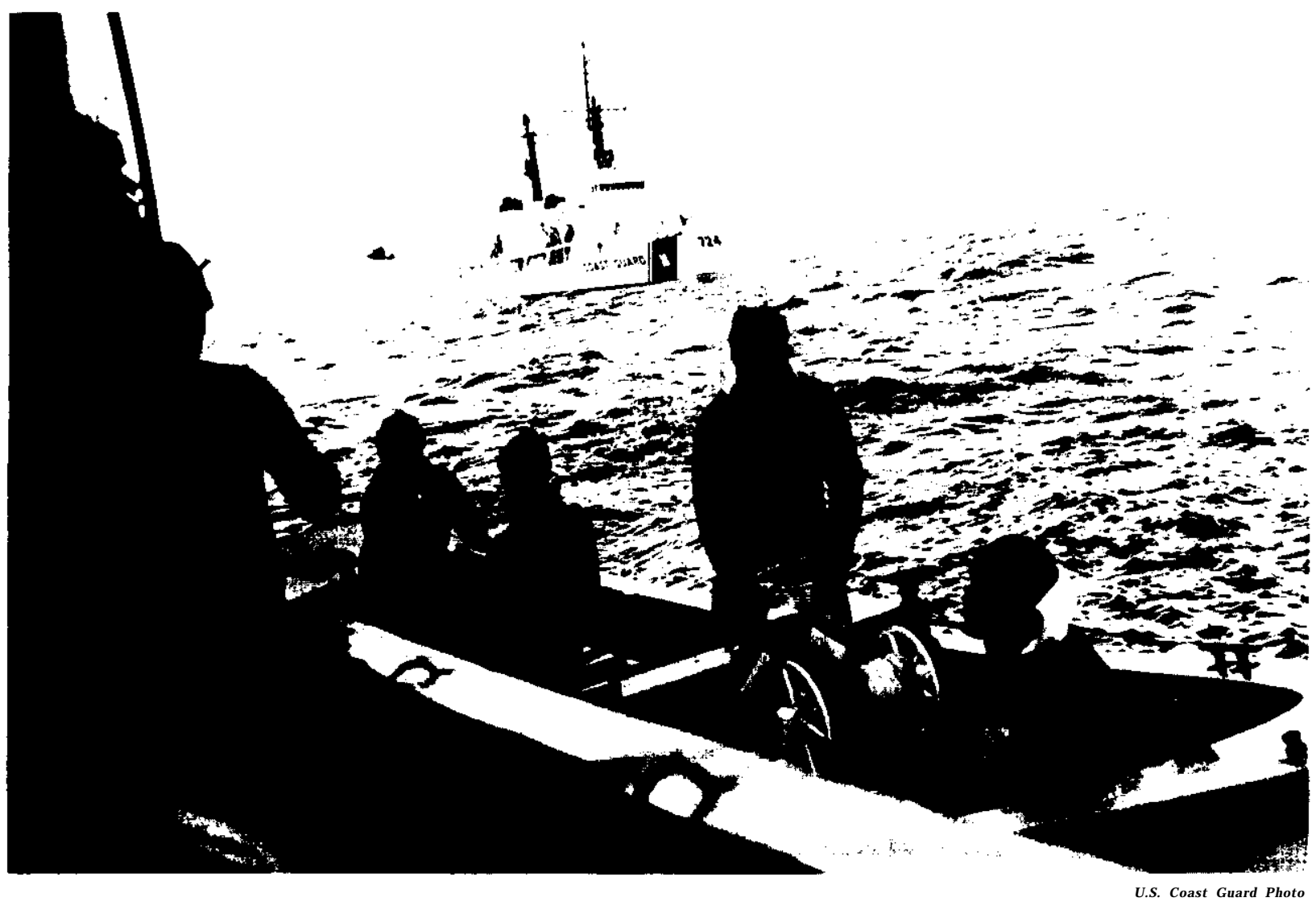

Under the new law, Coast Guard enforcement officers may board foreign fishing vessels to inspect the catch and fishing gear 
their fisheries. The interim regulations are not too different from those contained in the international agreements which have, in the past, been the only means of controlling fishing activity. The major immediate changes will be that the United States has taken on the responsibility for enforcement, will board and inspect foreign vessels for compliance with U.S. regulations, and will prosecute offenders itself instead of leaving that task to flag states. But as experience with the fishery zone grows, new types of regulations and enforcement techniques will be needed and used.
Nevertheless, certain basic types of violations can be anticipated, such as illegal fishing by foreign vessels which do not have permits; overfishing of quotas allowed for each species; violation of permit stipulations such as gear-, area-, or time-restrictions; and failure to comply with data-reporting requirements.

The specific regulations to be enforced and violations expected will affect the type of enforcement strategies and equipment to be used, Figure 4 is a matrix of likely enforcement needs and techniques.

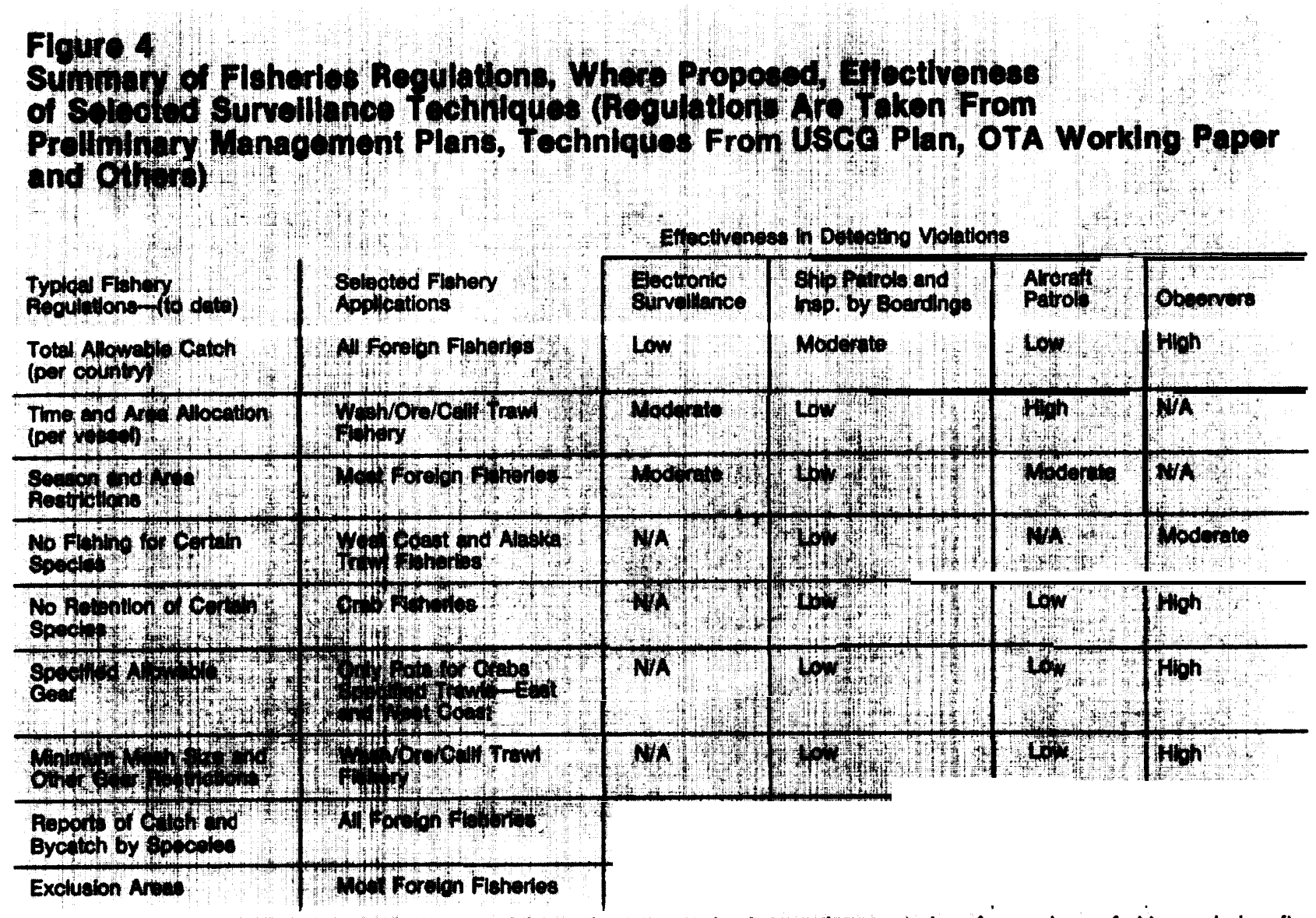

NOTE: The techniques ebove are judged on cepabilities of existing technology and present plans for numbers of ships and aircraft. 
Level of Enforcement

Just as important in determining what enforcement capabilities will be necessary is determination of the desired level of enforcement. In other words, should enforcement agencies mobilize to catch 50 percent of the violators, 75 percent, or 100 percent-in which case the costs could prove to be astronomical. Without a quantified level of enforcement, the allocation of enforcement resources becomes a matter of intuition rather than one of reasoned judgment.

Currently, the Coast Guard simulation model used for costing purposes indicates that the agency assumes it can catch or deter approximately 95 percent of the 2,150 expected annual violators within the budget appropriation level requested. ${ }^{24}$ That percentage, however, does not appear to have been set as an enforcement goal based on any policy decision as to what level of enforcement is desirable. In addition, the percentage shown may be much too high, depending on what types of violations (over quota, use of prohibited gear, fishing in closed areas) are being counted, A middle-ground approach is probably required and a specific definition of that approach would be desirable. This should be followed by regular assessment of changing enforcement needs as well as the actual level of enforcement compared to the desired level. Determination of the level of enforcement could also be enhanced by asking Regional Councils to make a projection of desired enforcement actions in their areas, possible compliance inducements for fisheries in their areas, and potential domestic-enforcement plans.
A major shortcoming of the Coast Guard's analysis of the appropriate level of enforcement is the lack of an adequate method for assessing the benefits that can be expected from various enforcement strategies. Since significant resources may be required to operate an effective enforcement system, the Coast Guard's current inability to systematically estimate the expected value of enforcement is a serious flaw. However, since the determination of appropriate enforcement strategies is only one part of the broader process of fisheries management, what is probably needed is a more general analytical system which could provide quantitative estimates of the impacts of alternative management techniques, including-but not limited to-the enforcement strategies, on the catch and profits of commercial fishermen, the quantities and prices of fish available to the domestic consumer, the state of recreational fishing, and other measures of the benefits of management.

One such general analytical system is currently being developed for NOAA by the Center for Technology Assessment and Resource Policy at Stanford University. This system is based on a generalized computer systems model which can integrate the best available scientific information about any particular fishery in order to assess the quantitative impacts of various management techniques on the fishery. Since even the initial approach to enforcement is expected to cost nearly $\$ 100$ million per year, benefits should be clearly identified and quantified to the extent useful. Some of the benefits may include:

- A future increase in stocks and yields due to tighter controls to prevent overfishing.

- Less pressure on stocks caught as bycatch due to better controls on gear and areas fished,

- Less conflict among fishermen for certain grounds and reduced gear conflict. 
-Assurance of proper allocation of quotas among foreign and U.S. fishermen.

An enforcement component is not presently planned for the Stanford model. Such a component, which would translate various enforcement strategies into impacts on foreign fishing activities, should be developed by the Coast Guard. The Coast Guard could then use its enforcement model in conjunction with the Stanford model, or any similar one adopted by NOAA, in order to determine the costs and benefits of various levels or enforcement or specific enforcement strategies.

The primary objective of the Coast Guard simulation should be to evaluate the effectiveness and the cost of a mix of vehicles, sensors, and personnel as they enforce the regulations applicable to the 200-mile fishery zone. Among other factors, the model should include:

- existing capabilities and possible future systems of sensors, vehicles, and personnel;

- short- and long-range enforcement needs;

-possible multipurpose use of systems and equipment by the Coast Guard for accomplishment of several of its missions;

. likely levels of assistance from the Navy, NASA, the Air Force, and NMFS;

- relative importance of various components of enforcement, such as surveillance, boarding, etc.;

- the effects of various types and levels of penalties, such as fines and seizures;

. likely regulations of all types;

- explicit yardsticks of effectiveness, such as percent of captured violators, amount of protection given to stocks, value of fines collected, value of regulation on foreign relations, comparability with other Coast Guard duties, etc.;

- behavior patterns of foreign and domestic fishermen in reaction to regulations; and

- monetary cost of programs.

A model which does a more adequate job of making cost-benefit estimates than the existing Coast Guard model will be exceedingly difficult to prepare since the efficiency of enforcement involves intangible as well as tangible costs and results. For example, how does the value of protecting and restoring a depleted stock compare with the value of improved international relations which may result in some specific sought-after agreement in another field? However, the model could present possible scenarios, impacts, and tradeoffs which may result from various levels of enforcement or differing amounts of expenditures.

Although the analytical models to be used by NOAA and the Coast Guard in fisheries management and enforcement are an important tool, there is considerable feeling among members of the Regional Councils and other interested parties that modeling techniques have already outstripped available data. The results of the OTA study also indicate that existing models have already identified large areas where there is insufficient information. Therefore, immediate emphasis should be on a program for long-term collection of consistent basic information. Models and modeling techniques can be improved while this basic data is being gathered. 


\section{Existing Capabilities}

The existing capabilities for enforcing Public Law 94-265 include three primary groups, within the executive branch, which would or could be involved in the future:

1. The Coast Guard has the primary responsibility for enforcement and exercises almost complete jurisdiction over activities in the foreign fisheries.

2. The National Marine Fisheries Service shares the enforcement function with the Coast Guard by providing personnel with scientific and biological expertise to aid in planning and carrying out enforcement strategies in the domestic fisheries.

3. The Department of Defense normally will have no enforcement function at all, except in the unlikely event that foreign warships should appear within the 200mile zone to contest U.S. regulations. In that case, U.S. military forces would be called upon under the terms of a memorandum of understanding between the Coast Guard and the Department of Defense. The memorandum and contingency plan for such a situation has been worked out by the Joint Chiefs of Staff and the highest levels of the Coast Guard and is classified information,

The Department of State, which has been involved in enforcement of fishery agreements in the past because of their international nature, has been given a limited role under the new law.

The Department of State's primary function is to negotiate the Governing International Fisheries Agreement, by which, foreign na- tions agree to accept the U.S. jurisdiction in the 200-mile zone. The State Department is also to exercise an advisory role, keeping the Coast Guard, the National Marine Fisheries Service, and the Regional Councils informed on foreign policy implications of fishery management.

Under the new law, as in the past, the State Department is consulted by the Coast Guard before any foreign fishing vessel is seized for violation of U.S. regulations. There are undoubtedly legitimate instances when the foreign policy or diplomatic implications of some action should take precedence over the fishery implications. However, the Coast Guard routinely allows the State Department's desire to avoid unpleasant diplomatic incidents to influence enforcement actions. There appears to be no formal mechanism to assure that State Department decisions to intervene in a fishery action are made at an appropriate policy level and that the Coast Guard exercises its statutory responsiblitity to make final enforcement decisions, with advice from the State Department being only one of many factors to be considered. There is obvious need for a clear and simple procedure which quickly leads to a decision-and review of that decision by the Chief Executive when necessary--on whether or not to seize a foreign vessel which is violating U.S. law or regulations.

The following discussion of the work of these agencies in regard to enforcement is not intended as a specific description of their planned operations. Rather, it is an overview and a critique of likely enforcement.

In its routine enforcement role, the Coast Guard provides personnel, vehicles, and sensing equipment. Its enforcement capability during 1975 came from its fleet of 39 aircraft, 39 ships, 94 helicopters, and various support facilities. These facilities were not dedicated 
solely to fishery enforcement, but were used also for other Coast Guard duties such as investigating oil spills, sea search and rescue, and general law enforcement. Approximately 2,500 days of ship time and 6,000 hours of aircraft time were devoted to enforcing fishery laws, regulations, and treaties during 1975, about one-haIf million square miles were patrolled, at a cost of $\$ 46$ million for the year. The Coast Guard spent about 5 percent of its total annual operational budget on fisheries enforcement

The Coast Guard's original plan for enforcement under the new law called for increasing ship time by 951 days to provide 2,616 patrol days inside active fishing areas and 823 patrol days in other areas; increasing aircraft time by 7,553 hours to provide 8,446 hours of patrol in active fishing areas and 3,068 hours of patrol in other areas. ${ }^{26}$

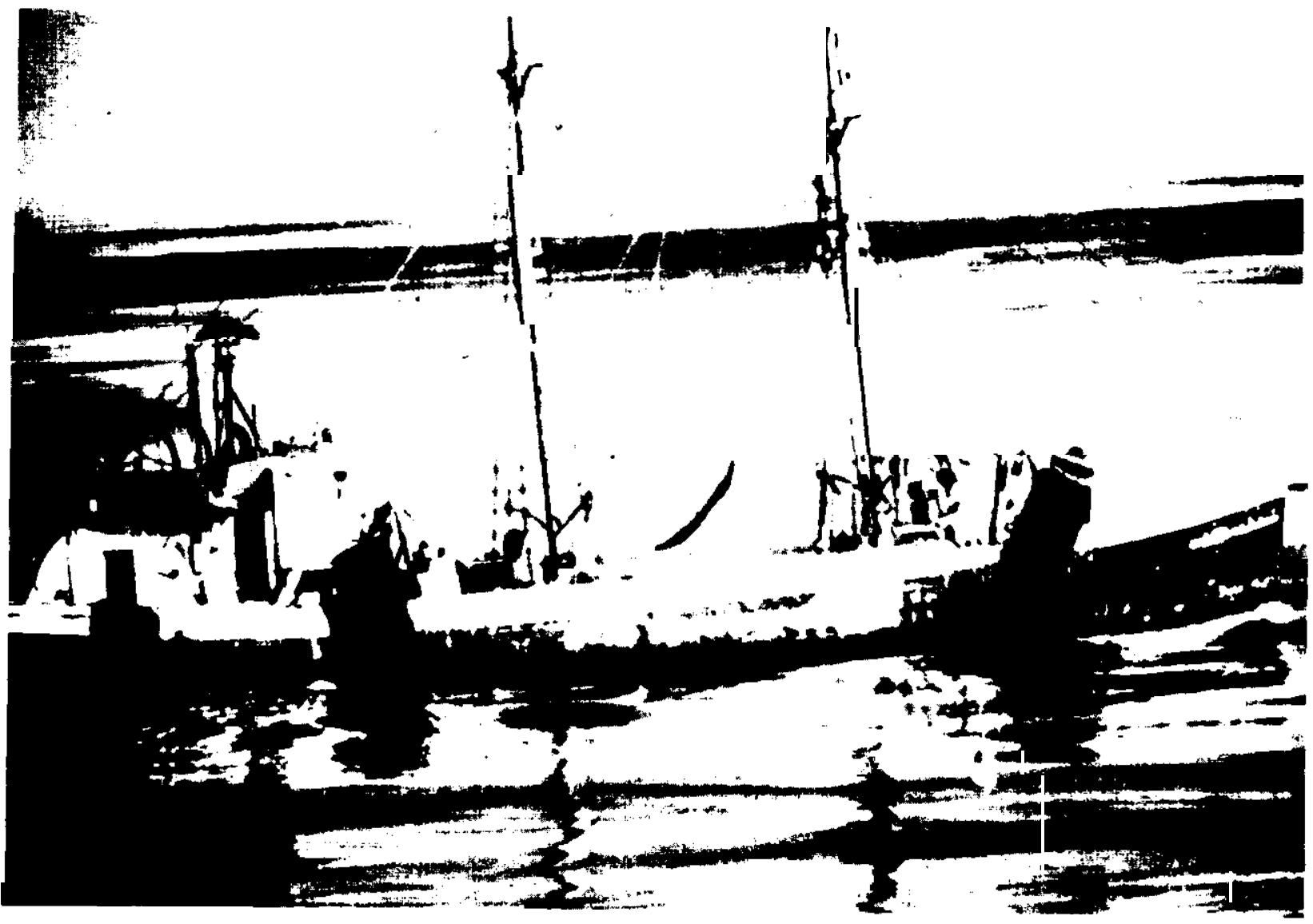

Trawlers operating out of New England ports work in the ground fisheries of Georges Bank, 
According to the Coast Guard plan, this, theoretically, would reduce the number of violations per year from the expected 2,150 to about 110, based on the assumption that detection and identification constitute enforcement (see figure 5). However, there is some question about the wisdom of this assumption since simple detection of a violation by an aircraft or other means does not guarantee that the violation will cease and that the violator will be penalized.

The Coast Guard plan would necessitate the addition of 10 fixed-wing aircraft, 5 helicopters, and 6 high-endurance cutters. Procurement and operation of these new craft was estimated at \$275.4 million through fiscal Year 1978, After appropriation of the fiscal year 1977 budget, this strategy was reassessed and it was determined that budget constraints dictated that initial enforcement focus on the active fishing areas only. For maximum effect in that area with appropriated funds, the Coast Guard revised procurement plans to include purchase of four C-130s and reactivation of four C-131s; reactivation of its last five spare, short-range shipboard helicopters, and temporary overscheduling of the crews of five others; and reactivation of one cutter-all of which could be in operation close to the March 1, 1977, effective date of the law. The package, with necessary support facilities, was estimated to cost $\$ 64.3$ million. $^{27}$

Most of the projected new vehicles are scheduled for use where the new U.S. jurisdiction now takes in more extensive fishing grounds, that is, in the Pacific Council area and off the Alaskan coast. Since these areas contain about 16 species of fish which have been overexploited in the past, the allocation of more vehicles to enforce regulations there will also aid in the conservation and recovery of these stocks. (See figures 6 through 10.)
Figure 5

Expected Number of Undetected Violations by Month Under "No Effort", FY 75 Level, and Planned Enforcement

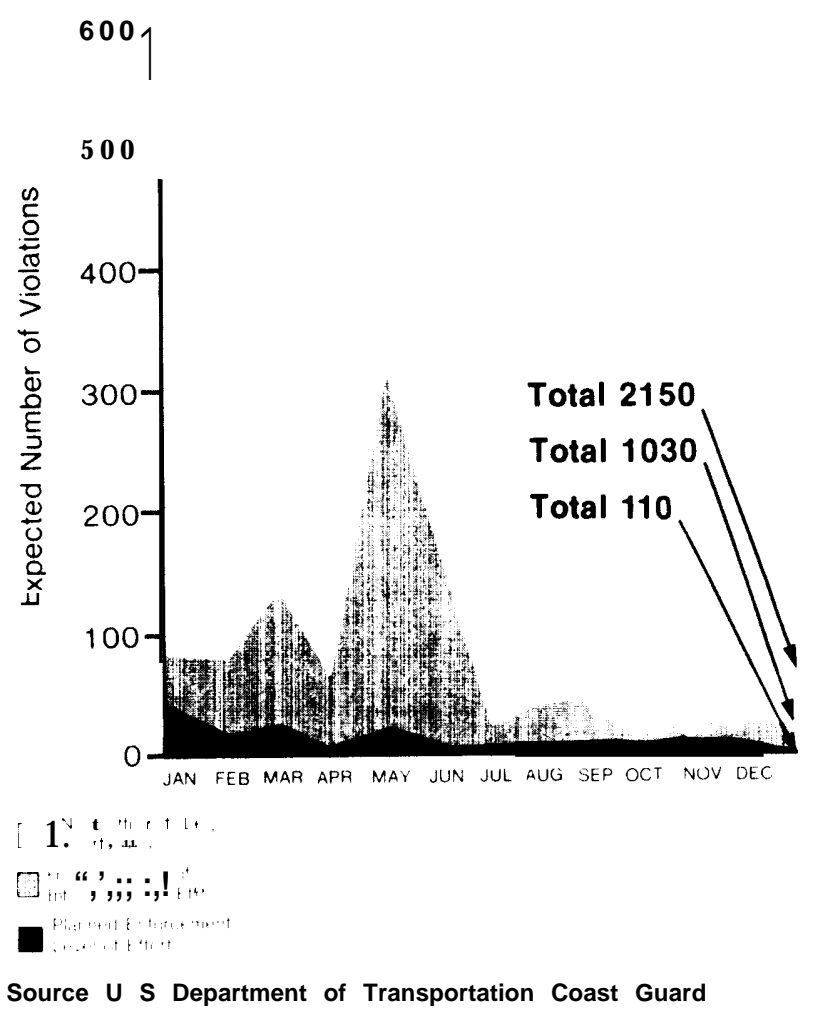




\section{New England}

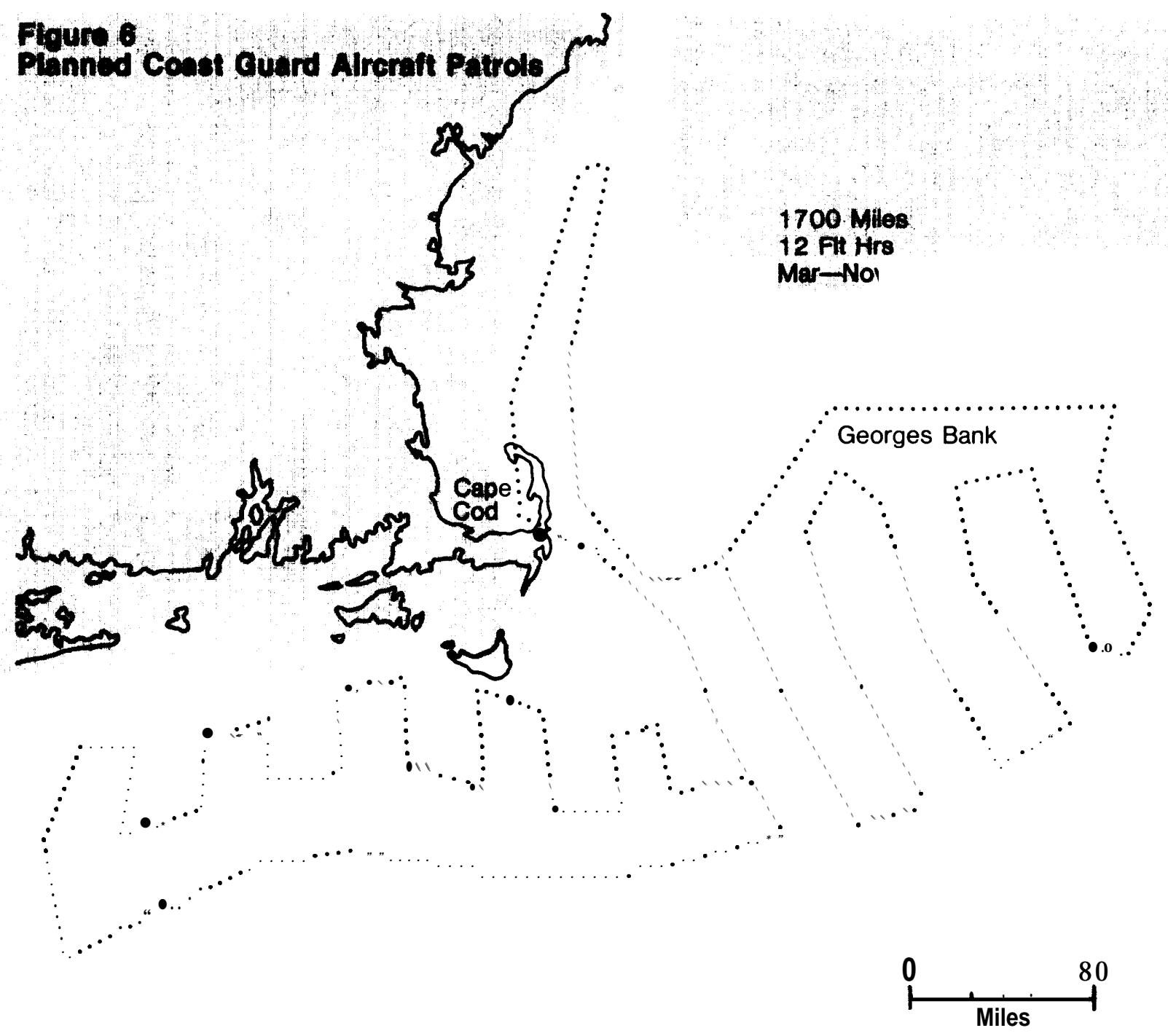


Mid Atlantic

Figure 7

Planned Coast Guard Aircraft Patrols

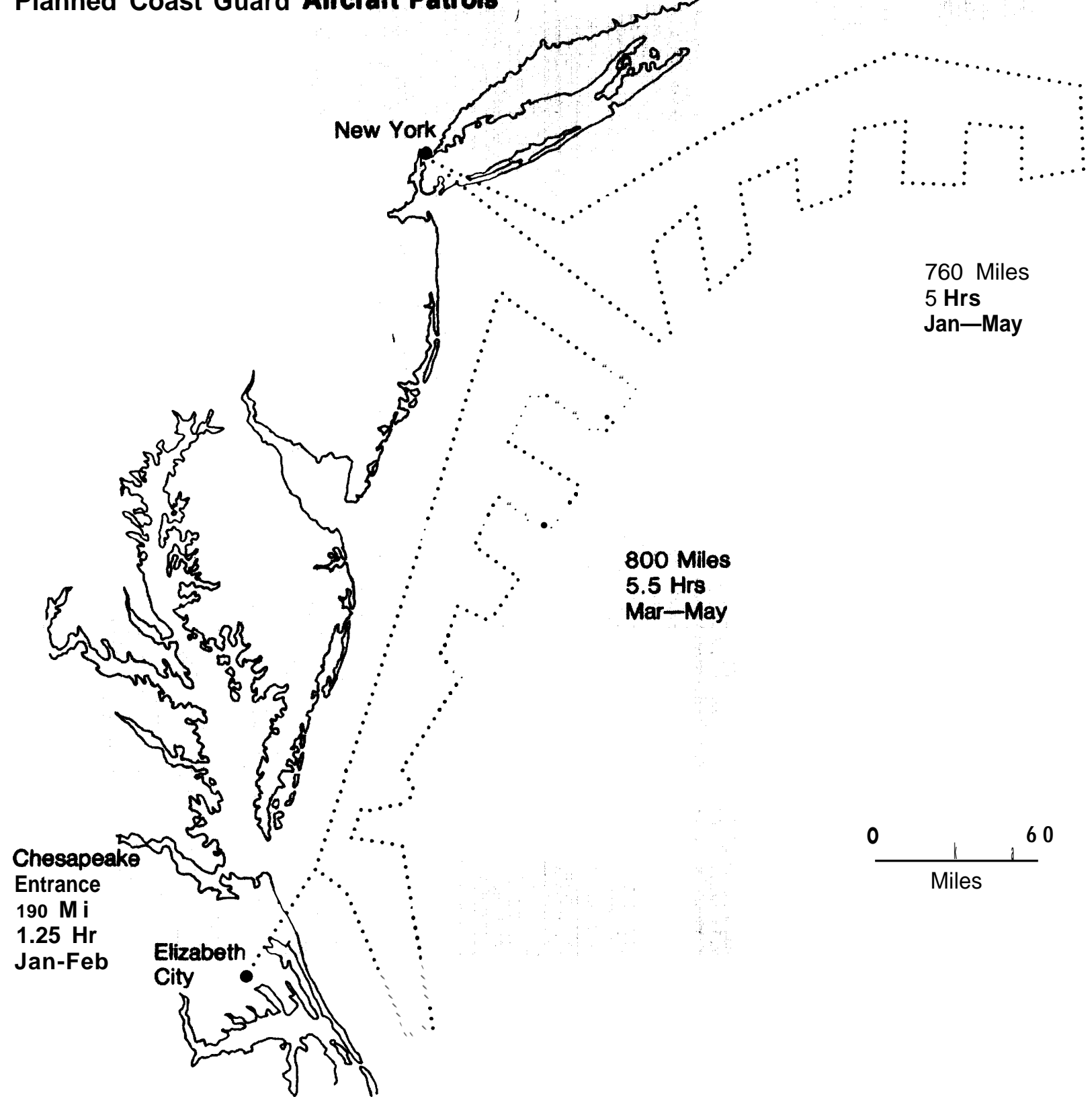

Source: U.S. Department of Transportation, Coast Guard 


\section{Gulf of Mexico}

\section{Plannod Coast Guard Alicratt Patrols}
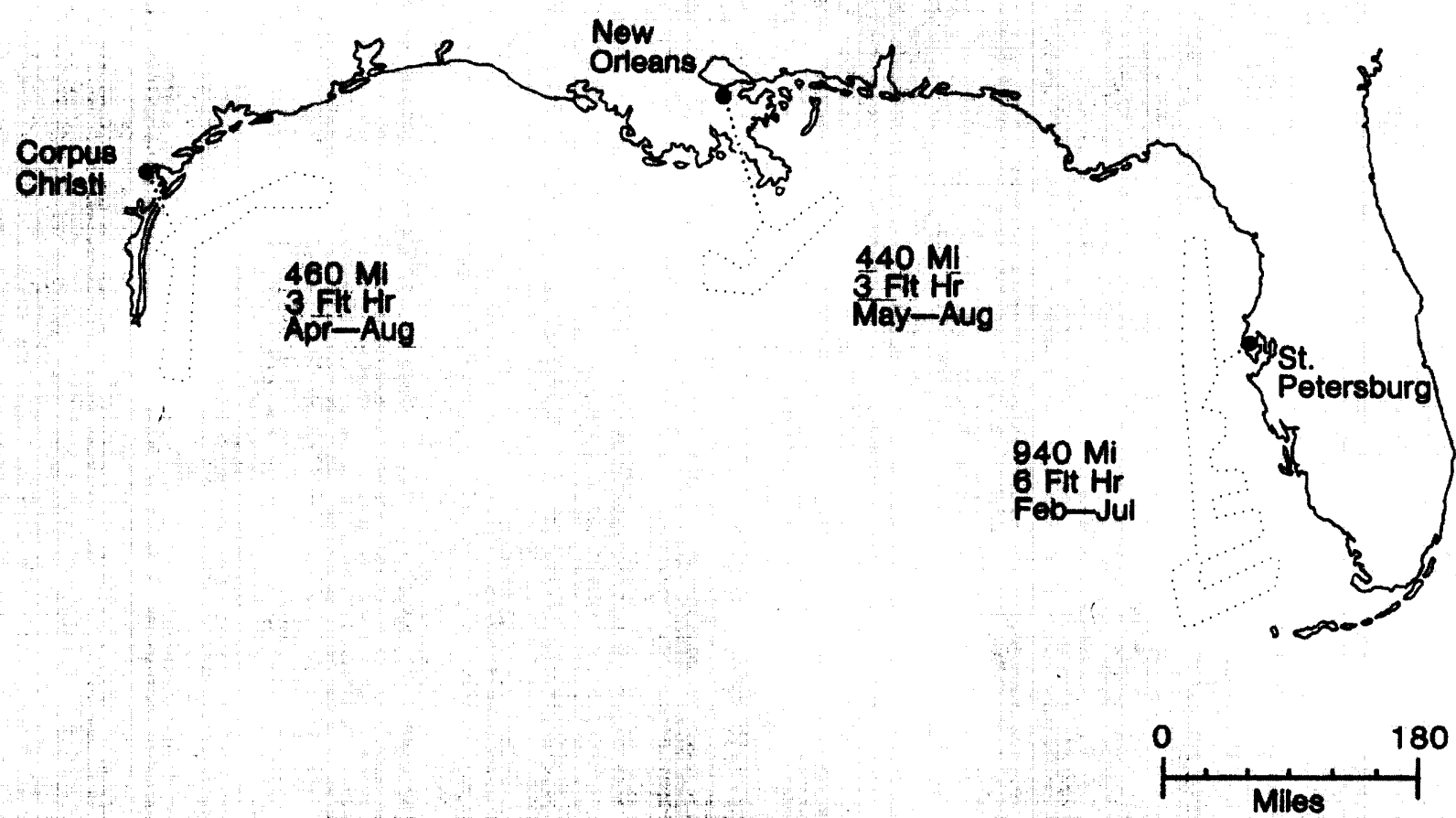

Source: U.S. Department of Transportation, Coast Guard 


\section{West Coast}

Figure 9

Pianned Coast Guard Aircraft Patrols

1070 Miles

$7.5 \mathrm{Flt} \mathrm{Hr}$

Apr-Nov

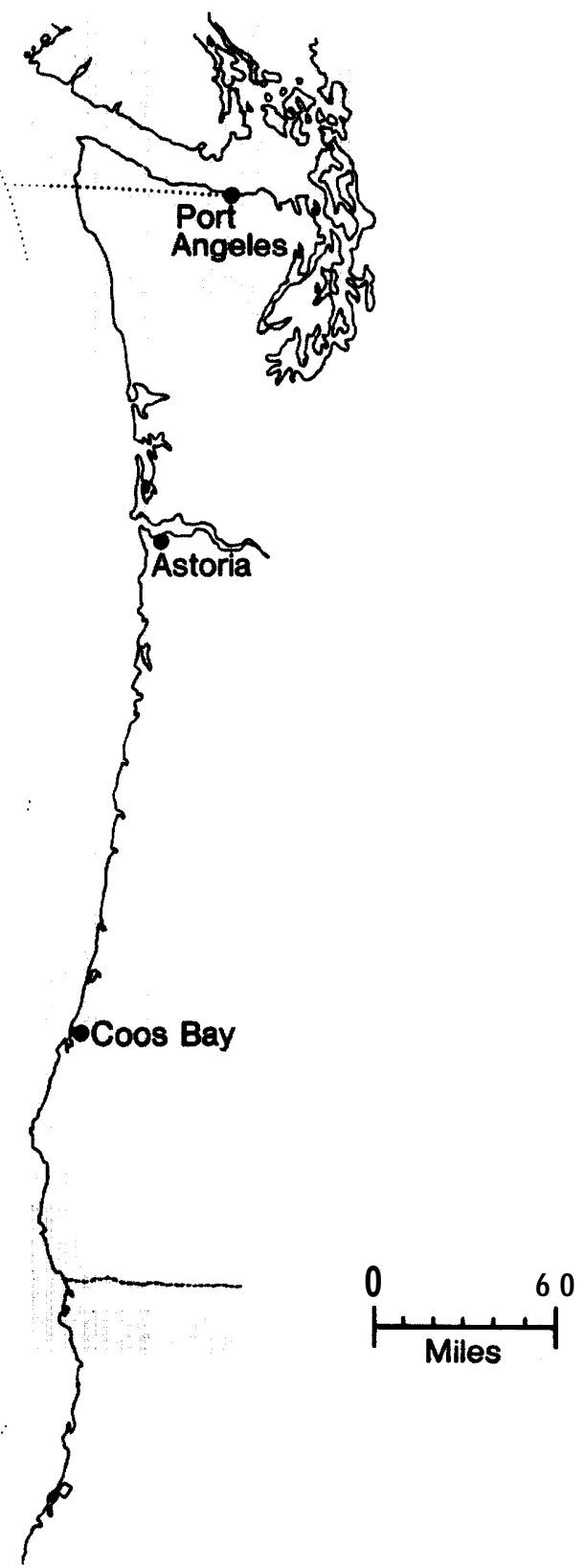




\section{Alaska}

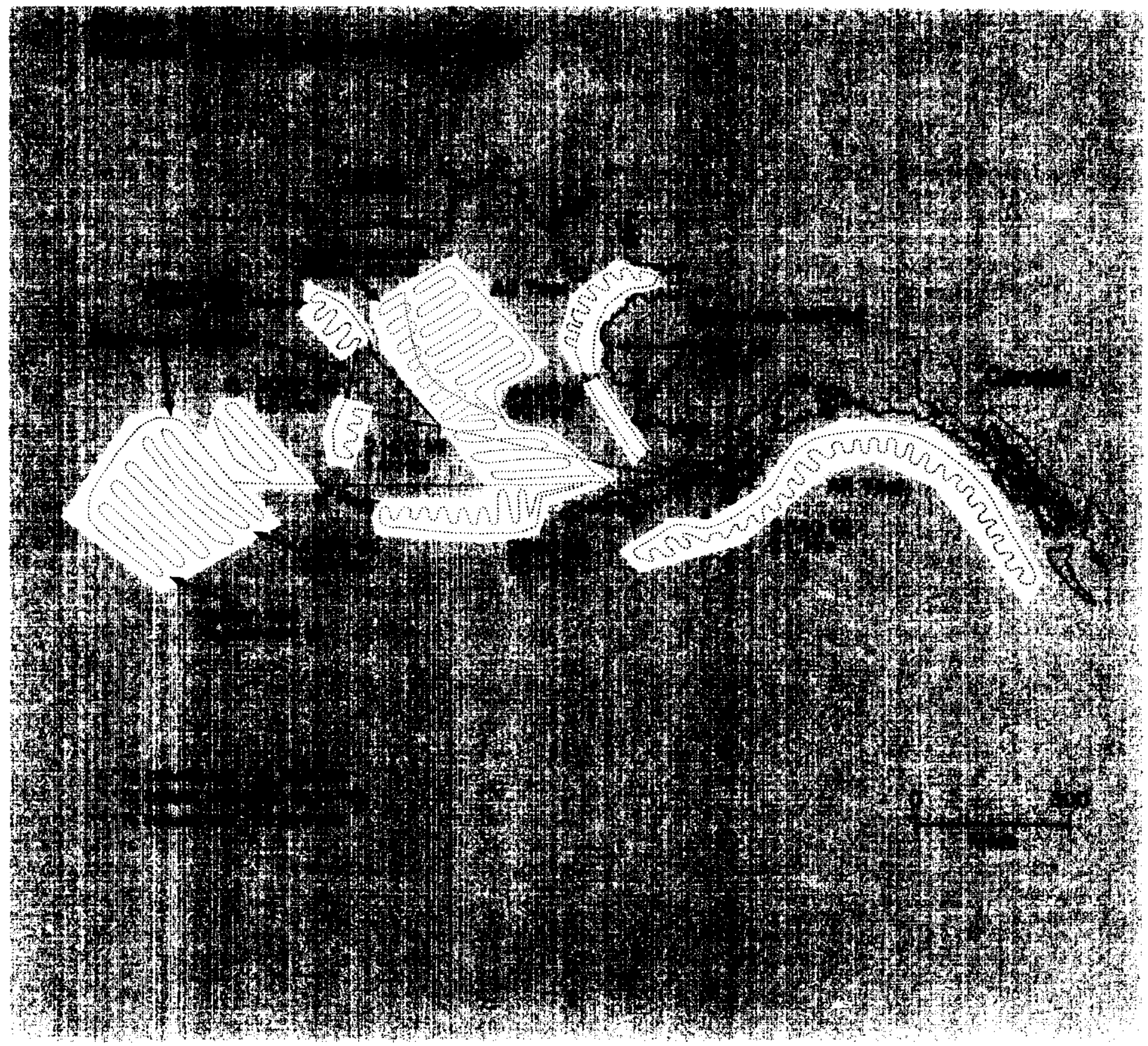


On the other hand, there are also many species in danger in the east coast and gulf fisheries. Three new aircraft have been assigned to the New England area and one to the Gulf of Mexico, but it seems reasonable that additional vehicles may be desirable on the east coast in the future even though fishery areas there are concentrated and not greatly increased by the move to the 200-mile jurisdiction.

As outlined by the Coast Guard, the planned enforcement strategy of increasing present capabilities is a reasonable first step. It is flexible in that enforcement resources will be added over a period of time and at a moderate first cost. As experience is gained, additional resources can be curtailed or accelerated if original assumptions do not prove out.

The Coast Guard enforcement strategy is, however, limited to preventing violations by foreign fishermen. Presently, there is no planning within the Coast Guard to deal with possible at-sea violations of the domestic fishery regulations. Only two domestic management plans have been drawn-up so far, but other plans will be a major order-of-business facing the Regional Councils in the future.

In the past, enforcement in the domestic fishery has been carried out by NMFS from shore, where officials observe offloading, weigh and inspect fish, and identify bycatch. NMFS will continue its enforcement of domestic fisheries from shore under the new law. If this dockside effort were to be combined with a program of boarding domestic vessels for inspections, it would probably be sufficient in most situations.
However, if regulations for domestic fisheries duplicate many of the gear and operational controls used in foreign regulations, some at-sea capability will be needed.

In the event an at-sea capability is needed for enforcement in domestic fisheries, the Coast Guard could use the same types of equipment and techniques planned for foreign fisheries, but would need additional facilities in order to cover the different areas used by domestic fishermen and the many additional fishing vessels of a greater variety of sizes and types.

Available information indicates that about 7,000 domestic vessels may spend most of their fishing time in the 3- to 200-mile zone. ${ }^{28}$ Although the domestic vessels catch far less than the foreign vessels, domestic fisheries enforcement-in terms of fishing units to be dealt with-is on a larger scale than foreign enforcement. The cost of any deterrence gained by domestic enforcement will also be higher than for foreign enforcement.

The Coast Guard has rightly given priority status to planning for enforcement in foreign fisheries. However, this OTA assessment indicates that at-sea enforcement will also be necessary in domestic fisheries in the near future and planning for such a job should be started as soon as possible." This will be a particularly sensitive enforcement job because fishermen, a politically powerful group, have traditionally enjoyed a great deal of freedom in how they conduct their activities. 


\section{Other Possibilities for Near-Term Enforcement}

The OTA study of enforcement strategies seems to indicate that several fairly simple techniques which could be activated almost immediately have not been given favorable consideration by the Coast Guard or the National Marine Fisheries Service.

Among these are:

1) the establishment of an efficient reporting system which would allow domestic fishermen to aid in observing foreign fishing vessels,

2) extensive use of observers onboard foreign fishing vessels, and

3) formulation of specific guidelines to be followed in granting annual permits and renewing the Governing International Fisheries Agreements.

The lesser of these strategies is the reporting system, which could be simply a well-defined and published procedure, which domestic fishermen could follow in notifying the Coast Guard by radio with information on the location of foreign vessels or on suspected violations of fisheries regulations.

The Coast Guard is not now planning a reporting system because of concern that it will increase the number of bogus complaints of violations and tax the already limited manpower and facilities of Coast Guard in the area. The Coast Guard argues that if fishermen suspect serious violations, they will-and already do-report these to the nearest Coast Guard facility,
Extensive use of a reporting system may not be likely because many domestic fishermen maintain radio silence in order to protect the location of their fishing areas. Still, it is likely that the lack of formal procedures for reporting may, in the future, cause the same kind of gap in coverage that was demonstrated when fishermen testified to congressional committees that some recent oil spills might have been prevented if fisherman had some system for reporting on the location of foreign tankers which are sited outside of established traffic lanes. ${ }^{29}$

Another minor improvement in enforcement could probably be gained by formulating a detailed list of specific criteria which will be taken into account in renewal of the Governing International Fisheries Agreements (GIFAs) with foreign governments and in annually granting fishery permits to the vessels.

The National Marine and Fisheries Service is now drafting civil procedure regulations which outline the sanctions, such as permit revocation, suspension, or modification, which may be used against violators or

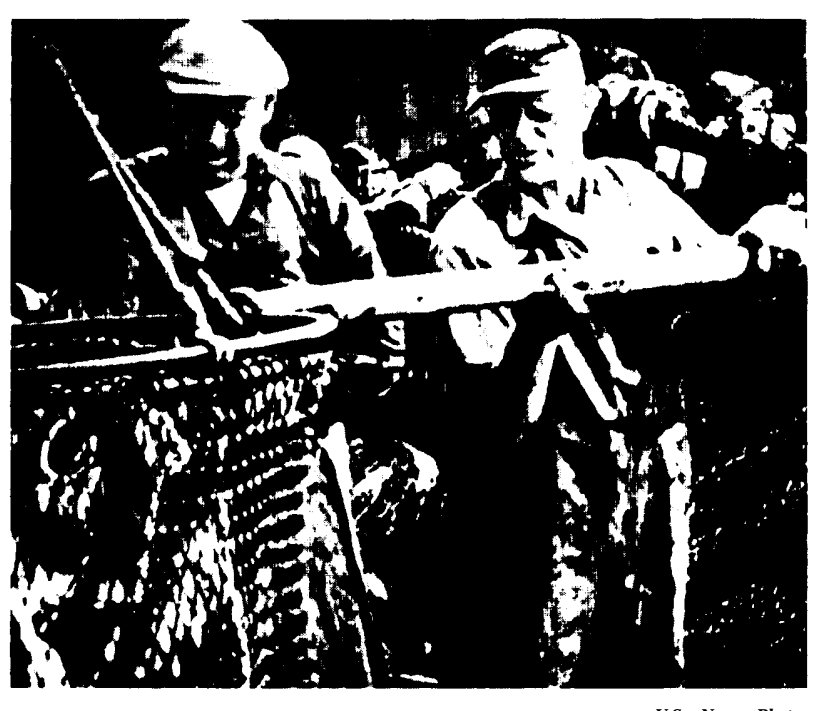

Much of the fishing activity is still conducted by hand, such as the job of emptying large nets. 
against those countries which have not paid fines and assessments. However, these procedures are not expected to include specific numbers or types of violations which would mandate nonrenewal of GIFAs or nonissuance of permits.

The Coast Guard has indicated that recording violations on the permits of individual fishing vessels may constitute one of the most potent regulatory tools available.$^{30} \mathrm{~A}$ system which works much like the points system used in revocation of drivers licenses and setting insurance rates is probably worth investigating in connection with fisheries permits. Such a system could be used initially in foreign fisheries, but would be equally useful in the domestic fisheries should some form of limited entry be adopted.

Under the law, GIFAs are negotiated by the State Department. However, the State Department has been given no regulatory functions. Therefore, the law may have to be amended in order to charge the State Department with preparing such guidelines for its negotiations or these guidelines could be prepared by NMFS along with guidelines to be considered in granting permits. Without these specific guidelines as to what violations constitute grounds for nonissuance of permits or GIFAs, it is likely that uneven and inefficient use of this potential tool will result.

It appears that the second strategy, the extensive use of observers onboard foreign fishing vessels, could be vital to the success of enforcement in the 200-mile zone.

Current plans call for placing observers onboard 10 to 20 percent of the foreign vessels granted permits to fish in U.S. waters. These observers will be NMFS personnel who will have no enforcement duties. They will be assigned randomly to vessels of foreign nations which in the past have been suspected of giving NMFS incomplete or inaccurate reports on their fishing activity.
The present plan is to place about 20 observers on vessels in the Georges Bank area of the Northeast fisheries and slightly fewer in the Northwest fisheries, primarily Alaska. The National Marine and Fisheries Service has estimated the annual cost of the program at approximately $\$ 750,000$, The cost per ship, with an observer onboard, may be as high as $\$ 15,00031$ for a cruise of several weeks. Under the terms of Public Law 94-265, which requires that foreign fishing vessels pay reasonable fees to compensate the United States for expenses incurred in the course of fishery conservation, management, research, administration, and enforcement, costs for observers will be billed to the individual ship carrying the observers. ${ }^{32}$

The cost will probably make little difference to vessels from countries which subsidize their fishermen, However, such a charge may not be taken lightly by fishermen who are independent operators. Since the vessels to carry observers will be chosen randomly within any particular country, levying the charge against the individual vessels may strain relations between foreign fishermen and the observer who must live onboard their vessel for extended lengths of time and make it much more difficult for the observer to gather accurate data. In the interests of easing this relationship, OTA suggests that charges for observers be spread evenly among all the ships in the fishing fleet of a particular nation. The law requires that the fee schedule which sets out charges to foreign fishermen be determined by the Secretary of Commerce in consultation with the Secretary of State.ss Therefore, a revised billing procedure for observer costs could be recommended to Commerce by State based on its negotiations with foreign nations. 
NMFS has used some observers for the past 2 years, primarily on Japanese vessels, and has termed the experience very successful as a tool for collecting information.

From the NMFS viewpoint, the observers are ideal for gathering scientific and management data, The observers could visually examine the rate of fish catch, effectiveness of fishing gear, and types and sizes of fish caught. This is information which will be vital to NMFS and the Regional Councils for use in the formulation of management plans for the foreign fisheries. Yet, none of these jobs can be adequately carried out by surveillance vessels or any of the remote-sensing devices which will be discussed later in this section. For these reasons, much more extensive use should be made of observers, in a dual role:

1) to collect data needed for management of the fisheries and

2) to observe operations for enforcement functions.

Observers could be utilized by the Coast Guard as part of its enforcement network. Among other enforcement-related duties, the observers could:

- verify proper use of specific fishing gear;

- check on bycatch or fish caught incidental to the species sought (In some fisheries more than half of a typical landing is not used and is dumped overboard.);

- communicate actual practices and fishing information quickly to a control center; and

- note violations, notify the Coast Guard, and even personally collect fines.

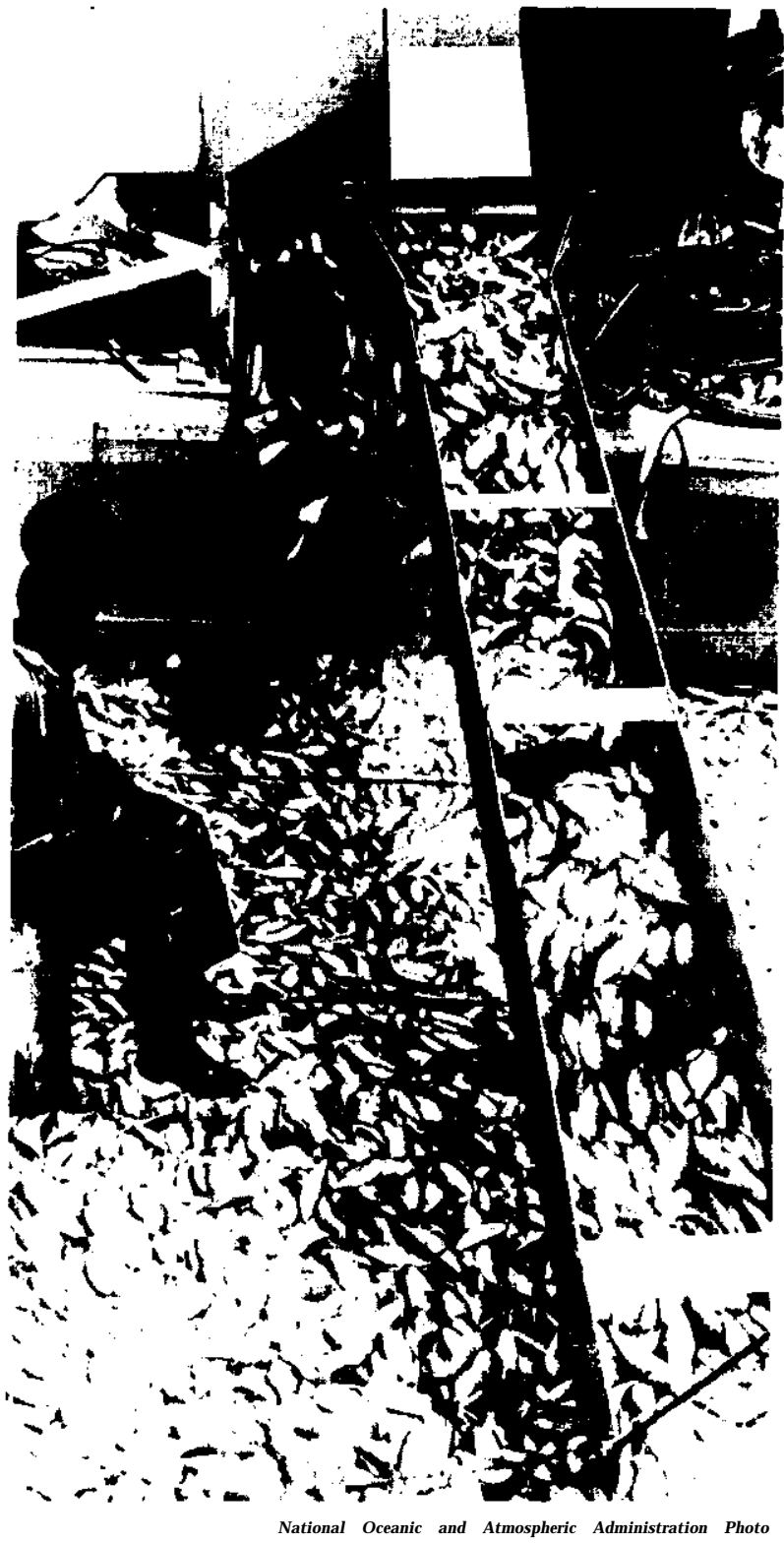

Observers on board fishing vessels may be in the best position to inspect catch for illegally retained species 
The Coast Guard has stressed the need for easily enforceable regulations as an important factor in successful enforcement. Aiming toward that goal, the Coast Guard favors a NMFS proposal to reduce most regulations to limitations on the amount of effort expended fishing or the number of days spent in a certain area. Such limitations are next to meaningless, however, because there is no dependable equation for measuring catch rates based on vessel time in an area. Past data used in such calculations haven't been verified. In addition, new technology and improvements in fishing techniques make any equation subject to constant change. Shipboard observers would be in the best position to provide analysis of the relationships between vessel time, fishing effort, and catch rate.

Foreign fishermen will realize that from their view the observer is primarily a policeman. The potential penalties for violations noted by the observer could be high, but the value of an illegal catch may be even higher. Therefore, foreign fishermen may attempt to bribe, harm, or deceive the observers, frustrating their scientific and enforcement functions.

Present thinking at the Coast Guard is that such drawbacks exceed the enforcement value of onboard observers although the observers would be very useful for collecting scientific and management data for NMFS. ${ }^{34}$

OTA research suggests otherwise: a nearblanket program of mandatory shipboard observers may be the simplest way to obtain the detailed information about fishing activities and response to fisheries regulations which will be necessary in developing a dependable, cost-effective enforcement program.

In addition, the Federal Government's failure to implement an extensive observer program will remove from the Regional
Councils the option of charging a fee for illegal bycatch. Some council members feel that such a fee, based on actual bycatch figures provided by observers, would be more successful than gear restrictions in reducing the actual amount of bycatch because it would force fishermen to find their own means of not catching fish which cut into their profit. ${ }^{35}$

The observer program is an area in which there are a wide range of opinions among the many parties interested in enforcement of fisheries regulations. However, the limited use of observers to date provides no basis for resolving these differences. A pilot project would offer actual experience on which to evaluate the cost and usefulness of observers in a combined enforcement - information gathering role. 


\section{Recommended Pilot Project}

The Office of Technology Assessment's analysis suggests that much could be learned from a pilot project in which a foreign fishery is nearly blanketed with shipboard observers who have both management and enforcement duties,

The New England region would be most suitable for such a pilot project for the following reasons:

- The fishing grounds are concentrated and foreign fishing practices are well known.

- Many of the foreign vessels fish in groups which could simplify the arrangement of vessels with observers and control vessels without observers.

- The stocks in that region are generally fee or tax on ex-vessel value of the catch could depleted and information for use in be reduced accordingly. restoring stocks is badly needed.

- Questions about bycatch are most significant in the area.

- There are important problems with gear restrictions and gear conflicts in the area.

About 150 foreign vessels, on the average, have traditionally fished within the 200-mile zone off New England. At this writing, the number of permit applications which had been received suggested that this number will probably go down because of the 1977 catch allocations. Therefore, it appears that a total of about 100 shipboard observers would be suitable for the pilot project. These observers should be selected on the basis of experience in fishing practice and knowledge of fishery matters. If they are given enforcement duties,

they should be Coast Guard personnel, instead of NMFS personnel. However, they should receive some training from NMFS in observing, collecting, and reporting information of value. Some familiarity with the nation on whose vessel the observer serves would also be helpful.

Based on NMFS estimates for their limitedobserver program, the cost of a 100-man pilot program would be roughly $\$ 2$ million plus funds for an accurate evaluation of the pilot. ${ }^{36}$

Under the law, this cost is passed on to the foreign vessels. However, other fees and charges are also levied, under the law, to reim burse the United States for management and enforcement activities in the 200-mile zone. Since the observer program would presumably make some other expenditures covered by these levies unnecessary, the gross tonnage- 


\section{Possibilities for Long- Range Enforcement}

It is likely that the proposed near-term enforcement capabilities described earlier will not be adequate for long-range demands. Factors like the following may contribute to the need for more sophisticated enforcement tools:

- Individual Regional Fishery Management Councils are likely to develop some unique regulations which demand more knowledge of vessel locations;

- Developments in technology may result in more efficient and effective equipment, for instance, land-based electronics systems could supplant some aircraft flights;

- There may be pressures for increased foreign fishing off our shores, such that the value of illegal fish could exceed the cost of being apprehended;

- Scientific data might reveal a greater danger to fishery resources than is presently realized or danger to resources in new areas not now covered;

- The costs of traditional enforcement may grow to a level that could not be easily justified in terms of resources conserved.

Such factors as these lead to the conclusion that plans should be made for further improvements in enforcement capabilities by use of remote-sensing devices and other advanced technology.

It is probably in the national interest to actively plan and pursue interagency use of some of these new technologies, especially those in which there already has been significant investment in development. However, it is unlikely that military agencies which now have such advanced technology will volunteer or be receptive to suggestions that they share their capabilities for use in enforcing fishery regulations.
In addition to the fact that such equipment is dedicated to military application and reportedly already heavily used, it would be necessary to develop a fast and efficient clearinghouse for processing and distributing information from the sensors before joint use of sensing equipment would be possible. The military has already developed specialized systems for correlating information from many sensors; however, these systems are crowded and translation of fisheries data would receive low-priority treatment.

It may be desirable to pursue the development of new facilities which could receive data from many sources, including such groups as the military, Bureau of Customs, NMFS, Coast Guard, and State and Federal law enforcement networks. This facility could correlate data, protecting classified or privileged information if necessary, and display all maritime activity, including that of fishing vessels $^{37}$ (see figure 11).

Such a data correlation and display center for coverage of the complete fishing zone would be costly, but it could also provide information on oil tankers, commercial cargo carriers, surveillance for search and rescue missions, and other similar activities. The Office of Technology Assessment's Working Paper No. 5, which discusses such a facility, estimates the initial set-up cost at $\$ 1.5$ million for a correlation facility to receive the information. Computer time would cost at least $\$ 14,000$ a month for operation of the facility. Expense to the Coast Guard for installation of hardware compatible with the correlation facility and operation of Coast Guard functions would be an additional cost which has not been determined.

\section{Recommended Pilot Project}

OTA proposes a pilot program utilizing one of the existing military systems for the collec- 


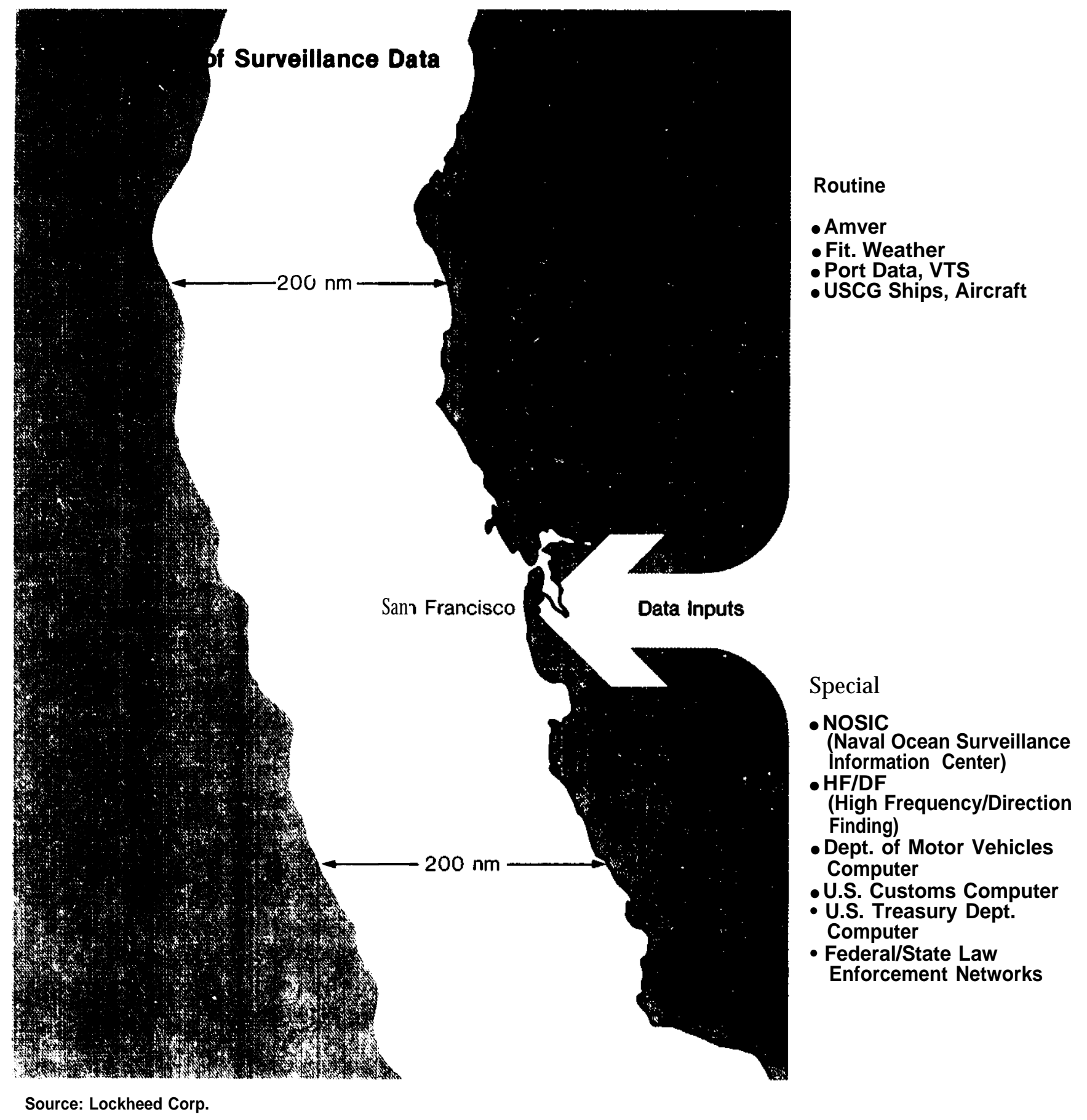




\section{New Technologies}

tion and transfer of available surveillance data for one specific region. Some precedent for such a project already exists at the Naval Ocean Surveillance Information Center where the Coast Guard has recently detailed one officer to work on data which are of interest to the Coast Guard and have not, in the past, been processed by Navy personnel. ${ }^{38}$

The Office of Technology Assessment has not investigated the feasibility of using a specific system in any region, but it appears that the Navy's west coast network could be a likely pilot region. Any pilot project should begin with an indepth investigation of the Navy's existing system and its ability to provide information needed for fisheries enforcement.

Some funding would be necessary to add personnel who would coordinate the transfer of fisheries-related data from the Navy to the Coast Guard district in charge of fisheries enforcement in that zone.

After a period of operation, the pilot project should be evaluated with special attention to determining the completeness of coverage provided, the cost, the timeliness and usefulness of data provided, and a comparison of this method with other methods of surveillance.

On one hand, there may be difficulties in working with and protecting classified information and there may be a danger that this extra task might not receive adequate attention in a facility oriented to an existing military mission. However, such an information-sharing program could ultimately cut costs substantially by reducing duplication of effort and facilities. It could also provide cooperative experience which might lead to sharing of other services and resources needed for enforcement and the opportunity to evaluate new technology which may be of use in fisheries enforcement.
Use of new technology, particularly remote-sensing devices, may make it possible to improve enforcement of fisheries regulations in the future by better coverage, better performance, and a reduction of the need for expanding conventional ship and aircraft patrols. Although it may be possible for several agencies (such as the Coast Guard, the military, and NASA) to share the cost of new remote-sensing devices, these systems are extremely expensive and their use should be thoroughly evaluated before any one system is adopted. Any analysis of benefits and costs of remote-sensing systems should not ignore the argument that national security could be compromised by making some of these systems available for other than military missions. Most of the security risks and financial costs of remote-sensing systems could be considered now; however, a clear analysis of the benefits or improvements that could result from the use of such new technology is not possible until overall strategies of enforcement and specific regulations are defined. When these strategies and regulations have been drawn up, it will be desirable to prepare a long-range plan; for example, a 5- to 10-year plan that would include specific analysis of the introduction of new technologies and techniques into enforcement plans.

The Coast Guard is presently in the process of formulating a research and development program for future enforcement of fisheries laws ${ }^{39}$ Such a program could make good use of an improved version of the existing computer model or a new model such as the one suggested in an earlier section for joint preparation by NOAA and the Coast Guard. The research program is expected to include plans for studying hardware and procedures for improving monitoring and surveillance, communications, data integration and analysis, and general operations. 
At present, the research and development program is directed toward bringing new enforcement technology into use in 10 years or more. It could be possible, however, to accelerate the applied development of new technology for which most of the research has already been completed by others so that it could meet some Coast Guard needs in about 5 years.

Because the budget for fisheries enforcement is only a small part of the overall Coast Guard budget (about $\$ 50$ million out of $\$ 1.2$ billion), the agency has determined that research funds in support of such enforcement can best be spent for technology transfer and for additions to related research contracts in other agencies. ${ }^{40}$

The Coast Guard is also following developments in the Department of Defense where much of the work on technology which may be applicable to long-term fisheries enforcement is classified.

If conservation and management of the 200mile fisheries zone is judged to have value to the United States beyond the present monetary value of fisheries-related products and employment, support for increased research at the Coast Guard level may be warranted. Further research should include determination of the best methods of utilizing classified systems for other than defense purposes.

It appears that a pilot project for cooperation and joint research could bring together the Coast Guard, DOD, and NASA to develop new systems and find efficient ways of using technology in a multimission context. Such a pilot project could include joint preparation of long-range plans for determining the most appropriate research and development strategy for new technologies, identifying the needs of all potential users of such technology, and analyzing the costs and benefits of developing and utilizing new technology, especially remote-sensing devices.

\section{Remote-Sensing Devices}

Since it appears that remote sensing will be an important enforcement tool as fisheries management develops, OTA commissioned a study of the technology of such systems. The following is a brief summary of the OTA study of remote-sensing devices and findings relative to the remote-sensing techniques which were analyzed for potential usefulness in fisheries enforcement. Figure 12 compares the various techniques for usefulness and cost.

Of the seven devices studied, microwave radar appears to have the best potential for use in fisheries enforcement. High-frequency, over-the-horizon radar was also judged to have good potential, but is not as highly developed for commercial application as microwave radar. Other remote-sensing systems in this group appear to have only limited fisheries application at this time.

Because of the sensitive nature of much of the remote-sensing technology, OTA has also prepared a separate classified document on these systems.

By definition, remote sensing includes any method of obtaining information about an object from a distance without any physical connection to the object. It must be remembered that remote sensing is a detection and identification tool only; it is not useful in apprehension.

For purposes of this study, research personnel with broad knowledge and experience in remote sensing have analyzed potential techniques for use in fishery enforcement and have determined that some of these techniques can be applied to fishery enforcement without resorting to the kind of high-priority, high-cost research and development used in defense and space exploration programs. 
Based on past experience and based on Navy and Coast Guard ocean surveillance functions, it is likely that a combination of sensors may be required to maintain an adequate picture of activity. When properly correlated and analyzed, information from visual, radio, and radar sensors can provide a picture that is much more complete and of greater validity than could be provided by any one or a few sensor systems. Ultimately, the problems of patrolling a 200-mile fishing zone may require the acquisition, correlation, and analysis of multisensory data.

The Department of Defense is the principal developer and user of most of the remotesensing technology which may be applicable to the fisheries enforcement problem. To a lesser extent, the National Aeronautics and Space Administration and the Federal Aviation Administration are also developers and users of new sensing technology. The Coast Guard is now working with these other agencies to determine what technologies would be suitable and how they could be utilized in fisheries enforcement.

\section{Transponders}

A transponder is an active beacon which can be used in conjunction with radar or other electronic transmission system to enhance the detection and location of foreign fishing vessels. The transponder transmits energy on the same frequency as the radar signal, but at a level several times higher than that which would result from unaided reflection of the signal.

Some transponders can be hooked into Loran $-\mathrm{C}$ receivers. Loran $-\mathrm{C}$ is a navigational aid by which the location of a vessel is automatically pinpointed by triangulation, using continuous signals from two shorebased stations at known locations. After the location is identified by Loran-C, the information is passed to the transponder which retransmits it, along with the vessel's identification, to a control station. These systems have good future potential for use in fisheries enforcement as an extension of patrols by cutters and aircraft.

Transponders can be built that emit a standard, preset signal or that respond to interrogation by a remote-sensing device by transmitting a wide variety of identification and fishing status information. The sophistication of transponders is limited primarily by cost considerations. However, the state-of-the-art in transponders is advancing rapidly, due largely to advances in digital storage and processing technology, so that improved performance at lower cost is possible in the future. From a fisheries enforcement standpoint, the major drawback of most transponders is that cooperation on the part of the vessel fitted with the transponder is required. A transponder that simply enhances detection or supplies a preprogrammed identification and location signal can operate independently on any input from the target, but to supply additional information such as fishing status or catch data the vessel must provide the information to be transmitted. Guaranteeing that such input would be provided or that input would be accurate could prove to be a serious problem, In addition, since such transponders could only be placed aboard vessels which had permits to fish, they would do nothing in identifying vessels which had illegally entered an area without permit status.

It has been suggested that in lieu of requiring transponders on foreign fishing vessels, such devices could be supplied to domestic fishing craft to emit a signal that would immediately identify them as ships with which the enforcement agency need not be concerned. 


\section{Flgure 12 \\ Summany of the Potentlal of Remoto-Soneing Tochnology To Support Enforcement of the 200-nmi Fishing Zone}

\begin{tabular}{|c|c|c|c|}
\hline \multirow{3}{*}{$\begin{array}{l}\text { Technology } \\
\text { Microwave Radar }\end{array}$} & \multirow{3}{*}{$\begin{array}{l}\text { Overall } \\
\text { Potential } \\
\text { Excellent }\end{array}$} & \multicolumn{2}{|l|}{ Dotection of Design Target } \\
\hline & & Unaided & Boacon-Asaiated \\
\hline & & $\begin{array}{l}\text { Dotection to } 200 \text { nmi from Alroraft; } \\
\text { Some Sea Clutter Limltations; Position } \\
\text { Accurecy< } 8 \text { nmi }\end{array}$ & $\begin{array}{l}\text { Defegtion to } 200 \mathrm{~nm} \text { from Alrcraft; No } \\
\text { Selu Clutter Umitations; Position Accuracy } \\
\text { Aocureoy }<2 \text { nmi }\end{array}$ \\
\hline $\begin{array}{l}\text { HF Over-the- } \\
\text { Horizon Rader }\end{array}$ & Cood & \multicolumn{2}{|c|}{ Clessitiled } \\
\hline $\begin{array}{l}\text { Microwave } \\
\text { Padiometry }\end{array}$ & Umiled & $\begin{array}{l}\text { Dottotion to } 10 \mathrm{kft} \text {; weather } \\
\text { Except in Extremely Heavy Rain; } \\
\text { Postion Accuracy, Rolative to } \\
\text { Plottorm, } 1 \text { to } 10 \mathrm{ft}\end{array}$ & Beacon Detection to Line of Sight \\
\hline $\begin{array}{l}\text { Optios and } \\
\text { Electro-optices }\end{array}$ & Limited & \multicolumn{2}{|c|}{ 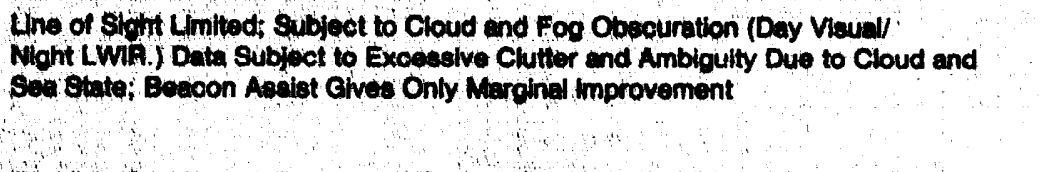 } \\
\hline $\begin{array}{l}\text { Eleotromagnetic } \\
\text { Intercept }\end{array}$ & Limited & \multicolumn{2}{|c|}{$\begin{array}{l}\text { Method Inherently Uses Target Tranemisetons as Beacon. Detection Limited Only by } \\
\text { Propagation and Interference Condliono. Bearing Accuracy } \sim 10 ; \text { Posilion Accuracy } \\
\text { by Trtangulation Limitted by Hearting Accurpey and GDOP to Erors } \geq \text { a Few Miles. }\end{array}$} \\
\hline Magnetic & Negligible & Extremely Short Range & Not Applicable \\
\hline Acoustic & Limited & \multicolumn{2}{|c|}{ Classified } \\
\hline
\end{tabular}

Source: Stanford Research Institute

The Coast Guard has a research program underway to develop prototype transponder equipment. The Loran-C system is one of several alternatives being considered. ${ }^{41}$ The Coast Guard is also following related hardware-development projects within other agencies, such as the Navy, and has added some of its needs to research contracts already
As the lead agency in developing transponder technology for use in fisheries enforcement, the Coast Guard is seeking to determine the specific contributions that can be made by existing equipment and to develop small, tamper-proof packaging for transponders to be placed on foreign vessels.

Estimates are that a minimum of 2-years work will be necessary before a suitable 
Figure 12 (continued)

Summary of the Potentiai of Remote-sensing Technology To
Support Enforcement of the 200 nmi Fishing Zone

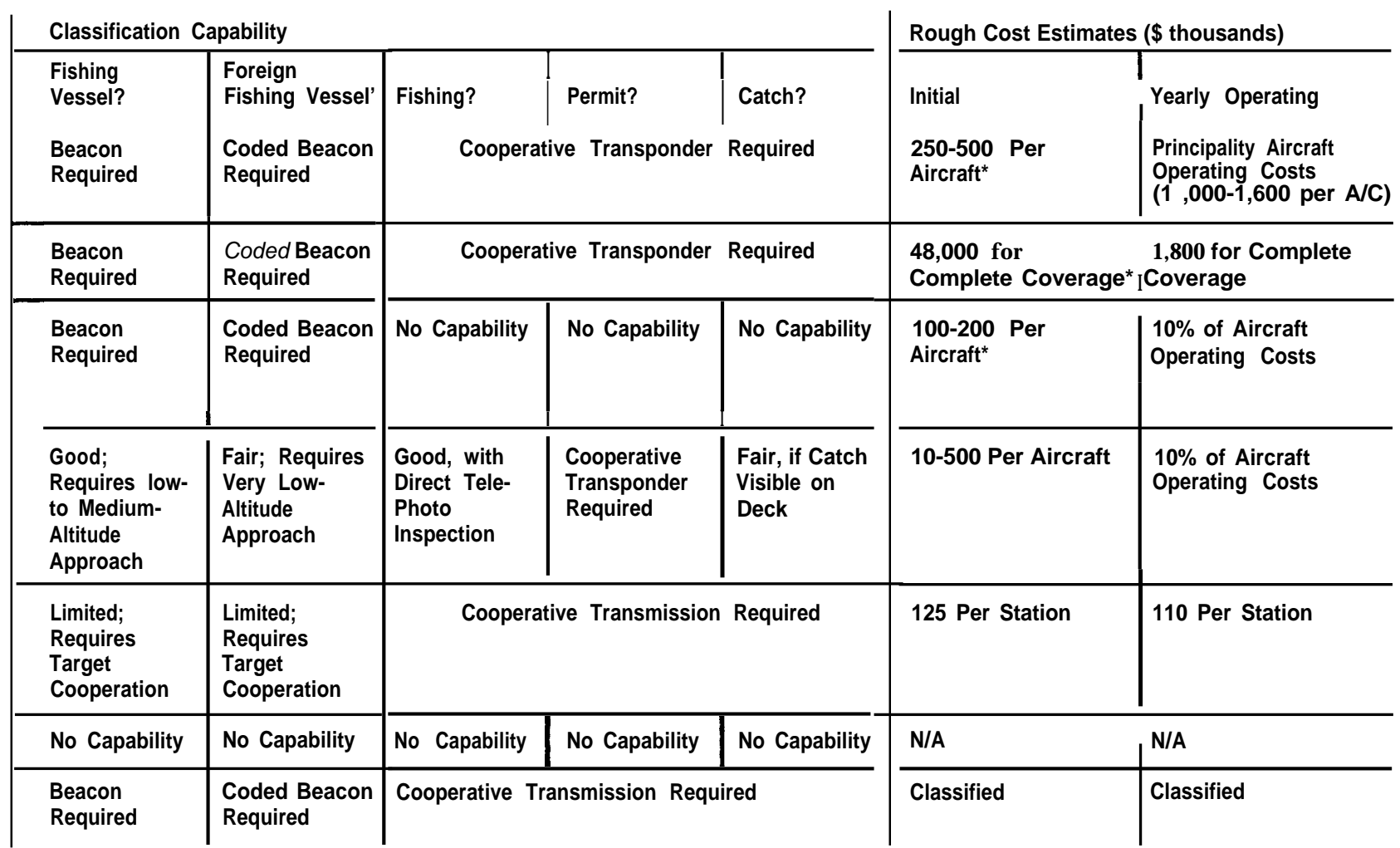

NOTE: Beacons or transponders on each fishing vessel would be in addition to the above and cost $\$ 500$ to $\$ 2,500$ per vessel.

Source: OTA

system can be put onboard foreign vessels and that as much as 7 years may be required before an ideal system with the best long-term application is devised. ${ }^{43}$

Recommended Pilot Program. - The Office of Technology Assessment suggests early implementation of a pilot program utilizing transponders in two specific regions-the Bering Sea off the coast of Alaska and Georges Bank off the New England coast. Since each of these areas is a traditional fishing ground, but with very different prevailing conditions, the usefulness of transponders could be evaluated for a broad range of applications by this pilot program.

The pilot programs would require the design and manufacture of Loran-C transponder equipment specifically for this pur- 49 
pose. The Loran-C network is now planned or in operation in the regions proposed. A licensing arrangement and installation technique for fitting transponders on each foreign fishing vessel entitled to fish in the region would need to be devised, Control stations and receivers on patrol ships or aircraft would need to be installed.

It is estimated that the transponder which would go onboard each foreign vessel would cost less than $\$ 2,500$. Once the system were installed, operational costs would be roughly equivalent to the operational cost of the aircraft carrying each control station, \$1 million to $\$ 1.6$ million annually. Funds for evaluating the pilot project would be in addition to these costs.

The Georges Bank pilot program would require about 150 transponder units and a control station most likely at a Coast Guard shore base in New England. Each vessel entering the 200-mile zone at Georges Bank for fishing would be required to activate its transponder which would automatically transmit identification and location to the shore base. The shore base would keep plots of all foreign fishing activity on the banks and give this to patrol craft. Regular patrols of the region would use this information to check on any fishing activity that wasn't reported by this system. At the end of one season, an evaluation of the usefulness of this system could be made.

In the Bering Sea region a similar network of transponders could be required aboard foreign fishing vessels, In this region it may be desirable to combine the transponder network with microwave radar systems already used aboard Coast Guard patrol aircraft and receiving stations. In this way a specific region could be covered by regular overflight, all vessels operating in the region located by radar, each vessel interrogated to determine whether an approved transponder is aboard stating ID and location, and any vessels without transponders investigated. ${ }^{44}$ There are several advantages to a system thus described, especially in Alaska where long distances and large areas can best be covered by aircraft and where frequent cloud cover makes visual observation difficult or impossible. After a season of operations with such a system a comparative evaluation of its usefulness would determine whether it could be beneficial to expand use or coverage.

\section{Microwave Radar ${ }^{45}$}

Microwave radar has been used for ocean surveillance by aircraft and ships for almost 40 years. The technology is highly developed and the design principles are so well known that it is possible to predict with high confidence the performance of any given design chosen for use. Microwave radar has better potential for large area coverage than any other system now in use.

Microwave radar operates by transmitting pulses of energy from a directional antenna, The pulses are reflected by any material object encountered. The reflected energy is subsequently received and analyzed to determine the position and characteristics of the reflecting objects. The direction of the objects can be determined by tracking the reflected signals and the distance is determined by measuring the time delay from pulse transmission to reception of the reflected signal.

The basic information for fisheries enforcement which can be supplied by microwave radar is:

- the presence or absence of a vessel in a given area; 
- the position of a detected ship at a given point in time;

- course and speed of a vessel when a series of position updates are available; and

- estimates of gross shape and size.

However, microwave radar by itself has almost no potential to classify vessels by type, nationality, or operation. Some classification may be possible by continuous tracking to establish movement patterns, but microwave radar's primary contribution to classification is in guiding patrol ships or aircraft to a position where identification can be made by visual means. Detection of fishing vessels by radar is enhanced, and identification and classification made possible, by adding transponders onboard permitted foreign fishing vessels.

Any modern commercial or military shipboard radar can easily detect fishing boats at a distance of up to 12- to 18-nautical miles (nmi), Existing ground-based, surface-search radars, such as the sea surveillance radars developed for the Pacific Missile Test Center by the Navy Electronics Laboratory Center, can detect fishing vessels at a distance of up to $40 \mathrm{nmi}$ from the land base. These systems are already in use by the Coast Guard which has some of the best available equipment.

The opportunities for improving the use of microwave radar lay in the use of more advanced radar systems from aircraft or satellites and the addition of transponders onboard fishing vessels in order to exploit the information-gathering potential of the combination. It is estimated that a single aircraft with radar could patrol the west coast out to and beyond the 200-mile fishing zone once every 4 hours (see figure 13), For satellite surveillance, the National Aeronautics and Space Administration (NASA) has estimated that

\section{Figure 13 \\ Useful Surveillance Coverage by a State-of-the-Art Microwave Radar on a 70-kft Altitude Aircraft}

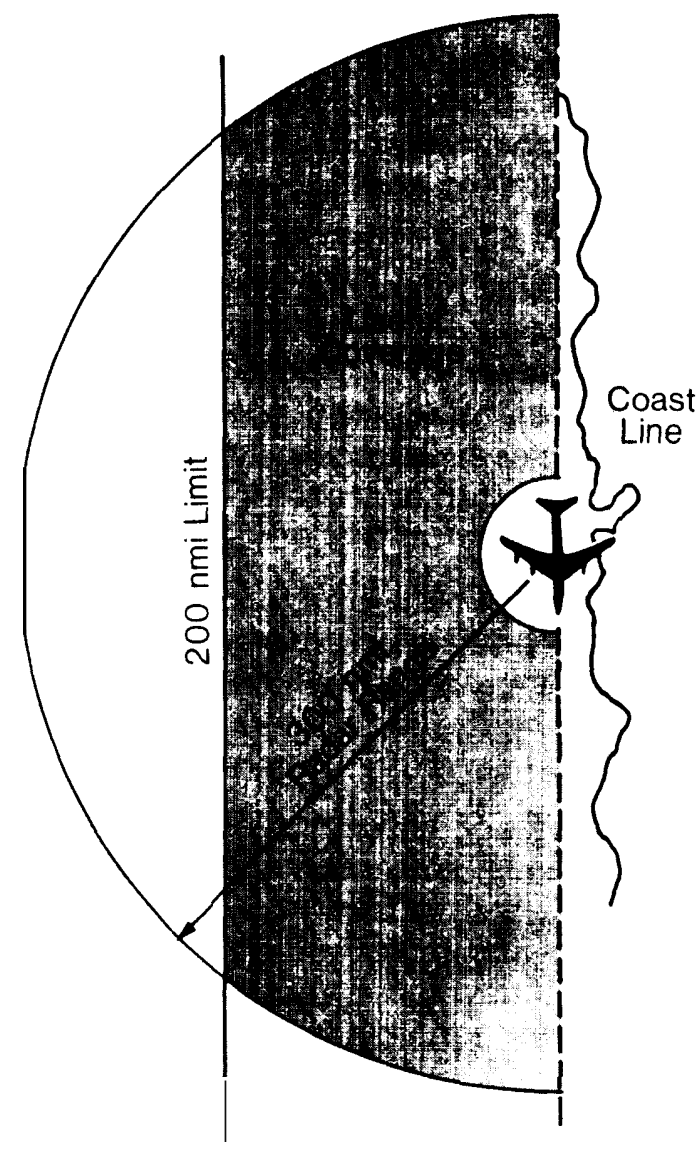

Source: Stanford Research Institute

twice daily imaging of the entire U.S. fishery zone could be provided by eight satellites.

Microwave radar technology operated from satellites is being developed by the Department of Defense and NASA and mav be available within 10 years, The system has the potential to supplement or supplant airborne 
radar, but the cost would be high and probably would have to be shared by several agencies.

\section{Over-the-Horizon Radar $^{46}$}

Use of over-the-horizon radar (OTHR) techniques would allow detection of fishing boats at much greater distances and would allow coverage of much larger areas than those covered by microwave radar.

This is because remote sensing using signals in the microwave and other very high frequency ranges is constrained by the essentially line-of-sight nature of the signal. For all practical purposes, this means that the sensors must be elevated in order to operate over significant distances.

The use of over-the-horizon radar reduces this constraint by making use of signals in the high frequency range in which energy waves are refracted by the atmosphere or ionosphere to follow the curvature of the earth.

High frequency energy has been used for communications since the earliest days of radio. The technology for generation, transmission, and reception of high frequency energy is well developed and the effects of the atmosphere and ionosphere on the signals are well understood. However, some aspects of using high frequency signals are not so well understood. Among these are the reflection characteristics of material objects at high frequency, Means of concentrating and coding high frequency transmissions to enhance radar operation and the processing of radar returns in order to extract more information about the object detected also are still being developed.

OTHR has been developed primarily for military use and several experimental systems, capable of performing a number of useful functions, have been built by the Naval Research Laboratory, the National Oceanic and Atmospheric Administration, and other groups.

Two types of OTHR might be useful in fishcries enforcement, a skywave mode and a groundwave mode:

Skywave OTHR takes advantage of the refractive property of the ionosphere, which causes the radar to curve back to earth at distances ranging from 500 to $2,000 \mathrm{nmi}$ (see figure 14). Thus wide area coverage is possible from a single site. For instance, a single skywave OTHR located in Utah could provide surveillance coverage over the entire Pacific Coast (see figure 15).

Groundwave OTHR, in which radio energy travels along the curved earth surface, provides much more limited coverage, but may be useful in specific regions. Groundwave OTHR has an operational radius of a few hundred miles. Thus, while ships out to and beyond the 200-mile zone could be detected from a shore station, many stations would be required to cover the entire coast.

Both systems can provide continuous surveillance of very large areas so that the general location of all fishing boats of at least a certain minimum size can be monitored on a full-time basis. If transponders are installed on the boats, detection can be enhanced and other useful information can be obtained,

Because of their capability to cover greater distances and larger areas, OTHR techniques have good potential for use in fisheries enforcement. However, due to both the classified 


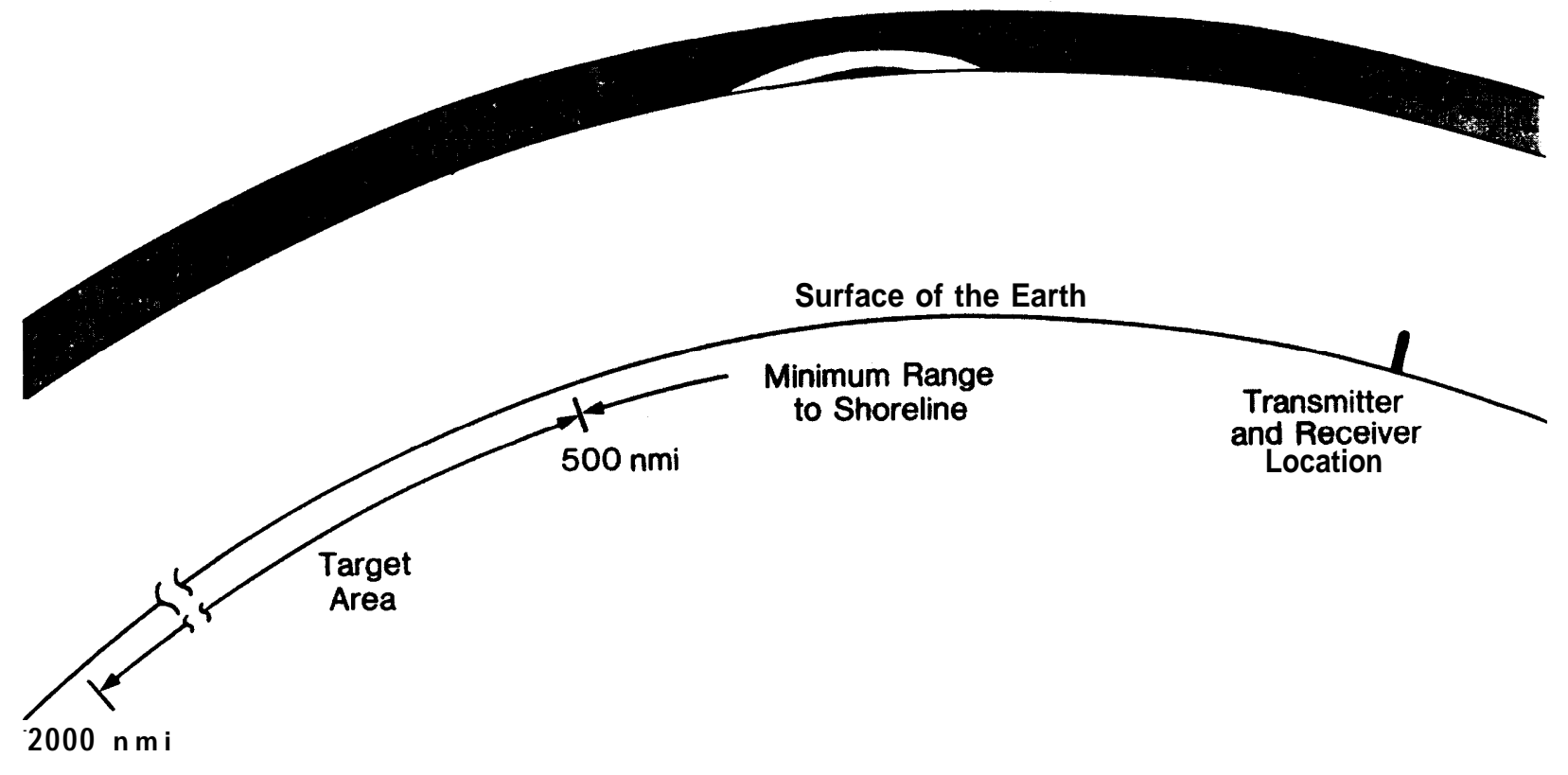

Source: Stanford Research Institute

nature of most of the military work in the field and the high cost of OTHR, use of this system will be contingent upon close cooperation between the Department of Defense (DOD) and the Coast Guard,

\section{Microwave Radiometry ${ }^{47}$}

Microwave radiometers operating alone offer very little promise as a means of identifying fishing vessels or their catch. However, if combined with transponders onboard ship, they are a promising system which would locate, identify, and classify ships in almost any weather, day or night and provide other data on sea state, sea ice, and rainfall rates as well.
A radiometer is merely a sensitive detector which receives and measures the brightness temperature of microwave energy naturally emitted and reflected by surfaces. Detection of a ship is possible because the microwave energy thus reflected by a ship is different than that of the surrounding ocean. A wooden ship appears radiometrically "warmer" and a steel ship "cooler" than the ocean. It is an entirely passive system, as opposed to active techniques which measure the reflection of signals which have been transmitted by radar. One of the advantages of the passive system is that it allows surveillance without radiation, therefore, the target does not know it is being observed.

Microwave radiometers have been used routinely in satellites to measure whether con- 


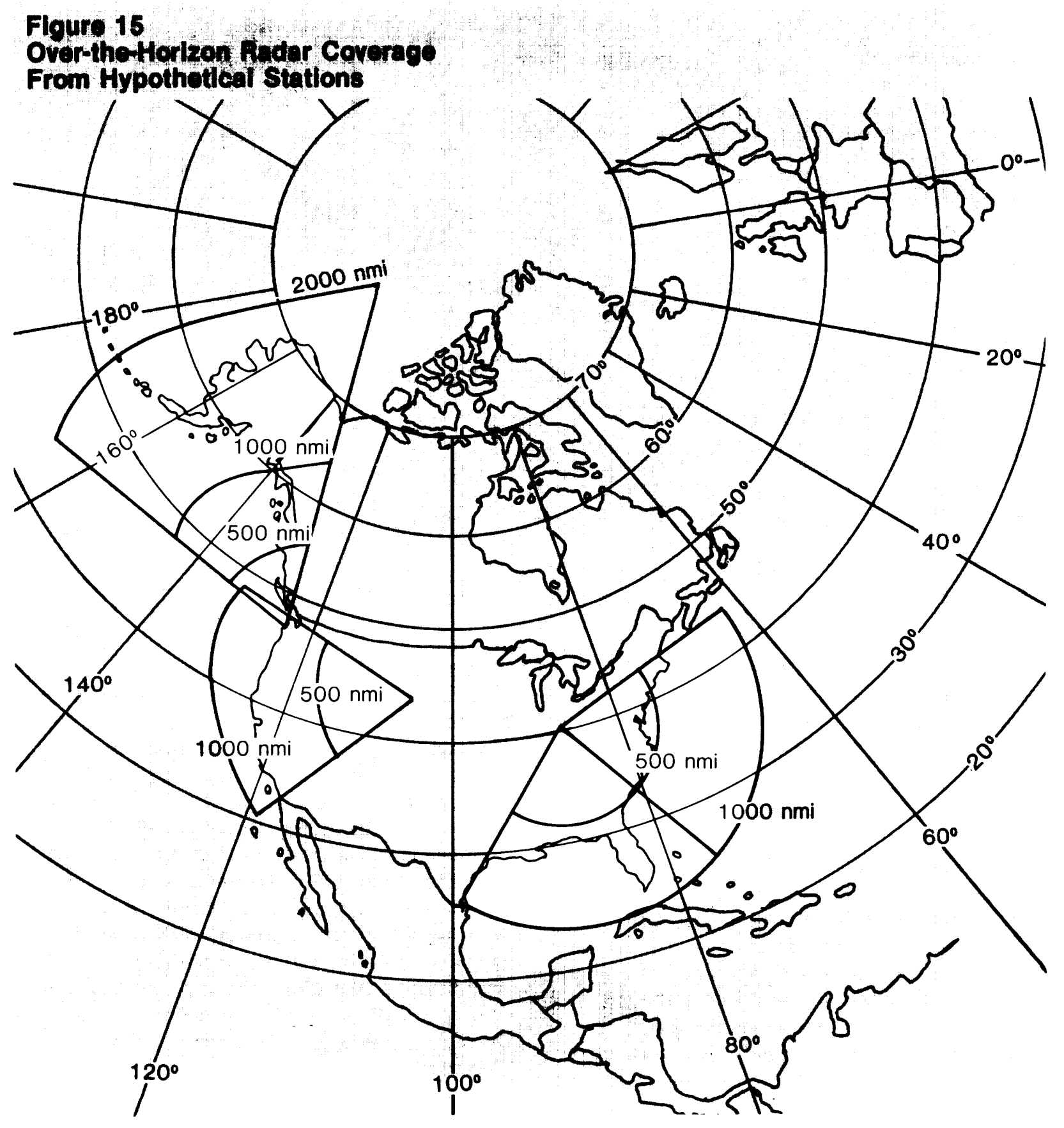


ditions and airborne radiometers have been successful in mapping weather fronts and sea states. Radiometric measurement of oil spills have been made with limited success and radiometers have been frequently suggested for use in missile terminal guidance systems.

Although there do not appear to be any operational systems at present that are specifically designed for detection of ships, such systems have been studied and prototypes have been tested. The existing technology is more than adequate for the detection of fishing vessels.

However, constraints on maximum frequency and the detectability of relatively small ships severely restrict the height from which a radiometer can effectively operate. Satellites could not be used for radiometer detection of fishing vessels, and aircraft would be limited at altitudes of about 6,000 feet. At that altitude fishing vessels could be located to within 2,000 feet in range and 2 degrees in bearing (see figure 16).

\section{Optical and Electro-Optical Techniques ${ }^{48}$}

With existing technology a variety of optical and electro-optical sensors can be built which could perform many useful functions in enforcement of the 200-mile fishery zone.

This category of sensors includes the traditional visual, aided visual, and photographic techniques-ranging from the human eye to electronically augmented viewing systems and film cameras--and the more sophisticated, recently developed methods of electrooptics such as low-light-level television and infrared or thermal mapping systems. These systems are likely to play supporting or auxiliary, rather than primary roles, in enforcement.

\section{Figure 16 Airborne Scanning Microwave Radiometer}

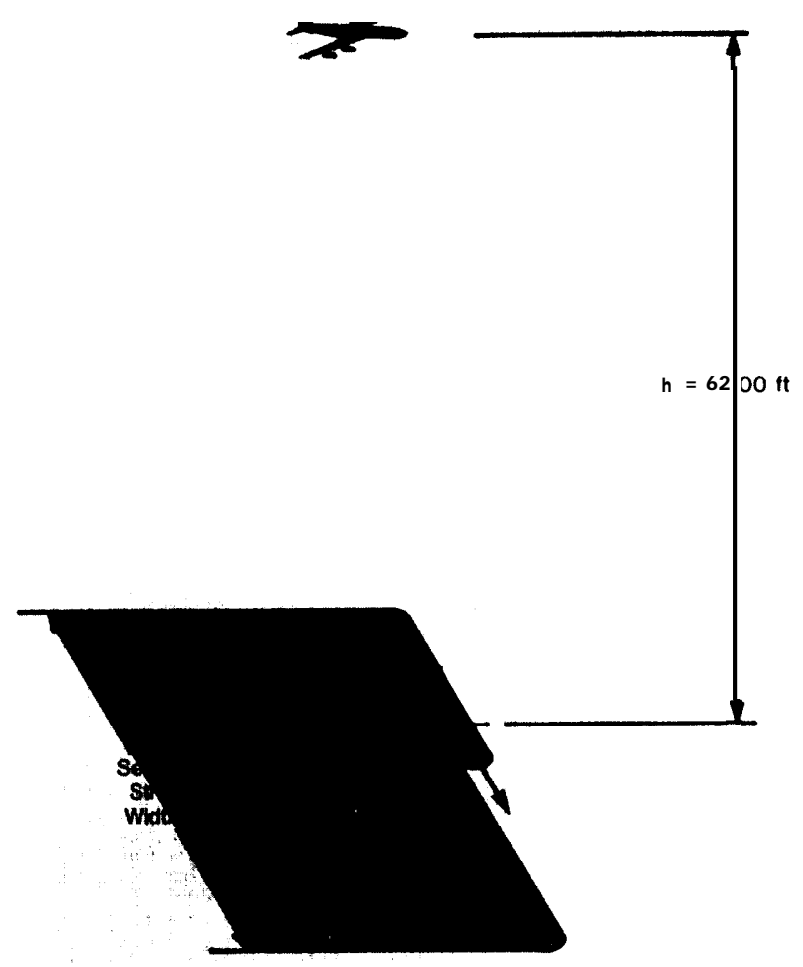

Source: Stanford Research Institute 
Optical detection and surveillance systems can be operated from satellites, aircraft, or ships. The combination of timeliness of coverage and operational economics makes aircraft seem the most useful surveillance craft for the near future, with some data being derived from existing or projected satellites, and with final follow-up performed by surface vessel.
One of the major problems of optical sensors is the processing and handling of rawdata output. Photographic film requires chemical development, usually at the end of a reconnaissance mission (that is, when the aircraft lands or ejected film capsules have been retrieved from satellites). In some cases, film from aircraft can be rapid processed in flight to allow for examination or data

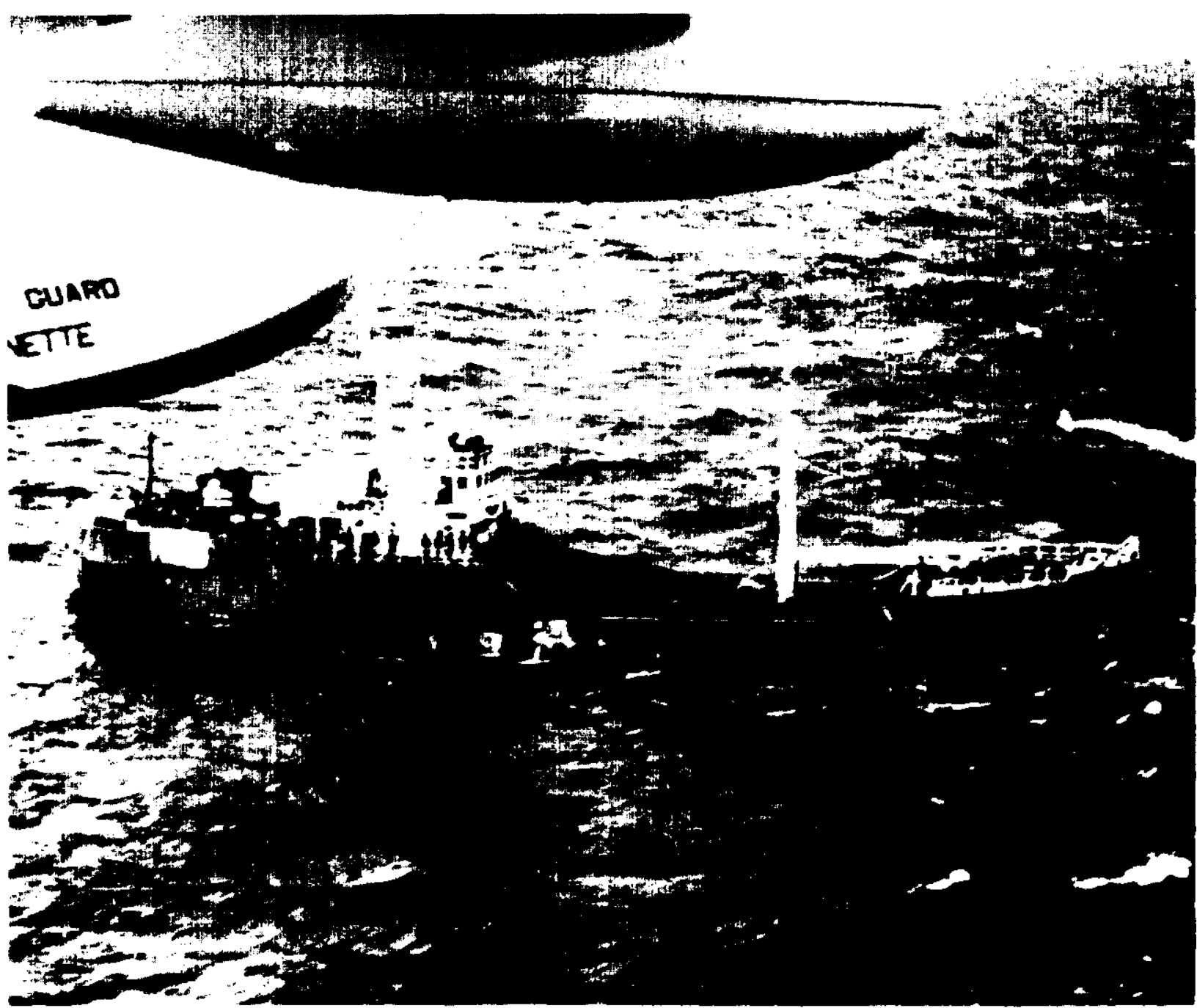

IS. Cimu tizant Photo

Coast Guard surveillance aircraft can be used for visual observation of the fishing grounds, facilitating detection and identification of foreign vessels 
transmission within minutes, for immediate interpretation of close-up photography. But images from long-range, high-altitude satellites need more extensive and detailed examination, often requiring several hours or even days by expert photo-interpreters before useful, specific data are developed. Most of the electro-optical systems can provide realtime outputs capable of immediate display and examination in the form of electrical signals readily amenable to interpretation or transmission to a shore-based facility.

Optical and electro-optical techniques vary widely and the choice of specific systems would depend on the enforcement strategies chosen.

\section{Electromagnetic Intercept Techniques ${ }^{49}$}

Because all ocean-going vessels are already equipped with radio equipment and most with navigational radar, it is possible to detect and classify foreign fishing vessels by intercepting and analyzing their radio or radar emissions.

Two techniques have potential in fisheries enforcement activities: the use of direction finding equipment to determine the position of detected vessels and the use of information from the intercepted transmissions to identify and classify the vessel.

The technology for both direction-finding and communications interception and analysis is highly developed and numerous systems have been developed for both military and civilian use. These systems can be operated from shore bases, ships, aircraft, or satellites. At high frequencies intercept is not limited to, but does work best, within line-ofsight of the detected vessel. An aircraft moving at 300 knots could have line-of-sight access to 200,000 square miles of sea surface per hour.
In the past, direction-finding equipment was used primarily for location of aircraft and ships in distress. Currently, however, it is in use largely for monitoring and surveillance. The Federal Communications Commission maintains a network to locate illegal radio transmitters and sources of radio interference; the Department of Defense operates several networks for surveillance and intelligence data collection.

It is possible that some signal intercept information from DOD files can be made available to the Coast Guard for fishery enforcement, However, most of the DOD operations are mission-oriented and are flown in areas of military interest, therefore it is unlikely much time is spent tracking fishing fleets. The feasibility of assigning military aircraft for fishery patrols would be expensive and would have to be worked out with DOD.

The Coast Guard could supply personnel to sort out fishery information collected by DOD or an entire direction-finding station could be dedicated to Coast Guard fisheries work. Because of the security implications of much of the data handled by DOD facilities, such coordination may prove difficult.

\section{Magnetic Techniques ${ }^{50}$}

Magnetic anomaly detector systems have been built and used for the detection of submarines and there is no reason why they would not be equally successful in detecting fishing vessels. The systems operate by detecting local changes in the direction and strength of the earth's magnetic field caused by any object, such as a steel-hulled vessel, with mag- 
netic properties. However, because detection is possible only at a much shorter range than with radar or visual systems and because no classification of vessels is possible, magnetic techniques presently have little potential for use in fisheries enforcement.

\section{Acoustic Techniques ${ }^{51}$}

Detection and classification of fishing vessels by use of acoustic techniques is possible because the technology for the generation, transmission, and reception of acoustic energy is well established and the factors that in- fluence acoustics in the ocean and atmosphere are well known.

The use of acoustic techniques for the detection of fishing vessels can be extrapolated from the Navy's experience in submarine detection. However, new equipment and new methods of use would have to be developed. Since most of the existing acoustic systems are highly classified it is not possible to describe them, except to say the equipment is very complex and costly to operate. Much development would be needed to determine the usefulness of these systems for fisheries law enforcement.

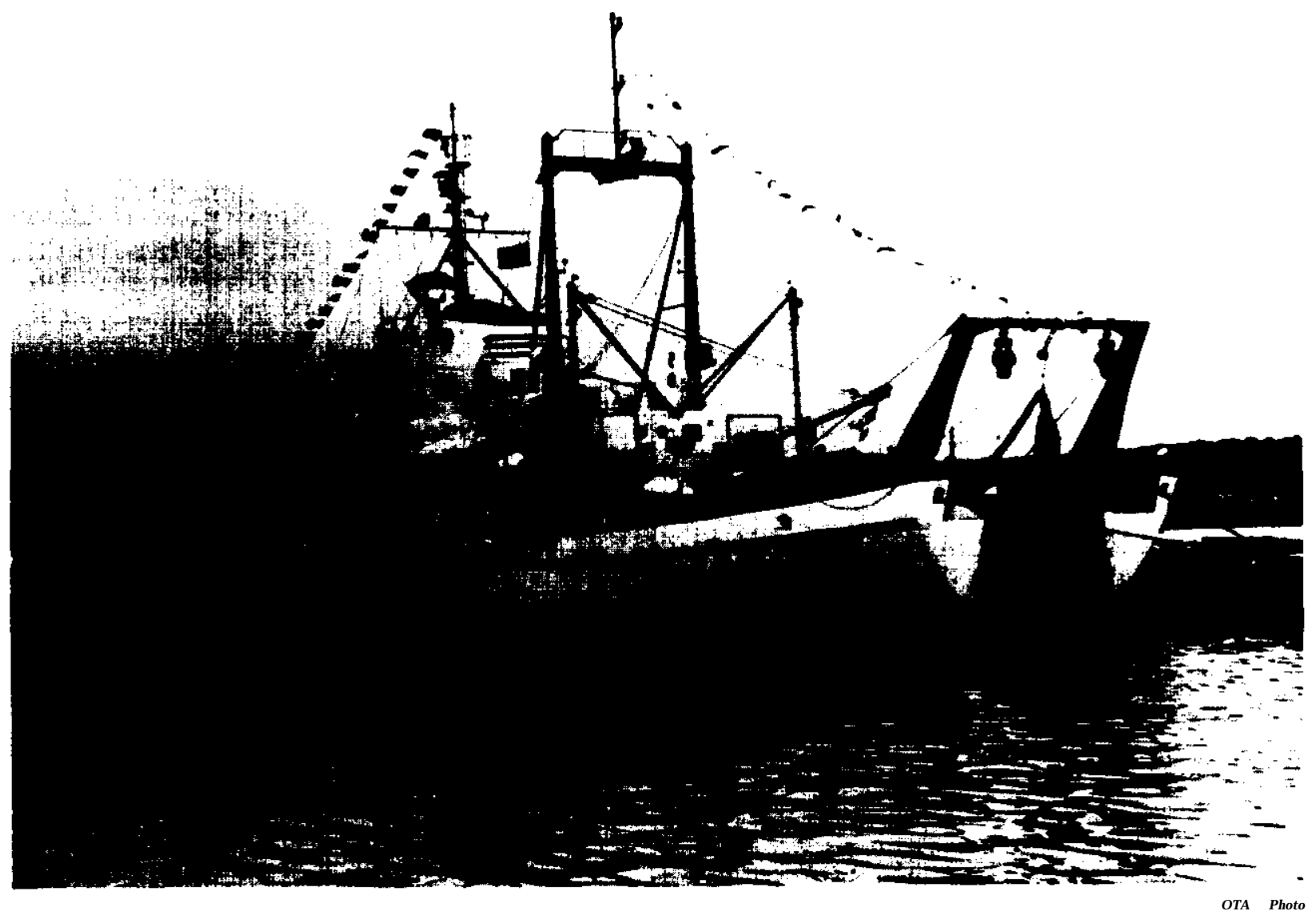

Oceanographic vessels, such as the Albatross II of Woods Hole, will be used in some fisheries research 


\section{Management of New U.S. Fisheries Zone}




\section{Background}

The Fishery Conservation and Management Act of 1976 (P.L, 94-265) is potentially the most significant institutional change in the history of U.S. fisheries management. The law extends the limits of U.S. jurisdiction out to 200 miles and incorporates some advanced ideas about ways to manage marine fisheries in the United States, Implementation of this law will require a level of understanding about the infrastructure of the fishing industry that has never before been attempted by the U.S. Government. Eventually it will require a thorough description of the entire cycle from spawning fish to fish on the dinner table. In the past, each section of the fishing industry-i e., fishing, processing, retailing, etc. - was concerned only with its own aspects of the cycle. There has been little correlation of information and no indepth analysis of the interdependence and the interrelatedness of the various segments of the industry. A better understanding of the fishing industry as a whole will be necessary in order to implement the management theories put forth in the new law.

Management, according to the law, means the use of "rules, regulations, conditions, methods, and other measures (A) which are required to rebuild, restore, or maintain, and which are useful in rebuilding, restoring, or maintaining, any fishery resource and the marine environment; and (B) which are designed to assure that:

(i) a supply of food and other products may be taken and that recreational -benefits may be obtained, on a continuing basis;

(ii) irreversible or long-term adverse effects on fishery resources and the marine environment are avoided; and

(iii) there will be a multiplicity of options available with respect to- future uses of these resources." ${ }^{15}$

Public Law 94-265 implies that proper management of U.S. fisheries will result in conservation of fish stocks, which means a reduction in overfishing of some species, increased fishing of underutilized species, and enhancement of stocks which are currently overutilized or depleted.

International pressures now exist to take the last available ton of some popular species from the ocean each year. For example, in its latest report to Congress under the terms of the Marine Protection, Research and Sanctuaries Act of 1972, NOAA concludes that about 10 to 15 major finfish and shellfish stocks have been overfished, primarily by foreign fleets; other stocks are in danger of being overfished, and numerous others are "intensively exploited." ${ }^{153}$

In this study, OTA examined many elements of fisheries management that are contained in Public Law 94-265--elements that many people believe have been neglected in the past-and that seem to be of great importance in effectively managing fishery resources in the future. The major elements of fishery management which were examined by OTA are:

. development of and use of the concept of optimum yield;

- establishment and operation of fishery management councils;

- preparation of preliminary management plans for foreign fisheries;

- preparation of final management plans for domestic fisheries; and

. evaluation of management effectiveness.

This section describes the status of these management elements, discusses some of the planning which is needed for future management, and describes specific information which will be needed for adequate management. The information needs were determined by special studies commissioned by OTA. These studies are referenced throughout this report as working papers and are being published separately. 


\section{Optimum Sustainable Yield}

One of the most important management principles set out in the law is that management plans should result in optimum yield. Optimum yield, according to the broad definition in the Act, is the allowable catch which (A) will provide the greatest overall benefit to the Nation, with particular reference to food production and recreational opportunities; and (B) which is determined as such on the basis of the maximum sustainable yield (MSY) as modified by any relevant economic, social, or ecological factors. ${ }^{54}$

Implicit in optimum yield is the idea that the concepts and data from all the fields indicated in the Act should be integrated and not treated as separate entities. Management plans based on the finest concept will do little good if their implementation results in dangerous depletion of the fish stocks or massive social disruption with attendant political agitation. Unfortunately, integration of biological, economic, and social information poses major problems.

In the past, it was considered adequate to analytically determine the total allowable catch that each species could sustain without damage to the parent stock. That figure was known as the maximum sustainable yield (MSY). However, most fishery experts would now agree that MSY cannot be determined for any species because there are too many unknown biological factors which influence the size and health of fish stocks. This situation is further complicated by the traditional common-property nature of fish resources and incomplete knowledge of the entire marine ecological system.
In addition, social and economic factors are of considerable importance in a free society and do, in fact, have a major effect on actual utilization of each species. The concept of optimum as opposed to maximum (or "best" as opposed to "most") is to take these social and economic factors into consideration.

Like an MSY figure, a precise optimumyield figure for each fishery is not attainable at this time. However, a process can be sought for considering all factors and reaching a compromise set of guidelines to follow for good management.

Such optimum yield concepts should be adaptable to changes in resource priorities, knowledge about the resource, information about its use, and the trade-offs that result from management. Optimum yield is the core of each management plan which will probably include such other items as: quantities and types of fish to be harvested; methods and techniques to be used; and measurements and evaluations to be conducted.

No specific process for seeking optimum yield for a fishery has been established yet. The yield figures used by the National Marine Fisheries Service in drawing up preliminary management plans are estimates based on existing data, which is mostly biological in nature. However, NMFS and the Regional Councils are wrestling with the problem of how to pursue optimum yield. A workshop of council members and Federal officials is being planned for purposes of devising a method of seeking the optimum yield for each fishery. New concepts need to be developed and much new information must be gathered in order to obtain an integrated view of the fisheries of the United States and to determine the optimum yield of a fishery. In the meantime, it is clear that at least the following factors should be considered: 


\section{Regional Fishery Management Councils}

- biologically based estimates or predictions of the maximum yield which can be expected from each stock without future depletion of that stock;

- quality of the predictions or the range within which they are likely to be accurate so that safety margins can be built into catch figures; ${ }^{56}$

- such relevant ecological factors as water quality, destruction of breeding grounds, disasters such as oil spills or severe weather; and

. economic and social factors of individual fisheries which will be relevant in determining the effect of management options on such interested parties as commercial fishermen, sport fishermen, food processors, marketing groups, fish-food consumers, and the general public. ${ }^{57}$

In reality, the exact meaning of optimum yield and the best method of determining it will be determined by the Regional Councils through their decisions in the coming years. In the absence of an analytical method, judgments may be used to modify a maximumyield figure to reflect the factors listed above. If data on these factors are not available or are unreliable, further judgments may be used. Even with an analytical method and reliable data, there will be uncertainty and techniques for dealing with that uncertainty will be necessary.
Public Law 94-265 establishes eight Regional Councils which will set standards, develop plans, and prepare regulations for the management of fisheries in each region, The regions and their jurisdiction are shown in figure 17. Each council includes members from industry and other parties of interest in the region as well as representatives of State fisheries offices, the Regional Director of the National Marine Fisheries Service, a Coast Guard representative, and a representative of the Department of State. The Secretary of Commerce, who appoints the voting members of the councils from lists of potential members submitted by the Governors of the States in each region, has been asked to seek an amendment to the Fishery Conservation and Management Act which would require that environmental interests be represented on the councils. Similar consideration should probably be given to consumers. Figure 18 lists the councils and their memberships on the effective date of Public Law 94-265.

The Regional Councils have broad authority to recommend fishery management plans to the Secretary of Commerce for approval and implementation. The management plans which the councils will be formulating must, under the law, take into consideration domestic fishing, foreign fishing, and recreational fishing. Once it is determined what portion of the allowable catch can be harvested by U.S. vessels, the remainder is to be allocated as foreign catch.

The general responsibilities of the councils are clear (see figure 19), but their relationship to the future operation of already established Federal agencies is not so clear. The Federal agency with the major responsibility in fishery management is the National Marine Fishery Service in the Department of Commerce. The National Marine Fishery Service (NMFS) has a dual-role of providing services to the councils, mostly in the form of biological stock 


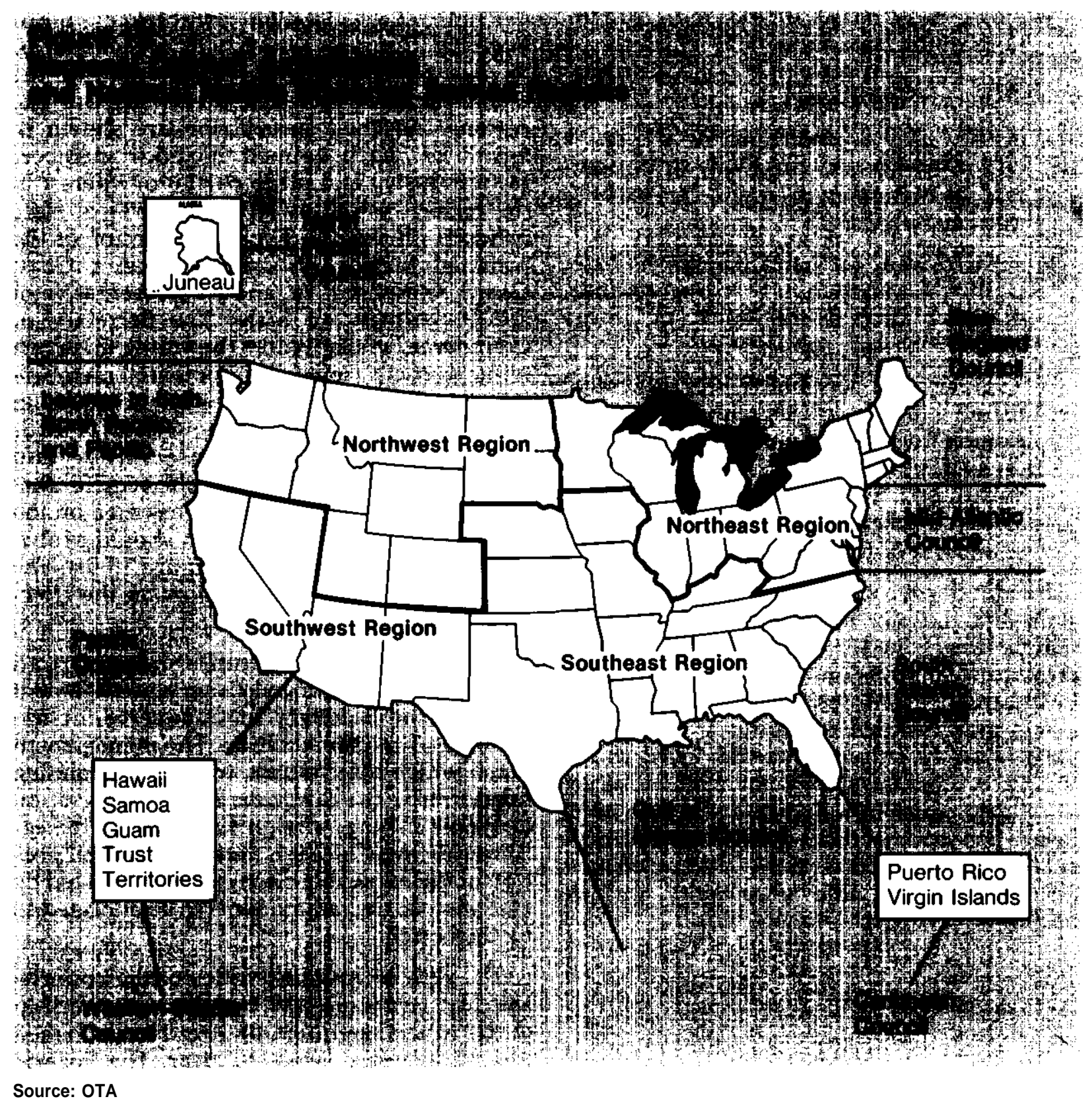




\section{Flgure 18 Appointed Voting Mombers of Roglonal Coundilec}

New England

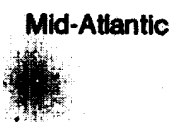

South Altantic

Gulf of Mexico
Spence Apolionio Exeouthe Director

John Burt

New Bedford Fishermen's Union

Jacob J. Dykstra

Point Judith Fishermen's

Cooperative Association

Henry Lyman

The Saltwator Sportamen

John C, Bryson

Executive Director

John H. Burger, Jr.

Burger Construction Co.

L. Eugene Cronin

Center for Environmentel and Estuerine Studies

Willam M. Foinberg

Attomey

(n)

Edrot I Whet

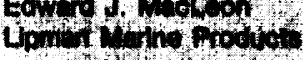

moris ing

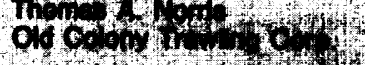

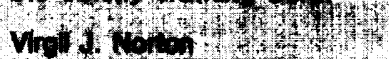

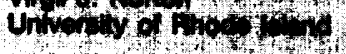
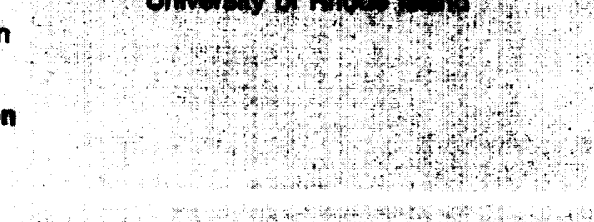

Nano $x$

Coup or Anotcals

sout 5 whe.

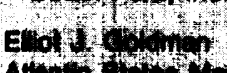

Allon.

cotity

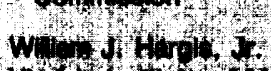

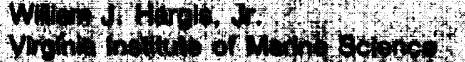

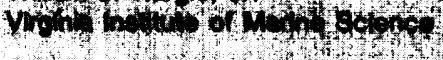

Dowd $\mathrm{H}, \mathrm{H} \mathrm{H}$

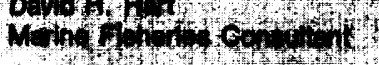

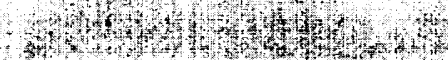

Thom P. Alool

Block laland Blueftah Invitetiond Toumenent

Chartes B. Stinson Sineon Cenning Co.

Richurd F Wadlation

Nen W. Haynte

2edta-Haynie Corp

John L. Mottugh

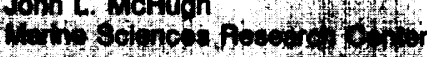

Whot 6

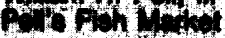

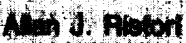
chot octporation

Gold IE. Gavaro

Cowmorcial Fithermen

(1)

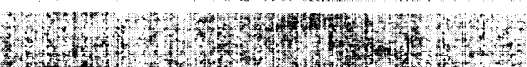

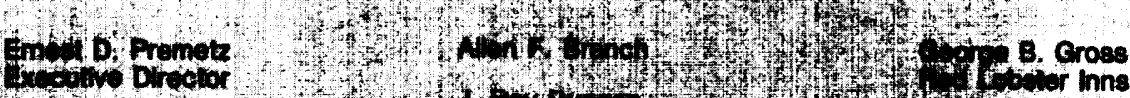

Nomnt in Now

Wort Carolns Floheries Alecolution, inc.

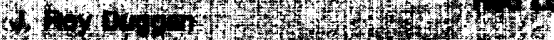

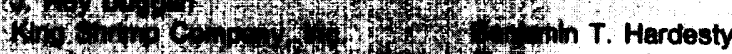

E.

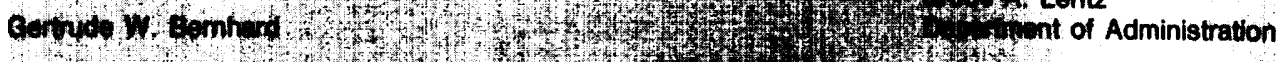

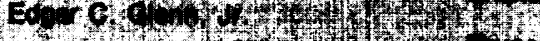

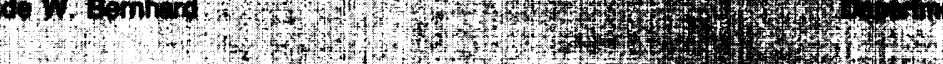

Wayne E. Swingle
Executtive Director

George A. Brumitield

Zapata-Haynie Corporation

Thomes H. Clark

Sun Circle Resort

Theodore B. Ford, iff

Loulying State University

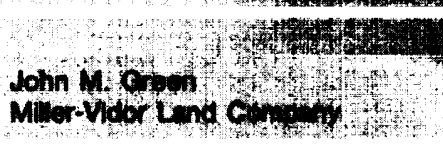

Robert P. Jones

Southeastern Fisheries Assoc., Inc. Liberty Fish and Oyster Company

C. Walton Kraver

Soefood Haven Inc.

Robert G. Mauermann

Texas Shrimp Association
Billy J. Putnam

Edward W. Swindell

Wallace Menhaden Products, Inc. 
Figure 19

Duties of Regional Counciis and Nationdl Marine Fisheries Service '

Required by P.L. $94-265$

\begin{tabular}{l}
\hline \multicolumn{1}{c|}{ Regional Councils } \\
\hline Modify preliminary management plans prepared \\
by NMFS for foreign fisheries \\
Prepare fishery management plans for domestic \\
fisheries. \\
Determine information, data and analysis needed \\
to prepare management plans \\
Test and evaluate techniques for determining \\
optimum sustainable yield and other management \\
factors \\
Secure needed information from NMFS or other \\
regional sources as necessary to complete \\
management plans
\end{tabular}

Depertment of Commerce (NMFS)

Prepare prellminary managument plans for fisheries with foreign allocations

Establish general regulations and ouidelines for preparation of all management plans

Provide the councils with data and information necessary to prepare management plans

Develop analytical mothods for determining optimum yield and other factors needed for effective management

Review and approve council prepared plans

Work with Coast Guard on enforcement of regulations

Work with Depertment of State to determine forelgn fishing allocations and regulations

\section{Suggested Additionel Duties}

Interpret scientific data and advice about stocks for interested public

Provide opportunity for access to information and debate of lseues by interested parties

Prepare projection of entorcement acthities needed within each jurisdiction, haluding possible compliance inducements

Study noeds of flehind industiy, oynthoske existing studies, provide missing data and recommend legislative and administrative changes which would be helpful
Prepare priontized list of domestic fisheries where management plans are most needed

Expand exioting Information services to reach more people with wide renpe of information from variety of sources:

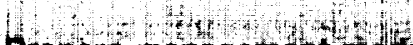
Prepare manapoment mo with cooperation of Coest Guard on enfojosing int component

Source: OTA 
estimates and other data, and of assuring that management plans adequately reflect the national interest and are consistent with national management standards. The Council and NMFS will also work with two other Federal agencies-the Coast Guard and the Department of State-in enforcing regulations and determining foreign fishing allocations and regulations to control foreign fishing.

With all this complex organizational and procedural set-up, it will undoubtedly take some time to develop a smooth operation. It appears that an important aspect of smooth operations is close-working arrangements between the Federal and regional levels. To date, there are no written requirements for work to be done by the councils and no firm criteria for use by NMFS in judging the plans developed by the councils. ${ }^{58}$ At present it appears that communications between Federal groups and the Regional Councils will be through NMFS regional offices when services or data are needed but through the NMFS Washington office when management plans are submitted for approval.

Presently, the NMFS representative on each council is the Regional Director. However, it is possible that better liaison with the councils could be accomplished if the director of the regional fisheries research center were the representative instead or in addition to the present appointee. The research centers conduct the service function of NMFS and will be supplying the councils with scientific and other types of data to be used in drawing up management plans. Presently the councils have no mandatory policy-level link with these centers and must work instead through nonpolicy-level representatives to the councils or through the Regional Director who has no authority at the centers. Placing the center director on the Regional Council could force the centers to be more accountable for the existence and reliability of data requested by the councils and improve working relations between the two groups.

Close coordination will be required in three areas of major problems which have not yet been resolved:

1. What budget allocations will the councils receive from NOAA and how much discretion will they have in spending funds for collection of regional data not available from NMFS and data not considered reliable enough for management decisions?

Roughly $\$ 30$ million are programed in the fiscal year 1978 Department of Commerce budget for implementation of the 200-mile fishery zone. Of this, about $\$ 10$ million will go to NMFS for its work, the work of its regional laboratories, and the work of the Regional Councils. The rest of the moneys go to NOAA for administration; Sea Grant for research by member universities; and the National Ocean Survey for operation of research vessels.

The councils' requests for funds must be approved by NMFS and NOAA before the moneys are made available. According to an NMFS spokesman, there is presently no conflict between the councils and the NMFS laboratories over funding for research work. However, conflicts over the division of the funds between NMFS laboratories and the Regional Councils can probably be expected in the future because of some local fishermen's lack of confidence in national NMFS operations and council desires to break out of the traditional NMFS research pattern. According to NMFS, "every consideration" will be given to the councils' requests for research funds; however, council funding will reflect NMFS decisions on who can best conduct specific research in the most cost-effective way. ${ }^{59}$ Presumably, the councils will be more successful in requesting money for research into social and economic areas, where little expertise now exists within NMFS, and less successful in requests for funds to conduct 


\section{Preliminary Management Plans for Foreign Fisheries}

biological research which is already welldeveloped by the NMFS labs. However, NMFS is already buttressing each of its four regional research staffs with the addition of a sevenman economic and statistical team. Conflicts may evolve over who does specific research tasks. There is presently no framework, other than informal negotiations between NMFS and the councils, for resolving such conflicts.

2. What national data and methods or analysis will NMFS undertake to collect and publish for the use of all councils in management planning?

When this report was written, no decisions had been made within NMFS as to how research and development of analytical methods would be divided. There was a division of opinions among NMFS professionals as to whether recommended data and methods should flow from NMFS to councils or from the councils to NMFS. Early work was of necessity under the constraints of a March 1, 1977, deadline undertaken by NMFS, but no firm guidelines have been drawn-up yet as to who, in the future, should do what specific types of tasks.

3. How will optimum yield be determined and can an analytical method be applied which will improve management planning ?

As noted earlier, it was not possible to determine the optimum yield for foreign fisheries in time to include the figures in preliminary management plans. Some judgments regarding social, economic, and ecological factors were used in determining optimum yield for the two domestic plans which have been proposed. Although a workshop is planned jointly by NMFS and the councils for mid-1 977 to investigate methods of determining optimum yield, there is now-as the councils prepare their first domestic plans and prepare to modify the preliminary foreign plans-no agreed-upon method.
Since the Regional Councils were not able to develop management plans for those fisheries with foreign fishing in time for the March 1, 1977 deadline for implementation of the Act, these plans were prepared by NMFS. The plans have been termed "preliminary" until they are approved or modified by the councils. Plans were prepared for 16 fisheries $^{60}$ in four general regions covered by six councils. However, only two regions have the major significant foreign fishing effort-the Northeast region, covered by New England and Mid-Atlantic Councils, and the Northwest and Alaska Region, covered by the Pacific and North Pacific Councils. Figure 20 lists the plans prepared for these regions.

In the preparation of these plans, no attempt was made to consider all the factors specified in the Act or to determine optimum yield which takes into account the economic, social, and ecological factors. Most of the preliminary plans state that the councils will determine the specific factors to be used to calculate optimum yield sometime in the future. In the meantime, NMFS has used totalallowable catch figures determined, for example, by the International Commission on North Atlantic Fisheries in the place of optimum yield figures which have not yet been determined by the councils.

The preliminary management plans establish a total allowable catch for species which are subject to foreign fishing effort, estimate the share of that catch which U.S. fishermen could harvest, and set a surplus figure which is available to foreign fishermen. It is this surplus which is allocated among those countries applying for permits to fish within the 200-mile zone. Allocations contained in the preliminary management plans (as of January 1977), excluding allocations for species under 10,000 tons and species with no allocations, are shown in figure 21 . 


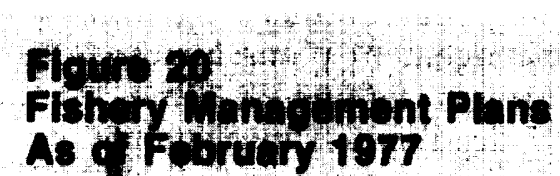

Prollithary Manigoment Plans Have Been Prepared by NMFs for the Following Fiahery Units Which Are Suldect to Forelgn Fiahing:

Pacificland North Pyciflc Council Regions:

Traw Fishery of the Bering Sea and Aleutan Islands

Trawl Fishery of the Cull of Alaska

Trawl Fiphery of Whington, Oropon and Celliomia

Sablofish of the Beind Sea and Northedetem Pactic

King and Tahner Cl of the Esstern Bering Sea

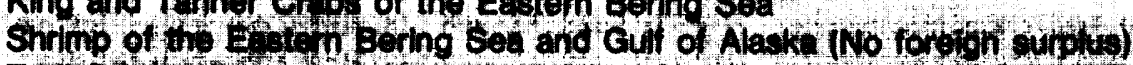

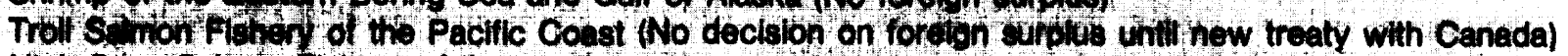

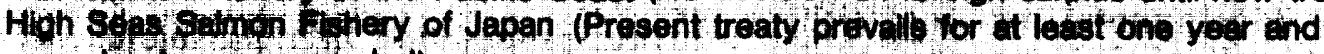

new tivaty recommonded)

Snalls of the Eastern Bering Sea (No restrictions except no increase in catch)

\section{Westem Pacific Council Rogion:}

Soamount Trawl Flohery of Hawall, Guan and American Samoa

Precious Cotals of Hawal, Guam and American Samoa

(No foroloth eurplus):

Now England and Mld Aluntto Councl Regions:

Hake Fritiries of the Now thwest Atantic

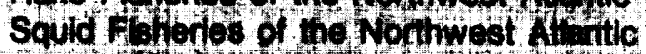

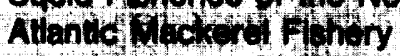

Attantio Hering Fterion

Finfleh Cayoht Incliental to the Traw Fishertes of the Northweat Allantic

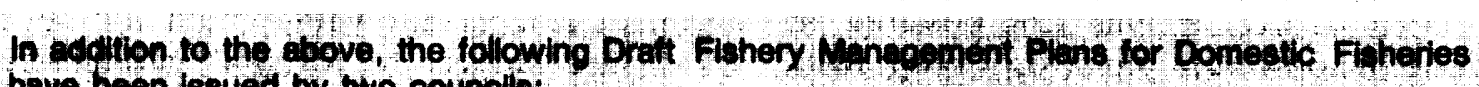
have been lesued by hivo counctls:

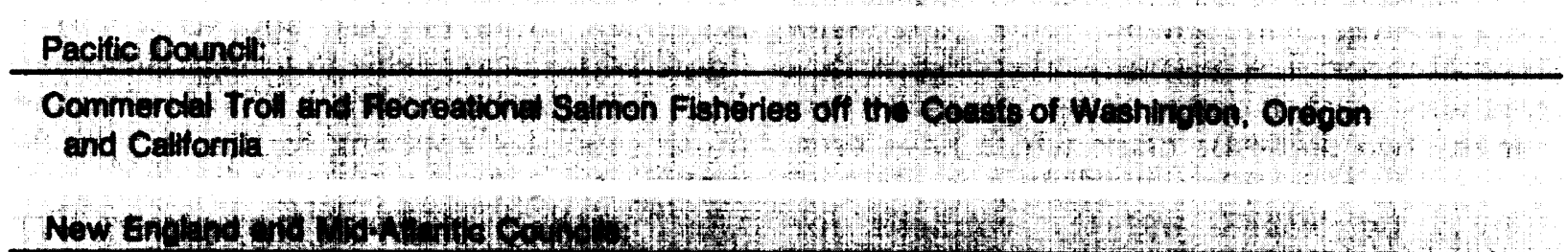

Source: OTA 
Figure 21

Preliminary Management Plan Allocations

\begin{tabular}{|c|c|c|}
\hline \multirow{2}{*}{ Fishery } & \multicolumn{2}{|c|}{ Metric Tons } \\
\hline & $\begin{array}{c}\text { Total } \\
\text { Allowable } \\
\text { Catch }\end{array}$ & $\begin{array}{l}\text { Foreign } \\
\text { Allocation }\end{array}$ \\
\hline $\begin{array}{l}\text { Trawi Fisheries } \\
\text { (Inciudes poiiack, sole, } \\
\text { mackerel, flounder, ocean } \\
\text { perch, rock fish, pacific hake) }\end{array}$ & $1,783,000$ & $1,672,000$ \\
\hline Sable Fish (not in above) & 36,000 & 25,000 \\
\hline King and Tanner Crabs & 142,000 & 10,000 \\
\hline $\begin{array}{l}\text { Shrimp } \\
\text { Region Total } \\
\text { Northeast Region }\end{array}$ & $\begin{array}{r}50,000 \\
2,014,000\end{array}$ & $\begin{array}{c}\text { None } \\
1,710,000\end{array}$ \\
\hline Red and Silver Hake & 164,000 & 128,000 \\
\hline Squid & 79,000 & 41,000 \\
\hline Mackerel & 55,000 & 50,000 \\
\hline Herring & 40,000 & 16,000 \\
\hline Other Finfish & 150,060 & 72,000 \\
\hline Region Total & $468 \$ 000$ & 307,000 \\
\hline
\end{tabular}

Theae are listed in three separate plans according to area.

Source: Preliminary Management Plans

The total foreign allocation for the year 1977 will be about 2.04-million metric tons. This compares to about 2.72-million metric tons which was harvested by foreign fisher- men in the same areas in 1974 and about 3.63million metric tons in 1972. While some reduction in foreign allocations is contained in the preliminary plans in order to reserve certain stocks for US. fishermen, the overwhelming reduction in allowable catch is assumed to be for the purpose of conserving stocks which have been substantially overfished in the past (see figure 22).

As in enforcement of fishery regulations, the Department of State may, in some cases, exert a practically unquestioned influence on foreign allocation figures. For example, foreign allocations for pollock were increased 100,000 metric tons by NMFS this year in response to State Department comments on the environmental impact statement relative to trawl fishery management plans for the Bering Sea.

As with enforcement, the foreign policy implications of some management actions and allocations may at times be more important than the fishery implications. However, some mechanism should be established to assure that fisheries managers are not intimidated by the Department of State and that Department of State requests are based on clear evidence that the allocations or other aspects of the management plans would be harmful for some reason.

These preliminary management plans are the first step in a complex process aimed at regulating foreign fishing. Because they are the prime management tool, they are of great importance and need careful scrutiny. As written and published before the March 1, 1977, implementation date, the preliminary management plans prepared by NMFS for regulation of foreign fisheries are not coordinated in content or format. In fact, NMFS has reserved the task of writing and publishing regulations for the presentation of management plans until after the law has gone into effect, Other rules and regulations for opera- 
tion of the councils and preparation of management plans, in very general language, were published in the Federal Register in draft form in September, $1976 .{ }^{61}$ This failure $t$. standardize operations within NMFS before the initial plans were written may have complicated the councils' job of preparing succeeding plans by failing to give them a model after which to pattern their work. It may also perpetuate regional differences within NMFS and complicate the national review process.
As the councils consider the preliminary plans and attempt to develop the management process, much must be learned about the effectiveness of management techniques and presentation of plans. The most pressing need for improvement, however, is in the area of developing and considering economic, social, and biological data to be used to modify the catch figures presented in the preliminary plans.

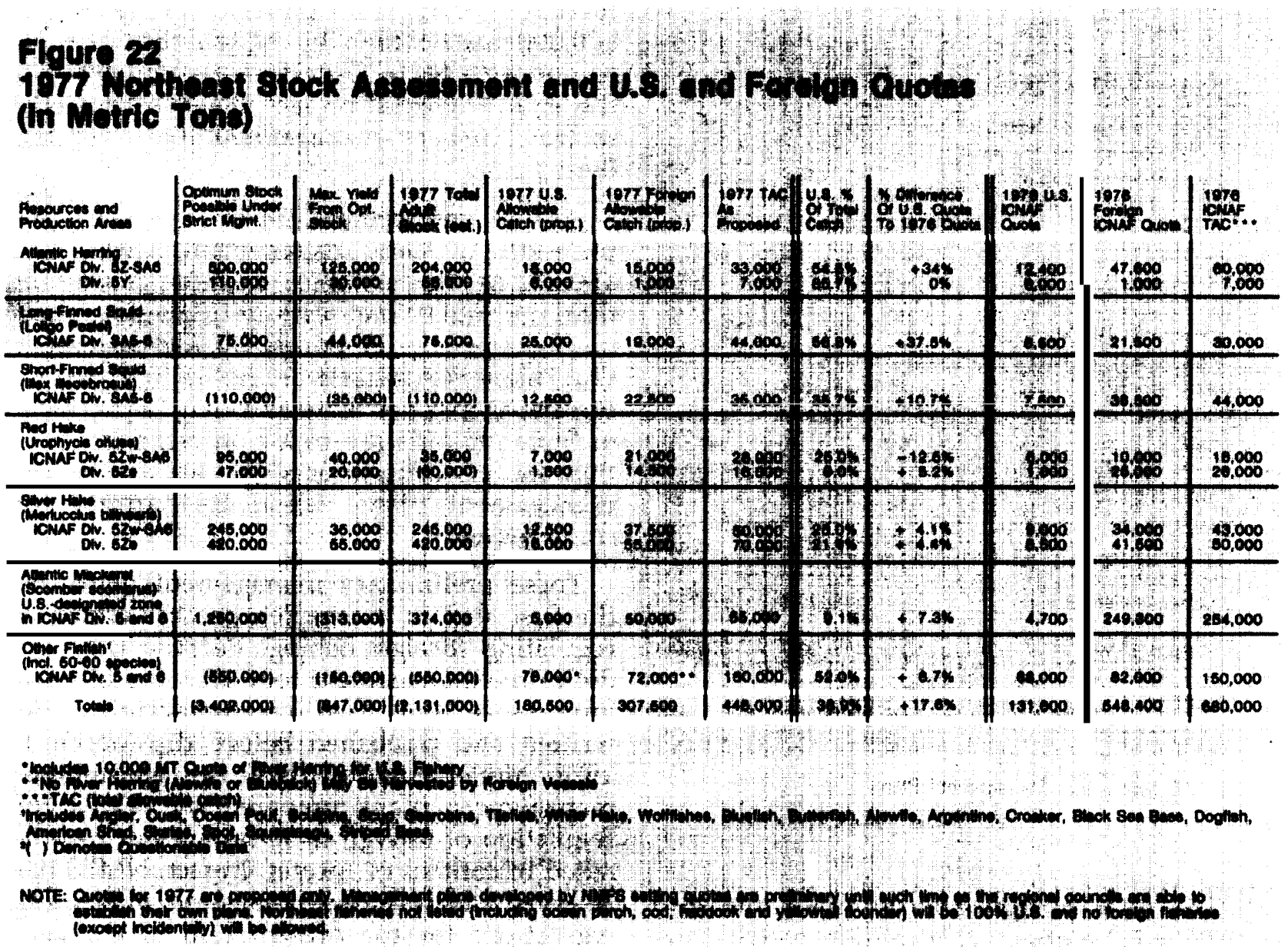

Source: National Fisherman 


\section{Final Management Plans for Domestic Fisheries}

As the councils become operational, they will assume their principal responsibility of developing management plans for domestic fisheries. There is no deadline for issuing specific plans. However, serious problems with heavily fished species have been recognized in two areas and emergency domestic management plans have been prepared to take effect simultaneously with the preliminary management plans for foreign fisheries. These plans were prepared by NMFS and there is some concern that they will not be well received by domestic fishermen because of the lack of local input to the regulations.

This possibility could have been avoidedand can be avoided in the future if additional emergency plans are deemed necessary before the councils are working fully-if NMFS were to detail or loan personnel to the councils for preparation of the plans. Such an arrangement would put the councils in charge of the preparation and ensure the input of industry and other interested segments of the public.

Although there are well-known administrative problems and costs in detailing personnel, such a system should be investigated because of its potential for making professional staff members available to the councils on an as-needed basis without the necessity of building up bureaucracies within the councils themselves.

Two draft domestic management plans were prepared by NMFS. One of the New England fishery for haddock, cod, and yellowtail flounder and one for the Pacific fishery for salmon.

For New England, some judgmental increases and decreases were made in maximum sustainable yield figures supplied by the NMFS lab and an attempt was made to set an optimum yield which reflects economic and social factors. The draft plan determines that there is to be no foreign catch and allocates the domestic catch between commercial and recreational fishermen. The plan also recommends that the stock be protected by some fishing regulations such as ones on mesh size, minimum catch size, and tying the allowable catch to the number of crew members per boat.

In the Pacific, the domestic catch is allocated among commercial, recreational, and native American fishermen and regulations are set, including fishing season, area closures, and bag and size limits.

Beyond these two emergency plans, there is no priority list of domestic fisheries for which management plans should be prepared. Since NMFS now has the most information on U.S. fisheries and the status of stocks in general, and since NMFS has the power to prepare domestic management plans if the councils do not do so, it would be helpful if NMFS would compile a listing of fisheries where management plans are needed. Such a listing should be a priority ranking and should delineate the needs for management plans in each case. Such a list would help focus the councils' early work and would be helpful in projecting their information needs.

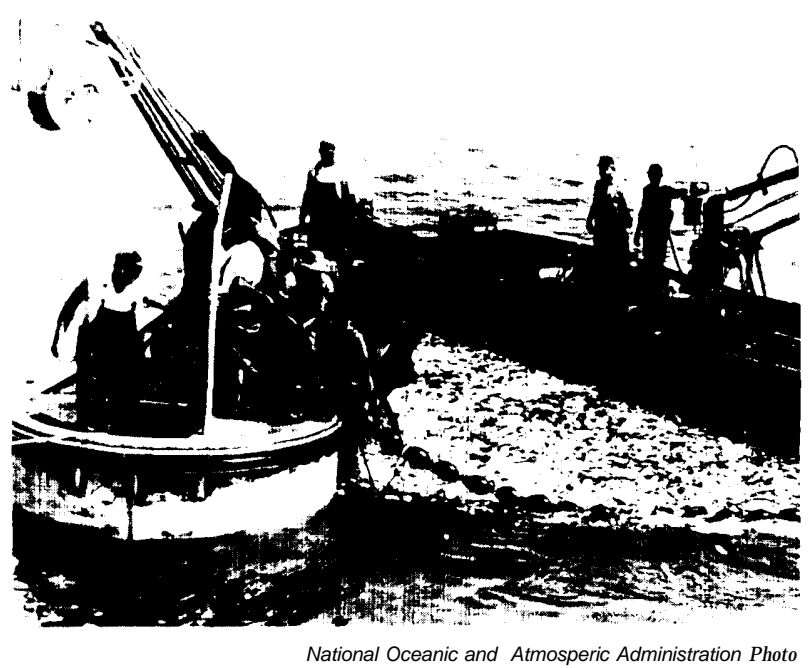

Small net handling boats close the purse seine around the catch before transferring it aboard a larger vessel 


\section{Evaluation of Management Effectiveness}

Both the councils and the Federal Government have the responsibility of measuring the effect of the new management systems that are being developed. In its interim regulations for the operation of the Regional Councils, NMFS has slightly expanded on the standards set forth in the law to be considered in evaluating management plans. These standards are: ${ }^{62}$

1. Conservation and management measures shall prevent overfishing, while achieving on a continuing basis, the optimum yield from each fishery.

2. Conservation and management shall be based upon the best scientific information available.

3. To the extent practicable, an individual stock of fish shall be managed as a unit throughout its range and interrelated stocks of fish shall be managed as a unit or in close coordination.

4. Conservation and management measures shall not discriminate between residents of different States. If it becomes necessary to allocate or assign fishing privileges among various U.S. fishermen such allocation shall be (1) fair and equitable to all such fishermen, (2) reasonably calculated to promote conservation and (3) carried out in such manner that no particular individual, corporation, or other entity acquires an excessive share of such privileges.

5. Conservation and management measures shall, where practicable, promote efficiency in the utilization of fishery resources; except that no such measure shall have economic allocation as its sole purpose.
6. Conservation and management measures shall take into account and allow for variations among and contingencies in, fisheries, fishery resources, and catches.

7. Conservation and management measures shall, where practicable, minimize costs and avoid unnecessary duplication.

However, scientific data are not available to backup these standards and it would be desirable to establish a baseline for evaluation as soon as possible. Later sections of this report and Working Papers Nos. 1, 2, 3, and 4 describe the lack or unreliability of necessary data for fisheries management. Until such data and analytical methods are developed, it is unlikely that management plans can be evaluated in any way which meaningfully reflects whether the plans have been effective in the past and what measures will be effective in the future. 


\section{Information Needs for Implementation of Public Law 94-265}




\section{Biological Information}

Fisheries management has traditionally been based on biological considerations. Therefore biological data are more sophisticated and research concepts are better understood than those for economic or social information, and biological research has been funded at a high Ievel by Federal and State agencies concerned with fisheries management.

The principal biological data tool is stock assessment, ${ }^{63}$ the study of marine fish populations in terms of their potential commercial yield, as well as the limits of that yield, Stock assessment attempts to develop an understanding of marine ecosystems and the effects of man's activities upon them. The mechanisms that drive marine ecosystems, as well as those that drive fishing activities, if understood and if properly applied, serve as one means to predict the effects of future activities. Therefore, stock assessments can and do contribute to fisheries management decisions.

Stock assessments seek to develop information on what the maximum sustainable yield (MSY) of a fishery is. That is, fisheries are viewed as a renewable resource, dependent upon:

- the introduction of young fish into the population (recruitment);

- their rate of growth;

- their natural mortality;

- the mortality caused by fishing activities.
The management goal is to not remove more from the population than can be replaced, thus allowing maintenance on a steady basis of an allowable surplus over and above the parental stock necessary to produce that surplus. The principle that catch should not exceed the MSY has found nearly universal acceptance in the international fishing community. ${ }^{64}$

Stock assessment has traditionally served two purposes: provision of information and data for the development of new fisheries, and provision of information to maintain a stock or to restore depleted fisheries.

There exist a large number of uncertainties with existing stock assessment science: problems with the data generated and more importantly, problems concerning the use of that data. ${ }^{65}$ Of paramount importance is the fact that offshore marine fisheries, particularly ground fish (demersal species), constitute populations that are nearly impossible to observe until harvested, As a result, assessment must depend upon inference, statistical probabilities, and the measures developed to understand the complicated and interrelated marine environment. As such, assessments depend upon the analysis of past information and trends to predict future fisheries developments.

Fishing activities have continually changed as technologies have developed. These changes force adjustments in past-data analysis to reflect future realities. Further, as fishing activities have varied, there are environmental fluctuations and trends that are long-term in nature and are, as yet, poorly understood. This understanding is extremely difficult when technological changes continually alter the data simultaneously. 


\section{Status of Current Information}

In the past, estimates of fisheries yields and advice on the health and viability of stocks has been given to management bodies like the International Commission for Northwest Atlantic Fisheries (ICNAF) without disclosure to the general public and with little involvement of domestic fishermen or other interest groups. The new Regional Councils could make a substantial improvement in this procedure by interpreting scientific data on stocks, publishing and widely disseminating stock data and advice, and providing an opportunity for continual access to information and debate of the issues by interested parties. Good scientific data by itself will not promote conservation or adequate management of stocks. Input by and involvement of users and other public parties is crucial.

At present, most population estimates of heavily utilized stocks appear to be quite accurate, in spite of some problems in gathering information and evaluating the effects of fishing activity decisions. However, projections of sustainable yields in the future are subject to large uncertainties due to effects of interspecies relationships, environmental change, fishing effort, and other unknown natural variations.

Public Law 94-265 has put tremendous pressure on the stock assessment science to provide a major part of the data base upon which quotas are set and restoration strategies are determined. However, presently no stock has adequate quantitative data on all items necessary to develop estimates of maximum potential yields that can be harvested without reducing the parent stock. The information necessary includes: ${ }^{66}$

- an understanding of species-stock biology;

- quantification of the commercial indices which allow trends in abundance to be followed;

- survey information that demonstrates changes in total stock abundance and age composition;

- survey information giving pre-recruit indices;

- accurate knowledge of species/stock abundance and area location;

- accurate age and size composition;

- historical catch-effort data;

- understanding of movements and migrations;

- knowledge of the effect of such factors as temperature and water quality; and

- knowledge concerning the interrelatedness among species.

Historically stock assessment has studied individual populations of fish, and the biological basis for management has thus concentrated on the "single species" approach. This approach has assessed the resource potential of one or another species of fish that has had commercial value to fishermen or that has promise of future value, However, to be of the most use in setting optimum yields, stock assessments must take a multispecies approach, looking at the relationship of one species to the survival of another. Biologists have not yet developed a multispecies approach which is generally accepted by the scientific community. ${ }^{67}$ 
Methods of Improving Information Base

The National Marine Fisheries Service budget for stock assessment is \$11.1 million for fiscal 1978, up \$2 million from fiscal 1977 with most of the increase needed to provide information for management in the 200-mile zone, ${ }^{68}$ The budget is projected to double in the next 5 years, but this may not be sufficient. The time and budget needs to provide additional information are enormous. Yet, while such information may well become necessary in the future, the immediate short-term needs for assessment data are for use in designing restoration strategies. Restoration does not demand the same level of accuracy in assessment data that is required for long-term management. In the meantime, increased accuracy of assessment data carries with it cost implications that may be enormous; therefore, it may be far more cost-effective to choose key indicators upon which to make decisions with all parties participating in those decisions aware that, in the end, yield judgments will remain judgments.

It would be desirable to establish clear research priorities for future stock assessment efforts and to define the level of assessment accuracy required for specific management decisions. In addition, clear relationships need to be established between fisheries stock assessment and the needs of other Federal agencies which are responsible for programs which require environmental baseline data. For example, the Department of the Interior requires such information in regions that may be leased for oil and gas development. If properly structured, much of the fisheries assessment work could also be utilized for such purposes and much of the duplication which now occurs could be avoided.
There are two basic problems which arise in the consideration of how to proceed with stock assessments: ${ }^{69}$

1. Because of the threatened status of many marine stocks, much stock assessment information is needed for immediate shortterm management decisions. Therefore, the pressures to expand existing assessment methods are great.

2. Fisheries managers have been pressured to treat stock 'assessment information with the same precision as other resource managers treat their data. However, while forest managers, for instance can count the board feet of available timber, fish populations cannot be counted with such accuracy. Therefore, the new pressures to determine sustainable yields may require more precision than stock assessments have delivered in the past or can be expected to deliver in the future.

These problems should be considered along with two other facts: ${ }^{70}$

1. Assessment history has demonstrated that existing methods have not been properly validated, primarily due to inadequate data, even concerning those species of traditional value to domestic fishermen.

2. The status of stocks-and, in fact, the primary motivation for extension of jurisdiction-requires a reduction of fishing pressure to the extent possible so that the marine biomass can recover. 
When these four items are considered together, it appears logical that a program should be undertaken to improve the stock assessment data which will be used. Such a program could include the following steps:

\section{Test the validity of existing assessment methods during a chosen restoration period}

During this period, fishing pressure on some stocks should be reduced drastically. Estimates of yields should be on the low side; then if they are incorrect, the major consequences are that stocks will recover more rapidly while some economic opportunity is delayed.

During this restoration period, time-series of data could be developed through accurate catch and effort figures gained via the use of observers on foreign fishing vessels and a strict enforcement system. In addition, automatic plankton sorting and fish-aging techniques could be developed along with design and development of hydroacoustics, expanded survey cruises for several wellknown stocks, and use of improved research vessels for survey dependability.

The accuracy of existing assessment methods could also be evaluated under this program to determine the degree of utility the information gained has for management decisions.

\section{While assessing existing methodology, establish} research priorities for the future

During the restoration period, the level of accuracy required for assessments under different management goals could be established. For each chosen goal (for example, "catch the last ton," "resource revitalization," "maximum yield for today," "maximum yield for the future, " etc.), the key indicators that will be required to achieve the determined level of precision could be outlined. Then, for each level of precision and those indicators that achieve that precision the following items could be determined:

- the probable cost;

- the time necessary to provide useful results; and

- the relationship of each variable to assessment accuracy under the existing system.

\section{Design a program strategy}

As the existing accuracy of assessment is determined, and as differing management goals have been chosen with regard to required level of accuracy, costs, time needs, and level of increased utility with regard to existing methods, the following program strategy could be established:

- a listing of information needs, their utility, and their cost;

- the precision of information necessary to achieve various management goals; and

- choices for a cost-effective and useful assessment research program. 


\section{Economic Information}

There has been some work in the field of fisheries economics during the past 25 years to begin a body of data and theory concerning the application of economics to fisheries management problems, and the impact of economists on Public Law 94-265 is clear.

However, additional economic information is necessary under the new law for several purposes:

.to determine the optimum yield;

-to project the domestic catch and capacity to catch;

- to promote efficiency in the harvest sector of the fishing industry;

- to understand and manage the impact of foreign fishing and imports of fish to U.S. markets;

-to determine the greatest overall benefit to recreational fishing; and

-to define fisheries on economically relevant terms. ${ }^{71}$

The following is a discussion of what information is important in each of these areas:

1) Optimum Yield. - The information base of the Regional Councils must be adequate to permit determination of the optimum yield. The biological data which exists or can be generated by existing procedures are not sufficient alone. Economic and social data are required under the law. Economic data necessary to help in determining the optimum yield would include cost and returns, price projections and regional employment considerations for a range of management options. Whenever management plans will cause variations in the quantities of fish which will reach markets, price- and market-structure analyses will be necessary for the people whose incomes will be affected. Expenditure and employment data will also be required on sectors of the economy, such as processing, transportation, and sales outlets which have strong links with the fishing industry and will feel induced or secondary impacts of fisheries management.

2) Domestic Catch Projections. - How much of the optimum yield will be harvested by U.S. fishermen depends, to a large extent, on new investments which are influenced by the economic returns of fishermen. Domestic catch, therefore, cannot be reliably projected without a knowledge of the cost and revenue relationships of the U.S. fleets. In addition to the normal free-market forces which affect cost and revenue, there are various domestic and foreign policies which are important. Among these are vessel-construction subsidies, marketing programs, fisheries development policies, and trade barriers to U.S. exports.

3) Efficiency in the Harvest Sector. -Efficiency in the harvest sector is one of the goals of the various management schemes which may be implemented. Consideration of efficiency requires a formal integration of biological and economic concepts and an adequate data base to express concepts in quantitative terms. The economic data required include cost and earnings information by vessel and gear type, demand relationships and potential nonfishing employment and earnings opportunities for fishermen.

4) Impact of Foreign Fishing and Imports.Economic information on foreign fleets is of particular importance where the fish harvested affect international trade of U.S. importers or exporters. On the import side, fish may 
be caught in U.S. waters, processed in a foreign nation and exported to U.S. markets with obvious implications for domestic prices, employment, and incomes.

A more subtle import market effect may also take place. A foreign nation may have inventories of fish products produced partly from fish caught in U.S. waters and partly in waters outside U.S. jurisdiction. Foreign suppliers could fill U.S. import demands with products made from fish caught outside U.S. jurisdiction and satisfy their own demands or other world markets with fish caught from U.S. waters. Under these circumstances the foreign nation could claim, correctly, that the fish captured in U.S. waters are not entering U.S. markets. However, the end effect in U.S. markets is the same as if fish caught in U.S. waters had been directly exported to U.S. markets.

In terms of U.S. exports, domestic exporters must be able to deliver products at prices competitive with foreign producers. One of the factors affecting competitive status is the level of subsidies received by foreign fleets and/or processors. Thus, to assess the international trade aspects of U.S. fisheries, information on the economics of foreign fleets operating in U.S. waters may be necessary.

This is a complex area because costs and returns of foreign fleets may include hidden impacts of government intervention, widespread subsidization, and various social welfare policies.

Public Law 94-265 specifies that foreign fleets fishing in waters under U.S. jurisdiction must supply certain information. For economic analysis, that data should include direct information on major inputs and costs of foreign fleets, in a form which permits isolation of operating costs in transit to waters under U.S. jurisdiction from the operating costs while in U.S. waters. It should also include information on capital construction costs and foreign subsidies. In addition, physical data on vessel construction, vessel size, and gear characteristics collected for management purposes may be useful in measuring technical efficiency of the fleets by analysis of variances in catch per unit of effort.

There is a further need for information on activities of foreign fishing interests which has arisen since the Fishery Conservation and Management Act was passed. The need is for accurate, up-to-date information in three areas: a) foreign investments in U.S. owned fishing vessels; b) foreign investment in processing plants and wholesale operations; and c) the impact of these investments.

a) Foreign investment in U.S. owned fishing vessels: By law, ${ }^{72}$ the U.S. Maritime Administration must approve the transfer of majority ownership of U.S. documented fishing vessels to foreign ownership. Under a policy published in the Federal Register in 1973, ${ }^{73}$ NMFS agreed to review all fishing vessel transfer applications, giving due consideration to all social and economic factors involved on an individual basis, to determine if such transactions were consistent with U.S. interests or if new regulations would be required to protect fishery resources. However, information on the reasons and results of the transfers is very limited. Through January 1977, more than 1,200 U.S. fishing vessels, ranging from 5 to 500 gross tons, have been transferred to foreign owners or foreign flags. ${ }^{74}$ Once the vessels carry foreign flags they are subject to the same regulations and quotas which apply to foreign-built vessels. 
However, these ships can be returned to the US. flag fleet by an equally simple procedure, and records should be monitored to determine if this is happening in order to give foreign investors access to U.S. fisheries.

There are also foreign investments of less than majority ownership which may influence the economics and activities of fishing vessels, But there are no data at all on these investments, although such investments may ultimately increase the number of U.S. vessels competing for scarce stocks. A larger number of vessels may cause the resource to be spread among more fishermen and make operation inefficient.

b) Foreign investments in processing plants and wholesale operations: The last look at foreign investments in this category was a very limited report which resulted from a special survey of foreign direct investment in the United States, conducted by the Bureau of Economic Analysis of the Department of Commerce in 1974.75

The report, prepared by the Economic and Marketing Research Division of NMFS in April 1976, showed that 47 U.S. commercial fish processing and wholesale firms were at least partially owned by foreign interests which held 10 percent or more of the voting stock. The total value of the foreign investment in U.S. firms was (in 1974) \$129 million. More than half of the firms involved had received foreign investments since 1970 and during 1974 investments rose 30 percent, according to the report.

More than half the total value of foreign direct investment in fishing firms at that time was from the United Kingdom, Japan, and Canada. Other countries investing were Denmark, Iceland, Norway, Kuwait, and Mexico. The firms in which these countries invested operate 107 facilities, located mostly in Alaska and the State of Washington, but also spread along the east coast.

In its report, NMFS acknowledged that a major reason for foreign investment is probably the desire to gain a more certain access to additional supplies of fishery products beyond what the countries can harvest off their own coasts. As the United States and other coastal nations moved to extend their jurisdiction over fisheries out to 200 miles, investments in firms which could export products appeared to be one way of keeping some access to fishing areas which might be closed to foreign vessels. Instead of being frozen out by the U.S. 200-mile fishery jurisdiction, foreign nations with investments in U.S. firms share in benefits and protections of the law.

Presently, there is no mandatory disclosure of the actual extent of foreign investment in U.S. fish processing and wholesale operations. Such disclosure would be necessary in order to determine if foreign investment has increased along lines that would support the NMFS theory that such investments could be used as a hedge against low-catch allocations for foreign fishermen.

In addition, there are no data on the point of origin of fish products imported to this country. Such data, which could identify if fish had been caught in U.S. waters, could be collected by the Bureau of Customs and would help in assessing the impact of foreign fishing activities.

c) The impact of foreign investments: Concern has been expressed by the public and some Members of Congress that foreign investments may allow some countries to circumvent some provisions of Public Law 94-265 or 
that foreign interests may directly or indirectly exert a political influence on policies for fisheries management and regulation. ${ }^{76}$

Concerns about foreign investments in fishing vessels and processing or wholesale operations are that any of the following may result:

- Less processing of fish may be done locally, leaving part of the work to be done in a foreign country by low-cost labor, thus reducing the value of the local industry.

-It may be possible for a vertically integrated company to operate a fish processing plant in the United States on a breakeven basis and take profits abroad thus escaping Federal and State taxes in the United States,

- The firms may be able to operate at lower cost or pay higher prices for fish, thus making competition difficult for firms wholly owned by U.S. interests.

-Large-scale export of products from U.S. plants owned by foreign investors may be a way of avoiding catch quotas and permit fees for foreign fishing vessels.

-Increased demand for fish from foreignowned firms which want to export products may cause increased pressure on stocks from U.S. fishermen.

On the other hand, there is also some support for foreign investment in U.S. firms. Supporters point out that the following can also happen: ${ }^{77}$

-Higher prices may be paid to fishermen for their catch,
- More money may be available for plant expansion and product diversification.

- Risk of production may be reduced by firm commitments from foreign markets for fish products.

- Good markets may be found for products not currently saleable in the United States.

- The fish trade deficit could be reduced which would be beneficial to the U.S. balance of payments.

As a result of passage of the Fishery Conservation and Management Act, NMFS is again pondering the meaning and impact of foreign investments in the fishing industry, but no specific studies have been undertaken yet to determine if these investments will have favorable or unfavorable impact on the overall U.S. fishery and fishing industry. In order to adequately address this problem, a wide range of economic information will be needed, including investment and export data plus all those factors already mentioned as necessary for assessing the impact of foreign fishing and imports,

5) Recreational Fishing.-Although the law is vague on details, it is clear that recreational opportunities in U.S. fisheries are to be considered by the managers. There is a substantial body of literature on recreational benefits, including recreational fishing benefits, but there are gaps in the data and in measurement techniques needed for devising a comprehensive economic data base for recreational fisheries.

6) Definition of Fisheries. - The resources most immediately affected by the law may be classified by species or type of gear and vessel used to harvest them. Classification by species is most relevant for biological data collection and research; however, that definition is not generally relevant to economic considerations. This is because multiple species fisheries are 
involved, and frequently the same vessel can be employed in fishing for several species. In many cases, the same vessel catches several species simultaneously. Classification by type of vessel and gear seems to be indicated for economic purposes, but there is no accurate inventory of vessels by size, gear, and fishing effort.

\section{Status of Current Information}

Presently the responsibility for collecting economic information relative to U.S. fisheries is left almost entirely to the Federal Government through the National Marine Fisheries Service (NMFS). There are no comprehensive regional data collection programs to augment the Federal information base. Few of the regional studies which have been made are based on primary data; most piece the Federal data together with an assortment of ad hoc studies done in the region.

The information in regional studies is often not current by the time they are published and the retrievability and validity of the raw data decay quickly because continuity is lacking and the institutional context of the studies is not favorable to maintaining a continuing data base. Most of the regional studies which have been done would be of limited use to the Regional Councils in their fisheries management work.

Two divisions of the NMFS have been primarily responsible for the collection of economic information. These are the Statistics and Market News Division (SMND), which is specifically charged with the collection of data and preparation of periodic statistical reports, and the Economics and Marketing Research Division (EMRD), which was oriented toward economic research and analysis of SMND and other data.
However, NMFS recently phased out EMRD. In view of the new economic information requirements of Public Law 94-265, this decision raises serious questions about the sources of data and analysis for carrying out provisions of the law.

In the past, the two divisions of NMFS collected information, either directly or from State agencies, on landings by species, value, area of capture, depth, fishing effort, and days absent from port for each vessel trip in the New England offshore fisheries and the Gulf of Mexico shrimp fishery. This information is stored on computer tape or market report sheets and is available at the Northeast Fisheries Center at Woods Hole, Mass., and at the Washington, D. C., office of SMND. Among the other data series collected by NMFS are: ${ }^{78}$

- retail price data for major fish products in New York,

- wholesale price data for selected fish products,

- ex-vessel price data,

- production and cold-storage holdings for many fish products,

- import-export data for various fish products,

- a limited amount of foreign statistics,

- supply, utilization, and stocks of selected fish products,

- commercial landings by State,

- regional summaries of landings,

- processing and foreign trade bulletins,

- historical statistics,

- economic analysis and indicators,

- market news, and

- recreational fishing statistics. 
These are generally accessible to the Regional Councils, but are of limited utility because the format is geared toward researchers rather than fisheries managers. Some, but not all, of these series are available in published form. The published data are more easily available to the Regional Councils, but are also likely to be of limited value because of the time lag between collection and publication.

There is another problem in gathering and using economic information which must be thoroughly considered before the law can be effectively implemented. That is the requirement that "any statistics submitted to the Secretary (of Commerce) by any person in compliance with any requirement (of P.L. 94-265) shall be confidential and shall not be disclosed except when required under court order." 79 The law specifically directs the Secretary to prescribe regulations to preserve confidentiality.

As long as the data made available are in such a form that individuals cannot be identified, there is probably no problem. However, the use of disaggregated data requires careful planning. Plans for using such data while still protecting its confidentiality were not included in the Interim Regulations ${ }^{80}$ formulated by NMFS for use as the councils and Federal agencies prepared for the March 1, 1977 implementation of the Act. Presumably sections on confidentiality will be published shortly because without clarification of how disaggregated data will be handled and protected, Federal employees may be reluctant to supply such data to researchers.
Methods of Improving Information Base

The existing NMFS data base is deficient in several areas if it is to be used to carry out the intents of Public Law 94-265 cited at the beginning of this section. The areas in which additional or more accurate economic information are needed most urgently are vessel inventories; costs and earnings data; vessel construction costs; demand analysis data; vessel size, employment opportunities, skills of the labor force; and recreational fishing benefits.

A continuing annual data base is probably not required in all these areas. However, continuing information is required for vessel inventories, costs and earnings, vessel construction costs, and some components of demand analysis. These data are needed for monitoring and management decisions, which are repetitive and continuous. Data in the remaining areas are needed for working out various isolated problems which arise and which involve more or less unique, nonrepetitive decisions. Special purpose studies or periodic updating, such as once every 5 years, would be adequate for such purposes.

It is estimated that a program to develop this data over the next decade would cost from $\$ 2$ million to $\$ 4$ million per year (see figure 23). This range is a substantial increase over the combined budget of the EMRD and SMND of NMFS, but less than 40 percent of the budget for stock assessments. This reflects the low-funding priority which has been accorded economic research in the past.

It is assumed that the agency responsible for collecting this data would be NMFS acting as lead agency and contracting with other Federal agencies, such as the U.S. Department of Agriculture. This may also be an area in 


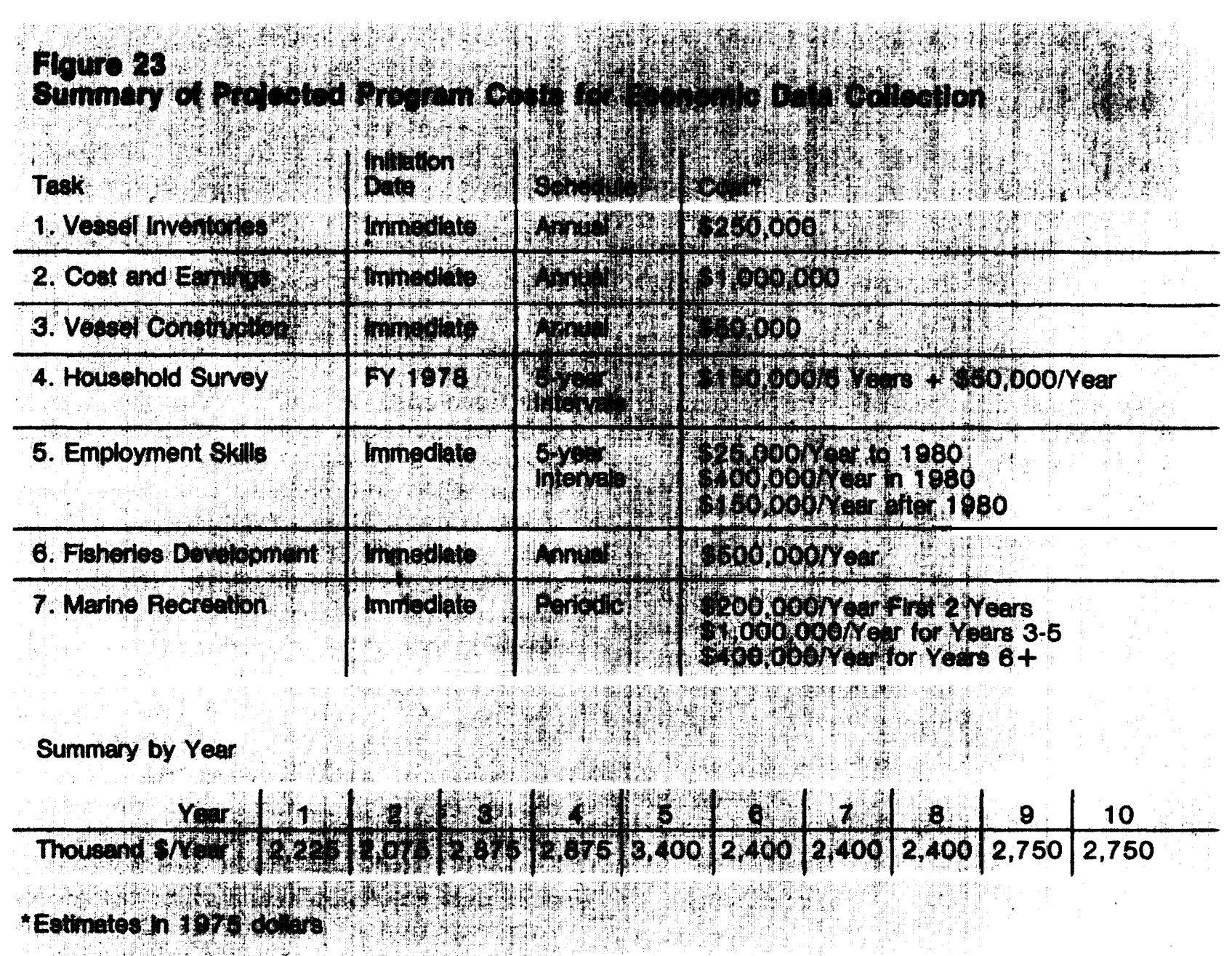

Source: OTA 


\section{Social Information}

which the Regional Councils would wish to contract outside the Federal Government for studies. Since only approximately eight-tenths of 1 percent of the NMFS personnel are classified as economists, NMFS has indicated plans to add economics and statistics staffs to each of the four regional Fisheries Research Centers. This would to some extent alleviate the shortage which exists. There are caveats, however. The plan to create these staffs has not been implemented. Concurrent with this, the economic analysis capabilities of NMFS have almost disappeared with the demise of the EMRD. Furthermore, several economists in the central office have left NMFS.

Even if the additions are made, it is questionable whether these regional staffs will have the time or direction to address economic issues from the national perspective which will be necessary in reviewing management plans. Therefore, although such regional economics staffs are desirable, they are not a substitute for a central economic research and planning capability.
To date, among social scientists only the economists have begun to build up a body of data and theory which is applicable to fisheries management. Other kinds of social scientists on the whole have not addressed fisheries problems in the United States. Social data on fishermen and the communities in which they live are almost conspicuously absent from the literature except for a small body of information on sociocultural systems of modern fishing communities in the United States and other industrialized nations. These data have been developed by anthropologists. Anthropologists have been attracted to fishing largely because of a growing interest in maritime communities and because traditional, rural fishing communities can be studied with the same sets of conceptual tools which anthropologists have developed for studying small, traditional societies in other parts of the world. ${ }^{81}$

Anthropologists who are now interested, prepared, and trained to deal with the social, cultural, and historical dimension of fisheries management could form the core of researchers who gather data on fishing cultures that will be required by fisheries managers. Historians might also be used for social data collection while other researchers with experience or interest in fisheries management are moving into this new field.

Extended jurisdiction and fisheries management will undoubtedly affect everything from fishing technology, crew size, catches, income levels, and employment levels, to migration rates, relative population of communities, and social problems such as the level of alcoholism, delinquency, and crime. Regional Councils will need to know the effect of decisions made under Public Law 94-265 in order to make sensible alterations in fisheries regulations as conditions continue to change. 
In order to develop a starting point in this field where little substantive work has been done, OTA commissioned a study of existing research and needs. This study, which is included in Working Paper No. 2, represents one view of the type of research which needs to be done in order to improve the social information base on fisheries. The OTA Working Paper suggests that three kinds of social data probably will be required by fisheries managers to determine an optimum yield that takes sociocultural factors into account, as mandated by the law: ${ }^{82}$

- baseline information on fishing communities in the United States;

- information on social and cultural factors influencing the acceptance of fisheries management proposals; and

- information on factors influencing the type and rate of technological change which can be expected in the fishing industry in the future.

1) Baseline Information on Fishing Communities. --Baseline data is essentially a picture of the total way of life of fishermen and the communities in which they live. The data will be necessary to the Regional Councils when they are faced with conflicting pressures to make regulations and alter the law in the face of changing conditions. In the absence of accurate baseline data, managers and politicians will have to rely on the recollections of interested parties. Under those conditions it will be difficult to assess exactly what effects specific regulations have had in the past.

Two kinds of baseline data need to be collected by different kinds of research techniques. First, there is a need for quantitative demographic, social, and economic data on a large sample of fishermen and fishing ports. This data could be obtained by:

a) administering a questionnaire to a representative sample of household heads of families in the fishing business to obtain data on family size; age and sex breakdown; range of occupations; consumption patterns; ethnicity; kinship ties; work experience; educational levels; alternative skills; political affiliations; fishing gear used; annual round; species caught; income; associational involvement; and some kind of indirect indicators of commitment to the industry, political awareness, etc.

b) filling out a data sheet on every port in the United States to obtain information on transportation facilities; fish processing capabilities; size of community and size of fishing population; alternate employment opportunities; fisherman's organizations; fishing grounds and stocks; fishery statistics; fleet characteristics; marketing patterns; and facilities necessary for a fishing industry (e.g., hardware stores, repair facilities, docks, etc.).

Second, qualitative information needs to be obtained on the entire culture and social structure of "typical" fishing communities in key areas of the coastal United States. Information on the status and roles of people in fishing crews and cooperatives, the organization of groups in the communities, the values and goals of people in those communities, the kinds of problems people face, and patterns of cooperation and conflict are of special importance. The result of collecting such information would be a set of standard monographs on fishing communities similar to those which anthropologists and sociologists have done in the past. Of course, these monographs would not attempt to cover every aspect of the life and culture of the total community, but rather they would focus on the people and families directly involved in fishing. 
2) Information on Acceptance of Fisheries Management Plans--In the past, many efforts to manage marine fisheries to benefit stocks of fish and the consumer have failed, primarily because the proposals have been massively opposed by the fishing industry.

When people oppose proposals that involve planned social change, there are usually two reasons: a) the change is not economically profitable for them, or b) the change is not congruent with existing social institutions. ${ }^{83}$

If fisheries management plans under Public Law 94-265 are to succeed, they must gain enough acceptance in the fishing industry that they will not invite massive opposition. To gain that acceptance, it will be necessary to understand the costs and benefits of management and who is affected by each.

In most cases, imposition of new fisheries regulations is likely to represent a loss of income to fishermen. This means that the costs of management (in terms of decreased catches) will be borne by the men currently in the fishery. The benefits will be gained by future generations of fishermen. Even if the benefits of management were to, occur relatively quickly, the men currently in the fishery would bear the costs, but they would have to share the benefits with others who are lured into the industry by improved conditions.

Solid information will be needed on the way management plans will affect the costs and receipts of fishermen, distribution of income, and the traditional political, social, and institutional patterns which will be disturbed by changes.
This phenomenon of present fishermen bearing the cost of regulation while future fishermen gain the benefits is another argument for accurate information on foreign investments in U.S. fishing vessels and government subsidies of the foreign fishing companies which may make these investments. Such vessels may be able to bear short-term financial problems more easily than Americanowned domestic vessels because the foreign investment or subsidy provides a cushion. In addition, the extra vessels made possible by foreign investments and subsidies will make it necessary to spread domestic allocations over a larger number of vessels. ${ }^{84}$ This may have social as well as economic impacts on the U.S. fishing community,

3) information on Technological Change.Under the law, catch limitations may be established for all species of fish. Foreign fleets will be allocated that part of the catch which the American fleet is incapable of harvesting. If the American fleet expands, in time foreign fishing efforts will decrease, perhaps cease entirely in some fisheries.

The boats that will do best under catch limitations will be modern boats that can catch fish quickly, before the allocation is used up, The larger, better equipped boats, and larger catches will require larger piers, better maintenance facilities, larger processing plants, and better transportation facilities. But the U.S. fishing industry will not revive or expand if there are no markets for fish, if capital for new boats and technology is not available, if piers, transportation facilities, and other kinds of infrastructure are not present.

The people of coastal areas will have little control over some of these factors, but it is reasonable to assume that the impact of extended jurisdiction and fisheries management 
will depend, in large part, on the degree to which the people of coastal areas can take advantage of the opportunities which arise. Fishermen can respond to the new economic opportunities presented by extended jurisdiction by adopting new boats and sophisticated fishing equipment or by using existing equipment coupled with new fishing and marketing strategies. If large numbers of people are willing and able to change existing practices or to invest in new boats and processing equipment embodying new technology, then the effects throughout the social and economic structure

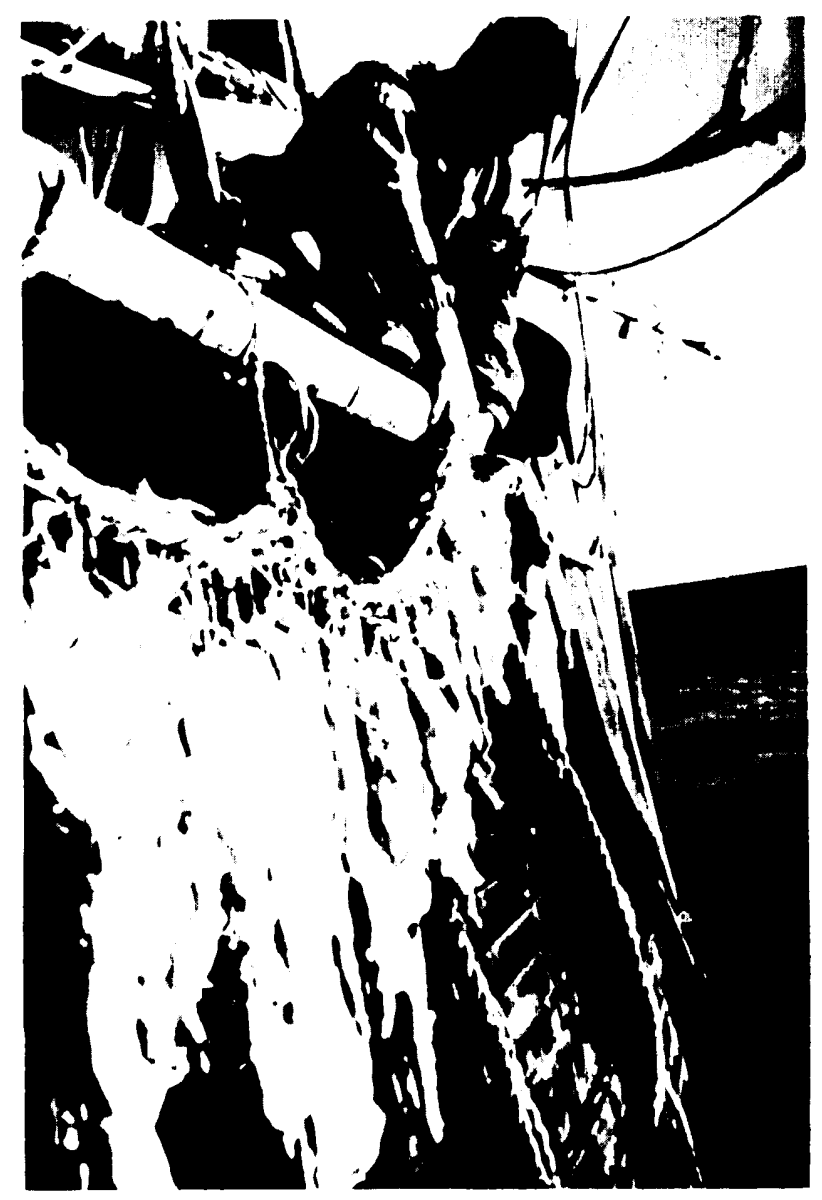

U.S. Navy Photo) Many innovations may be necessary in the care of equipment and catch if the domestic fishing industry is to expand of the coastal communities will be enormous. If fishermen cannot or will not respond, offshore fishing may be gradually taken over by large corporations.

A central problem then is to understand the ability of the people of the coastal areas to adopt innovation, particularly sophisticated fishing equipment. The effects of changes on the rest of the social system cannot be assessed until this is understood.

In order to assess this ability, fishery managers must have the answers to several basic questions.

a) What assets must men have to successfully adopt new fishing technology?

To answer this question, it is necessary to have data on ability to amass capital, ability to save, lending institutions, certain kinds of kinship ties, skills that influence the maintenance and output of fishing boats and determine success in commercial fishing, crew organization, social ties, and the norms which regulate entry into fisheries.

b) How many men in a particular area have the requirements for a successful largescale fishing operation?

Some insight into the answer to this question could be gained by studying the strategies which men currently engaged in large-scale fishing have used in getting assets necessary for adoption of better fishing technology.

c) How many of the men who have the requirements for a successful large operation, or can easily acquire them, are interested and motivated to invest in modern equipment?

In order to study patterns of adoption of new innovations, data should be gathered from both large and small operators about the characteristics of men who were "early adopters" of innovations in the past; the factors 
necessary for successful adoption of new technology; the social, economic, and cultural factors which in the very recent past have impinged on the decisions of men to innovate or not; and biographic and motivational information on men who control the requirements for adoption of new technology.

\section{Status of Current Information}

Almost none of the information is available to complete the kinds of studies suggested here.

There are only a few monographs on modern fishing communities and a few books on ancillary topics such as organization of fishing crews and marketing. Of course, the National Marine Fisheries Service compiles information on landings and fish prices. The National Marine Fisheries Service, however, collects little data about the fishing fleet and no information about fishing effort or any other kind of data on social and political institutions or economic performance. The Bureau of the Census has compiled general data on fishing as an occupation and on communities where fishing is done. The Census' data are very superficial and are aggregated in ways that give a picture of units no smaller than towns. Existing studies do not give sociocultural data on the U.S. fishing industry as a whole.

\section{Methods of Improving Information Base}

The information needed for these studies overlaps a great deal. The first studies to be completed would be indepth studies of important fishing communities, since all the other studies can to some degree draw on the information generated. It would be reasonable to expect, if 10 to 15 community studies were begun at the same time, a set of monographs could be completed in 2 to 3 years.

The second study should be a survey of attitudes towards management proposals and factors necessary for technical innovation. The questions to be included might very well depend on the part of the country being dealt with.

The amount of time such a study would take depends greatly on the number of interviews needed to obtain statistical reliability. It is estimated that as many as 6,000 interviews would be necessary in the entire coastal region of the United States, and it could take a year or more to collect and tabulate the data.

Once this information was available, the remaining studies on innovation and the acceptability of management alternatives could begin. All of these would involve indepth interviews-perhaps at the same locations where the community studies were done. These studies would take another year of interviews and analysis. However, these two groups of studies could not be done by the same person in any given area, since the kinds of people who have the analytical tools to analyze costs and benefits of various management alternatives probably would not be able to concentrate on the very different issues connected with studying technical innovation and impact.

A group of projects similar to those which are used as examples here could be completed in 4 to 5 years. However, these suggestions and others which may be offered should first be tested and refined by social scientists in order to devise an acceptable research plan. Such a plan should be implemented on both the regional and national level in order to develop data which will be useful to NMFS and the Regional Councils, 


\section{Future Developments in the Fishing Industry}




\section{Background}

One of the purposes of the Fishery Conservation and Management Act of 1976 is to encourage the revitalization of the U.S. fishing industry, particularly through development of now underutilized stocks.

Development of the fishing industry is a complicated subject about which little reliable information has been accumulated in the past. With the stimulus provided by the Act, however, new efforts are being made to determine the needs of the industry and the role of the Federal Government in meeting those needs or aiding the industry in meeting them.

Because several other studies ${ }^{85}$ were already underway dealing with the needs of the fishing industry, the OTA analysis of this subject was limited to a very general look at the industry. It was intended that once surveys mandated by the Eastland Resolution are completed, that information, together with data collected by the General Accounting Office and OTA, should be correlated and analyzed before further study of the industry is undertaken.

In the meantime, there appears to be general agreement among the Eastland group, GAO, and OTA about the status of relationships between the Federal Government and the fishing industry:

1) The capability and equipment exists for catching almost any kind of fish. Some of this capability is vested in foreign fishing fleets, but it could be adopted for domestic use if there were incentive to do so. What is needed most is a dependable resource and good markets for the catch. These two factors would cause increased interest in technology transfer and new equipment and would allow industry to generate capital for such investments.
2) The Federal Government does not have much dependable information about technology in the fishing industry.

3) Fishing technology is very uneven within the industry, ranging from very poor equipment which results in unsuccessful operations to modern, sophisticated equipment which results in highly successful operations - all in use in the same fishery.

4) Assessment of fishing equipment and the development of new equipment is difficult without "hands on" experience in the fishing industry.

5) Established fishermen and boat operators generally do not favor Government development of new fishing technology.

6) The industry generally prefers that the Government limit itself to technology transfer and information services rather than massive financial or research support.

The following discussion of future developments in the fishing industry is based on OTA research on the west coast and in the New England ground fishery. It is divided into three areas which are key to improving the overall picture of domestic fishing:

1) stock enhancement (increasing the total amount of product available to the fishermen),

2) creation of new markets for fish which are not presently harvested by U.S. fishermen because they are not a saleable product, and

3) methods of revitalizing the fishing industry.

Each of these areas is discussed in terms of what will be necessary in order to develop useful programs. 


\section{Stock Enhancement}

The Fishery Conservation and Management Act of 1976 could be a stimulus for comprehensive stock enhancement programs which would improve many of the U.S. fisheries. For example, the National Marine Fisheries Service (NMFS) has projected that enhancement could result in the ultimate restoration and a 100 percent increase in the catch of U.S. groundfish. ${ }^{86}$

Basically stock enhancement is the use of procedures which will increase the total amount of edible biomass by increasing the number of fish and/or the size of fish in the population.

Stock enhancement is a complex subject, and in spite of erratic periods of intense interest by various private and governmental groups, detailed studies are not numerous. In general, certain fisheries, such as salmon, are better understood in terms of stock enhancement than others. Various reasons can be given for this lack of data, but one major factor is the problem of control and recovery of stock by the government responsible for the enhancement activities. By extending fishery jurisdiction to 200 miles, the United States has taken control over the fisheries which would benefit from enhancement and has assured that US. citizens or permit holders could reap the harvest of stocking programs.

There are a number of commercially important species which could benefit from enhancement programs. Some of these are cod, haddock, yellowtail and blackback flounder, ocean perch, pollock, Gulf shrimp, Pacific salmon, Alaska crab, Atlantic herring, and Pacific pollock. ${ }^{87}$ Enhancement possibilities and the benefits to be gained are different for each. These species were selected somewhat arbitrarily in order to study enhancement possibilities as described in OTA Working
Paper No. 4. The heavy fishing of these species in the past, with the depletion of stocks of some, and the existing well-developed markets for products of these species make them likely targets for enhancement. However, if a comprehensive program were to be undertaken in reality, careful analysis should go into the selection of the species for enhancement and the specific enhancement methods to be used with each species.

The most commonly used methods of enhancement are control of the harvest, recruitment, development of new stocks, habitat management, and aquiculture. The following is a brief description of how each of these methods is used:

1) Control of harvest: If the amount of biomass removed from the stock is properly regulated, then the maximum sustainable yield can be achieved. However, a depleted stock, such as haddock, might increase in biomass by natural processes if the amount of fishing is decreased. The levels of harvest which allow this natural recovery are not always easily determined and must be evaluated constantly.

2) Recruitment: to Assist a natural population in attaining a maximal size consistent with the marine ecosystem, additional fish can be added to the stock, Many fish can be reared in hatcheries under man-controlled conditions and then released into the natural environment when they are large enough to survive the predation and environmental hazards encountered by very young fish. Hatchery programs related to Pacific Coast salmon and many freshwater species, such as trout and bass, provide excellent examples of successful recruitment. Unfortunately, many marine species have not yet been reared under hatchery conditions although some attempts have been made. 
3) Development of new stocks: Utilizing standard breeding and genetic selection techniques, new stocks which have desirable traits, may be developed and introduced into marine waters or into confined waters for aquiculture purposes.

4) Habitat management and environmental quality: Some species spend a portion of their life cycle in estuaries, rivers, or near shore environments. Poor water quality can have a detrimental effect on the size of the stock either through a marked increase in mortality or sublethal effects such as stunted growth. Programs of pollution abatement will assist in stock enhancement. In addition, some attempts at habitat manipulation may increase the availability of a suitable habitat for a species, such as artificial reefs or an increase in the level of nutrients by artificial upwelling. These nutrients stimulate the growth of phytoplankton, making more food available.

5) Aquiculture or mariculture: Animal husbandry of marine organisms has been extensively tried within the 3-mile limit; however, open-sea mariculture experimentation is now underway. Typically aquacultural techniques are used with organisms that are confined to a specific area for harvesting as opposed to nursery programs where organisms are usually released to natural bodies of water,

Any of these enhancement techniques have implications for data gathering programs because specific information is necessary for carrying out the procedures, beginning with an understanding of the genetic and functional differences-the different stocks or populations - that exist within one species of fish. Most of the economic, social, and stock assessment information mentioned in the previous section would also be necessary to design and implement enhancement programs which carry out the spirit of Public Law 94-265.

Decisions for improving an existing fishery or developing a new fishery by enhancement techniques would require an intensive and integrated examination of all facets of a fishery: resource assessment, harvest and processing technologies and costs; market potentials; and institutional factors including artificial barriers to trade. But the absence of viable industry for the fishery make it likely that special studies will be necessary to collect data and project economic effects. If the enhancement efforts were successful, these special studies could become the starting point for the continuous monitoring and periodic collection of statistics which will be part of management and conservation programs in established fisheries. 


\section{New Markets for Fish}

Extended jurisdiction will undoubtedly open new markets for species now caught as well as markets for species not caught by U.S. fishermen at present. It is reasonable to assume that the response to these economic opportunities will be highly varied. Some of the factors influencing acceptance or rejection of these opportunities are similar to those affecting technical innovation. In addition, the responsiveness of fishermen to new markets depends on their ability and willingness to catch new species and to process them in ways that make them saleable. Two questions are paramount:

1) Under what conditions will fishermen exploit new species and markets?

2) How many fishermen will exploit a set of species under a given set of conditions?

Studying the conditions under which fishermen will exploit new species is simplified by the fact that fishermen now often exploit many different species over the course of the year. At present, it appears that price is one of the primary factors influencing the decision of fishermen to catch various species. That is, they choose the species which will give them the highest revenues relative to costs. If this is generally true, then a change in the economic climate, especially changes in ex-vessel prices, would be one of the key factors influencing the responsiveness of fishermen to exploit new species. In addition to the prices which might be paid for new species, stock assessments and projections of yields from new species are needed in order to determine if the stocks can sustain a market.

In addition, some social information maybe needed to determine the preferences fishermen will have for entering some markets and avoiding others. Their unwillingness to accept certain innovations may limit their ability to enter some markets. This may be true in spite of changes in prices.
In order to study the social, cultural, and economic factors influencing the decision of fishermen to enter certain markets at present, two kinds of studies are needed:

1) Data needs to be gathered comparing fishing practices of boats which exploit a wide range of species over the annual cycle with practices of those that do not. Emphasis should be placed on such factors as the prices paid for fish, the catch of various species, the locations where fish are caught, etc. Interviews should be obtained with fishermen concerning their decision to enter a given market (i.e., exploit a given species requiring certain handling and processing procedures), and the social and cultural factors inhibiting them from entering others.

2) A set of questionnaires might be administered to a carefully selected sample of fishermen to obtain data on their preferences concerning entry and exit from particular fisheries,

3) Information needs to be gathered to identify factors which affect the price paid for fish at the docks, the stability or flexibility of that price, and how the price affects the fisherman's willingness to direct his efforts toward certain species. This information should be supplemented by identification of ways in which prices could be stabilized or otherwise manipulated by Government or industry in order to encourage fishing activity.

This kind of information is of particular importance for fisheries managers. A knowledge of the factors affecting entry and exit into different markets would allow managers to draw up management plans influencing exvessel prices paid (e.g., taxes and subsidy) and to manipulate the relative fishing pressure on various species. 


\section{Revitalization of Fishing Industry}

Presently, the fishing industry may be unable to take advantage of opportunities which could be offered by stock enhancement or new markets because many sectors of the industry are experiencing economic difficulty and are unable to attract capital and labor. Yet, no coherent program has been developed to assist the industry or fishermen,

As noted in the previous section of this report, economic information about the fishing industry is not available in the quality or quantity which is necessary to evaluate problems in any segment of the industry. The status of investment in new harvesting technology and systems, however, has been used as a measure of economic well-being. Many studies of the New England fishing industry conclude that technology is old and inefficient. It is clear that investment in new ships and harvesting technology in New England fisheries was at a low point until passage of the Fishery Conservation and Management Act of 1976 was assured. The Act stimulated new confidence in the future of the fishing industry and at least 20 new boats were ordered for fishing fleets in New Bedford, Mass., and Point Judith, R.I. However, there is concern among some Regional Council members ${ }^{88}$ that investment in U.S. fishing vessels may continue to lag, in part due to the industry's lack of success in getting import duties levied or increased on fish products from countries which subsidize their fishing industry.

Members of the fishing industry have long contended that the flow of subsidized products into the United States adversely affects the competitive position of the U.S. fishing industry (see figure 24). Imports from Canada are of particular concern because the United
States and Canada share access to many fish stocks. The Canadian Federal and Provincial Governments have traditionally provided grants, bounties, and other forms of direct and indirect subsidies to their groundfish industry and the cumulative effect of these grants and subsidies has been calculated to reach 35 cents (Canadian) a pound for some types of fish products. In 1975, 150 million pounds of major groundfish species which may have benefited from such subsidies were exported from the Atlantic fishery in Canada to the United States. ${ }^{89}$

By law, ${ }^{90}$ the Bureau of Customs may levy a duty on imported products which are produced with the support of a foreign government subsidy or increase an existing duty if there is proof the import is injuring a U.S. industry, Such duties could help protect both the U.S. fishery resources and U.S. investments in fishing vessels. They could also, of course, raise the price of foreign fish products to U.S. consumers and possibly encourage retaliation by foreign governments against some U.S. products.

Under existing practices, ${ }^{91}$ the Tariff Affairs section of the Treasury Department considers duties on fish imports on a case-by-case basis as some segment of the U.S. fishing industry requests that a particular duty be levied or increased. Treasury does not routinely monitor duties on fish imports in order to determine their effects; does not initiate action to counterbalance any unfavorable effects; and does not develop the case when a U.S. industry requests some change in a particular duty situation, Therefore, the full burden of proving that changes are needed in duties on imported fish products falls on individual fishermen or firms which initiate action.

This is an extremely difficult task. There are no established criteria for demonstrating that subsidized imports injure U.S. producers, but the fishermen must generally prove that par- 
Subsidies

Federal Grant for

Performance Improvement

\section{Subsidies}

Grants, Loans, Loan

Guarantees by Federal

and Provincial Governments

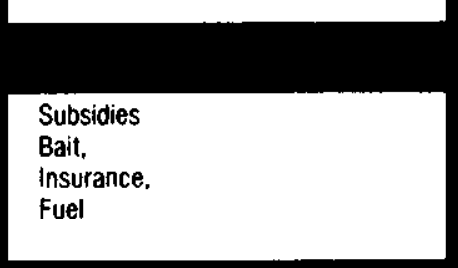

Subsities

Federal and Provincial Payments

to Vessel Owners Per Pound of

First Quality Fish Landed

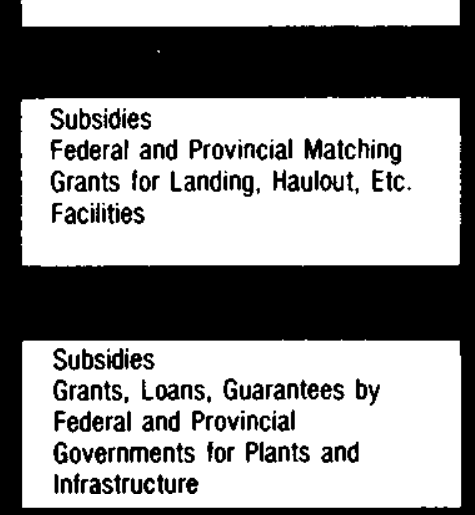

\section{Subsidies}

Paid Per Pound, Fresh and

Frozen Fillets and Blocks

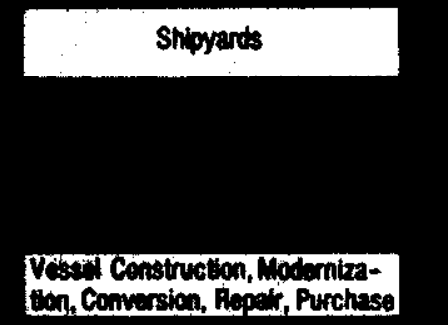

Effect

Makes Shipyard Services

Available at Lower Price

\section{ten, Comversion, Repeit, Purchese}

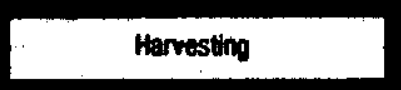

Effect

Reduces Current

Operating Outlays

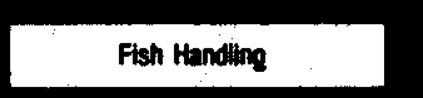

Elfect

Increase Supply and

Lowers Price of First Quality

Landed Groundfish

\section{Landing Facilltios}

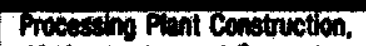

Modernication and Expersion

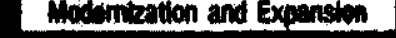

Effect

Substantially Reduces Required

Investment in Processing Plants,

Raises Proportion

of New, Efficient Plants

Fish Processing
Effect

Reduce Required Outlays by

by Fishing Vessels

Source: Center for Ocean Management Studies, University of Rhode Island

Effect

Reduce Margin Necessary to Break

Even on Processing. Increases

Supply of Fresh Fillets, Frozen

Fillets and Blocks 
ticular subsidized imports have caused declining production in the United States, unemployment, or decreased markets for U.S. products. Therefore, large corporations with experienced tariff attorneys are frequently successful in winning their cases, and small industries and fishing groups which generally develop their own cases are less successful or are discouraged from making a request,

To date, in spite of the urging of fishermen, no overall review of duties on subsidized fish imports has been made in order to determine how the U.S. fishing industry in general is affected. Such a review would allow investors to assess the competition from foreign products accurately before putting money into vessels or other fishing operations. Some Regional Council members feel that encouraging U.S. interests to invest in the fishing industry is unrealistic and counterproductive until such basic assessments can be made.

In addition, there has been a general decline in some fisheries which has been evident in terms of technology and investment, employment and income, productivity and profit.

To provide some insight into conditions of technology in the fishing industry, OTA informally surveyed fishermen on the west coast about their gear and sources of technical information. The survey consisted of a short questionnaire which was included with other materials distributed by the Eastland Resolution Fisheries Survey group at their west coast meetings. About 100 fishermen from a variety of fisheries responded to the questions.

The survey showed that nearly all crabbers, aquaculturists, and charter-boat operators considered their gear the best available for their operation; a majority of the trollers and seiners were equally confident about the

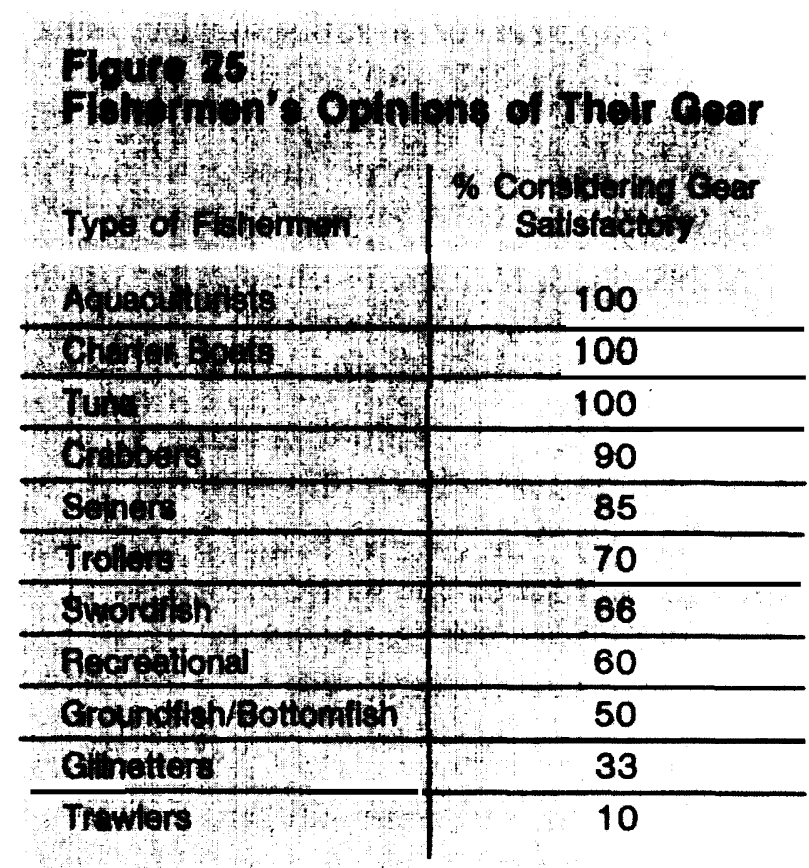

Source: OTA

quality of their gear; and half or slightly more of the tuna, bottom, swordfish, and recreational fishermen were satisfied. Gillnetters and trawlers reported very low levels of satisfaction, indicating that improvement in their gear is badly needed. Figure 25 illustrates responses to the question of whether gear was satisfactory. Several specific types of needed improvements were cited:

. better nets for groundfish;

-better gillnets; 
-development of a multipurpose, small scale mid-water trawl; and

- more efficient equipment to freeze, handle, and store fish onboard fishing vessels.

Although more than one-third of the fishermen responding expressed an interest in modernizing equipment and using electronics onboard their vessels, many fishermen emphasized that the job could better be done by private industry than Government.

However, Government assistance was strongly advocated for work in several areas of more public concern, such as:

- habitat improvement;

- location of fish;

- identifying migration patterns of fish;

- improving dissemination of weather and water-surface temperature data to fishermen;

- finding solutions to localized pollution problems;

- stressing the need for conservation; and

- improvement of stock assessment information.

OTA also asked the Pacific fishermen how they presently receive technical information and how useful that information is to them. The major source of information was the Sea Grant program through an information system similar to the Agricultural Extension Service. Other sources of information were individual State programs or State universities and fishermen's publications. Information from these sources reached about two-thirds of those surveyed, but only slightly more than half of the respondents considered the information useful (see figure 26).

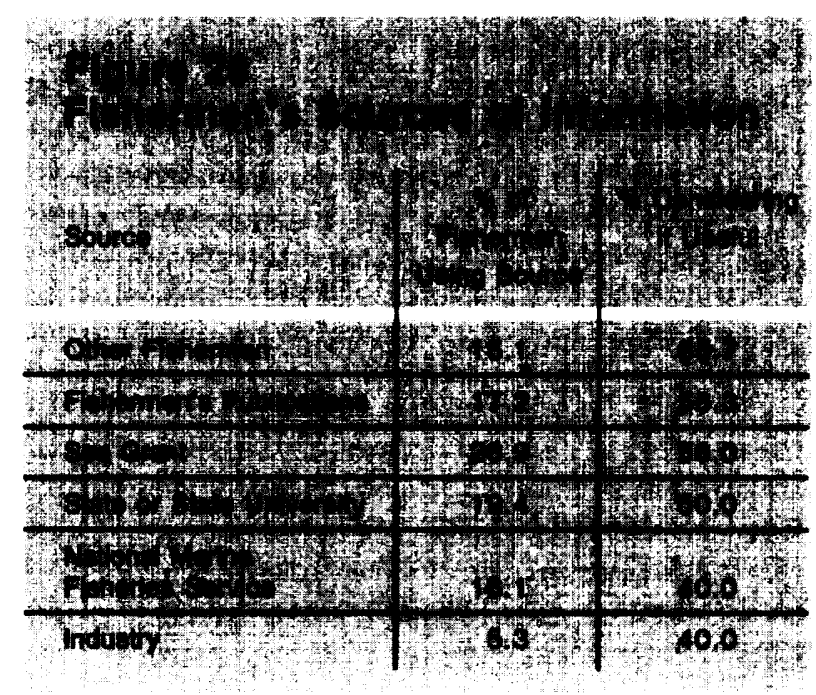

Source: OTA

The National Marine Fisheries Service and some industry sources also provide information, but only 40 percent of the respondents found it useful.

A small group of fishermen got their information only from other fishermen, but such information had the highest reliability rating of any of the sources of information mentioned.

Since the Federal Government through NMFS and Sea Grant already has some structure for disseminating information to fishermen, it appears likely that this structure could be expanded and improved to reach a larger segment of the fishing population. It should provide more information from a variety of sources, including trusted segments of the fishing industry itself. Such an information 
system could make use of a clearinghouse concept that gathers and distributes data and perhaps daily NOAA radio reports with weather forecasts, water temperature, weekly reports of fish landings, announcements of current research programs, results of research, and information on grants and financial assistance available to fishermen. Such information could be provided with relatively little effort and expense. Other information which would be useful to fishermen, but would require additional research and expense, includes reports on foreign fishing techniques, data on migration patterns of fish, and reports on stock assessment, marketing, distribution, and handling of fish.

The equipment and information needs of the industry will inevitably be debated by the Regional Councils in the course of formulating regulations for the domestic fishery. Gear particularly will come under scrutiny as the councils consider gear restrictions as a means of regulating catch. Such restrictions will limit the efficiency of existing gear and are sure to be challenged by the fishermen. The result may be an increased need for innovations in gear or it may be that councils will be forced to find alternate ways of regulating catch. (For example, a system of fees for illegal bycatch, instead of restrictions on mesh size, may be used, leaving fishermen free to find their own ways of modifying gear or fishing practices so that illegal fish are not taken.)

Since the councils will be deeply involved in this area, they should be charged with studying the needs of the fishing industry in their areas and proposing appropriate actions to the Federal Government. In this way, such proposals are likely to more accurately reflect the thinking of the industry and be compatible with industry desires an-d fishery management plans. The councils, through NMFS, should also be charged with sharing with other regions what knowledge they have gained about industry practices and problems, proposed Government actions, and successful or unsuccessful management techniques.

Revitalization of the U.S. fishing industry is the subject of a recent report by the General Accounting Office ${ }^{92}$ and a study by the Eastland Fisheries Survey which will be completed soon. Programs for assisting the industry or removing constraints are being proposed by both groups. But sufficient data about various segments of the fishing industry are not now available for evaluating what revitalization proposals are justified. At least the following questions should be addressed for each industry segment so that Government agencies, fisheries managers, and private industry can determine what programs are needed and what actions are best suited to each group:

1) What is the status of the fish product involved, including history and trends of catch, value, prices, market demand, and distribution? What competition with imports exists?

2) What is the status of the technology used for harvesting, its efficiency, its productivity, the effect on the resource, and the cost of production?

3) What is the status of the labor force and earnings in the fishery?

4) What is the normal and possible area of coverage of the fishery? What mobility and flexibility is available to expand or change? 
5) What is the status of the resource? Is there foreign competition for the same resource or another species in the same ecosystem ? Can the resource be enhanced or the yield increased? Are there other underutilized resources available for the same industry?

6) What is the economic condition of the industry? What future changes are likely with assistance programs and would they provide short-term or long-term solutions?

These questions could be tested on specific industry segments and with specific revitalization proposals in order to develop a comprehensive program which addresses national needs most completely.

That job could be undertaken by a committee of representatives from each of the Regional Councils. The council committee could synthesize information on industry needs which has been collected by the Eastland Survey, the General Accounting Office, OTA, and NMFS. The council committee could then identify important information which is still missing, gather that information itself or through contracts, and recommend a specific course of action for Congress to follow if it desires to take legislative action which could encourage growth in the fishing industry. The council committee could also recommend specific changes which could be made administratively by NMFS, NOAA, or other agencies currently responsible for programs which include financial aid, research or information pertinent to the fishing industry. 
7. Glossary 
acoustic-relating to, containing, producing, arising from, actuated by or carrying sound.

aquiculture-cultivation of natural fauna resources of water.

biomass-the dry weight of living matter, including stored food, present in a species population and expressed in terms of a given area or volume of the habitat.

catch effort-the ratio of amount of fish caught to some measure of fishing effort such as the number of days a typical vessel is fishing.

demersal fish-living at or near the bottom of the sea.

electro-optics - the study of the influence of an electrical field on optical phenomena, as in the electro - optical Keer effect and the Stark effect. Also known as optoelectronics.

ex-vessel-price received by fisherman for fish, shellfish, and other aquatic plants and animals landed at the dock.

finfish-classes cyclostomata, elasmobranchin and pieces of the phylum vertebrata; excludes other marine organisms.

fish meal-a protein rich, dried-food product produced from inedible portions of fishes by dry or wet rendering. Also known as fish protein concentrate.

fish oil-oil obtained from fish such as menhaden, herring, sardine, and pilchard; used as a drying oil in paint and as a raw material for detergents, resins, and margarine.

gear-implements developed for the capture of all aquatic animals. gill net-a wall of webbing suspended vertically in the water by means of weights (lead) on the bottom line and corks on the top line. The webbing may be made of cotton, linen, or synthetic material. The mesh is selected according to the fish which will be captured.

groundfish-broadly, fish that are caught on or near the sea floor. Bottom fishes, rockfishes, and flatfishes, cod, haddock, pollock, and Atlantic ocean perch.

hydroacoustics-study of the propagation of sound waves in water, especially in the oceans, and of phenomena produced by these sound waves. Also known as underwater acoustics.

landings-commercial quantities of fish, shellfish and other aquatic plants and animals brought ashore and sold. Landings may be in terms of round (live) weight or dressed weight. Landings of crustaceans are generally on a live-weight basis except for shrimp which may be on a heads-off basis.

Loran-C-a low frequency radio navigation system by which hyperbolic lines of position are determined by measuring the difference in the times of reception of synchronized pulse signals from two fixed transmitters; as compared to Loran-A, time difference measurements are increased in accuracy through utilizing phase comparison techniques in addition to relatively coarse matches of pulse envelopes of received signals within the Loran-C receiver.

magnetic-having properties of a magnet; exhibiting magnetism; phenomena involving magnetic fields and their effects upon materials.

maximum sustainable yield-the balance between the capacity of the resource to renew itself and the harvest that man can take. 
mesh size-a size of screen or of particles passed by it in terms of the number of openings per linear inch. Also known as mesh.

microwave radiometry-a receiver for detecting microwave thermal radiation and similar weak wide band signals that resemble noise and are obscured by receiver noise; examples include the Dicke radiometer, subtraction type radiometer and tworeceiver radiometer.

over-the-horizon radar-long range radar in which the transmitted and reflected beams are bounced off the ionosphere layers to achieve ranges far beyond the line of sight.

pelagic fish-organisms living in the open sea, including both plankton and nekton.

population-a group of organisms occupying a specific geographic area.

recruitment-young fish that just become available (vulnerable) to the fishing gear. In long-lived species only a portion of a year class may be recruited each year until finally all are vulnerable.

remote sensing-sensing by a power supply, of voltage directly at the load, so that variations in the load lead drop do not affect load regulation.

seine net-a net used to catch fish by encirclement usually by closure of the two ends and the bottom.

seining-surrounding a shoal of fish with a long net, suitably buoyed and gradually drawn closer until the fish can be readily removed.

stock-a population of a species which occupies a specific geographical location, especially at the time of reproduction. stock assessment-the study of individual populations of fish in order to determine the size and composition of the population as well as estimates of possible yields.

stock enhancement-procedures whereby the total amount of edible product (biomass) is increased by increasing the number of animals and/or size of animals in the population.

trolling-method of angling whereby an artificial line or natural bait is drawn behind a moving boat at any depth from the surface to the bottom and at varying speeds according to the species of fish being sought. Accomplished in all types of craft.

trophic level-any of the feeding levels through which the passage of energy through an ecosystem proceeds, examples are photosynthetic plants, herbivorous animals, and micro organisms of decay.

utilization-use of all fishery products both edible and inedible. Estimated disappearance of the total supply of fishery products both edible and inedible on a roundweight basis without taking into consideration beginning or end stocks.

year class-all of the progeny of the reproduction from any particular year. In species with fluctuatory spawning success the progeny of the successful spawning of one year class may dominate the population at successive ages for several years. 


\section{Footnotes}


1. "Resources of the Oceans," Bulletin of the American Fisheries Society, Vol. 1, N. 3 (May - June 1976) p. 20.

2. U.S. Department of Commerce, National Oceanic and Atmospheric Administration, National Marine Fisheries Service, Fisheries of the United States, 1975, Current Fishery Statistics No. 6900 (Washington, D. C.: Government Printing Office, March 1976) p. 73.

3. Comptroller General of the United States, The U.S. Fishing Industry-Present Condition and Future of Marine Fisheries, Report to the Congress, Vol. 1 Pubn. No. CED-76-130 (Dec. 23, 1976) p. 7.

4. Op. cit., "Resources of the Oceans," p. 20.

5. Op. cit., The U.S. Fishing Industry-Present Condition and Future of Marine Fisheries, p. 11.

6. Ibid.

7. Ibid.

8. Op. cit., Fisheries of the United States, 2975, p. 31.

9. Op. cit., The U.S. Fishing Industry-Present Condition and Future of Marine Fisheries.

10. Office of Technology Assessment, "Fisheries Technology Assessment: An Interim Status Report" (Washington, D. C., January 1976, Xeroxed) p. 10.

11. U.S. Department of Commerce, A Marine Fisheries Program for the Nation (Washington, D.C.: Government Printing Office, July 1976) p. 7.

12. Op. cit., "Fisheries Technology Assessment: An Interim Status Report," p. 5.
13. Fishery Conservation and Management Act of 1976, P.L. 94-265, 16 USC 1801 (1976), Sec. 2 (a) Findings (2).

14. Ibid., Sec. 2 (c) Policy.

15. Op. cit., Fisheries of the United States, 1975, p. 82.

16. Op. cit., A Marine Fisheries Program for the Nation, p. 3.

17. US. Department of Transportation, U.S. Coast Guard, "Study of Coast Guard Enforcement of 200-Mile Fishery Conservation Zone, (PL 94-265)," 1976 (Internal, Xeroxed) Appendix A.

18. Op. cit., A Marine Fisheries Program for the Nation, p. 1.

19. Op. cit., The U.S. Fishing Industry-Present Condition and Future of Marine Fisheries, p. 22.

20. Op. cit., "Study of Coast Guard Enforcement of 200-Mile Fishery Conservation Zone (PL 94-265)," p. II-8.

21. Ibid., p. A-1.

22. Ibid., p. B-1.

23. Ibid., Appendix C.

24. Ibid., p. III-4.

25. Interview, Ocean Operations Division, U.S. Coast Guard, Washington, D. C., January 17, 1977.

26. Op. cit., "Study of Coast Guard Enforcement of 200-Mile Fishery Conservation Zone (PL 94-265)," p. V-2.

27. William T. Coleman, Jr., U.S. Department of Transportation, to Congressman John J. McFall, Washington, D. C., January 19, 1977, Enforcement of 200-Mile Fishery Conservation Zone. 
28. Sig Jaeger, North Pacific Fishing Vessel Owners Association, to Peter Johnson, Washington, D. C., May 21, 1976, Commentary on Draft Copy of USCG Plan for Disposition of Enforcement Resources and Estimated Effectiveness Under PL 94-265.

29. Commerce Committee hearing, January 24, 1977.

30. Op. cit., Interview, Ocean Operations Division.

31. Ibid.

32. Interview, Office of Program Planning and Evaluation, National Marine Fisheries Service, Washington, D. C., February 4, 1977 (By Telephone).

33. National Marine Fisheries Service, Draft Fee Schedule, "Fishing by Foreign Vessels in Waters Under the Jurisdiction of the United States of America," Federal Register 41, N. 248, December 23, 1976, p. 55925.

34. Op. cit., Interview, Ocean Operations Division.

35. Interview, New England Regional Fishery Council, Washington, D. C., February 2, 1977.

36. U.S. Department of Commerce, Rules and Regulations, "Part 601-Regional Fishery Managment Councils," Federal Register 41, N. 180, September 15, 1976, p. 39436.

37* Working Paper No. 5

38. Op. cit., Interview, Ocean Operations Division.

39. Ibid.

40. Ibid.
41. U.S. Department of Transportation, U.S. Coast Guard, "R \& D Plan for the 200Mile FCZ", Washington, D. C., January 7, 1977. Draft (Xeroxed).

42. Op. cit., Interview, Ocean Operations Division.

43. Ibid.

44. Working Paper No. 5.

45. Ibid.

46. Ibid.

47. Ibid.

48. Ibid.

49. Ibid.

50. Ibid.

51. Ibid.

52. Op. cit., Fishery Conservation and Management Act of 1976, Sec. 3 (2).

53. Op. cit., The U.S. Fishing Industry-Present Condition and Future of Marine Fisheries.

54. Op. cit., Fishery Conservation and Management Act of 1976, Sec. 3 (18).

55. Working Paper No. 4.

56. Ibid.

57. Working Papers No. 1 and 2.

58. Interview, Office of Policy Development and Long Range Planning, National Marine Fisheries Service, Washington, D.C., February 1, 1977.

59. Op. cit., Interview, Office of Program Planning and Evaluation.

60. U.S. Department of Commerce, National Oceanic and Atmospheric Administration, National Marine Fisheries Service, Council Memorandum, Vol. 1, January 1977, p. 2. 
61. Op. cit., "Part 601-Regional Fishery Management Councils."

\section{Ibid.}

63. Working Paper No. 3.

64. Ibid.

65. Working Paper No. 4.

66. Working Paper No. 3.

67. Op. cit., Interview, Office of Policy Development and Long Range Planning.

68. "NOAA Program Levels," Marine Fish Management, Vol. 3, N. 1 (January 1977) p. 1.

69. Working Paper No. 3.

70. Ibid

71. Working Paper No. 1.

72. Shipping Act of 1916, Sects. 9 and 37.

73. State of Alaska, Division of Economic Enterprise, Japanese Investment in Alaska (Alaska: Department of Economic Development, August 1974) p. 13.

74. U.S. Department of Commerce, Maritime Administration, Applications for Sale of Foreign Fishing Vessels, FY 1971 thru January 1977.

75. U.S. Department of Commerce, National Oceanic and Atmospheric Administration, National Marine Fisheries Service, Economic and Marketing Research Division, "Foreign Direct Investment in the U.S. Commercial Fisheries Industry," Washington, D.C., April 9, 1976.
76. Op. cit., Japanese Investment in Alaska.

77. Ibid.

78. Working Paper No. 1.

79. Op. cit., Fishery Conservation and Management Act of 1976, Sec. 303 (d).

80. Op. cit., "Part 601-Regional Fishery Management Councils".

81. Working Paper No. 2.

82. Ibid.

83. Ibid.

84. Op. cit., Interview, New England Regional Fishery Council.

85. Op. cit., The U.S. Fishing Industry-Present Condition and Future of Marine Fisheries and The Eastland Resolution Fisheries Survey Report to be published in 1977.

86. Op. cit., A Marine Fisheries Program for the Nation.

87. Working Paper No. 4.

88. Op. cit., Interview, New England Regional Fishery Council.

89. Environment Canada, "Canadian Exports by Commodity, 1975."

90. The Tariff Act of 1930, Section 30 (a) (1) as amended by Section 331 of the Trade Act of 1974.

91. Interview, Tariff Affairs Division, U.S. Department of Treasury, Washington, D.C., April 7, 1977 (By Telephone).

92. Op. cit., The U.S. Fishing Industry-Present Condition and Future of Marine Fisheries. 


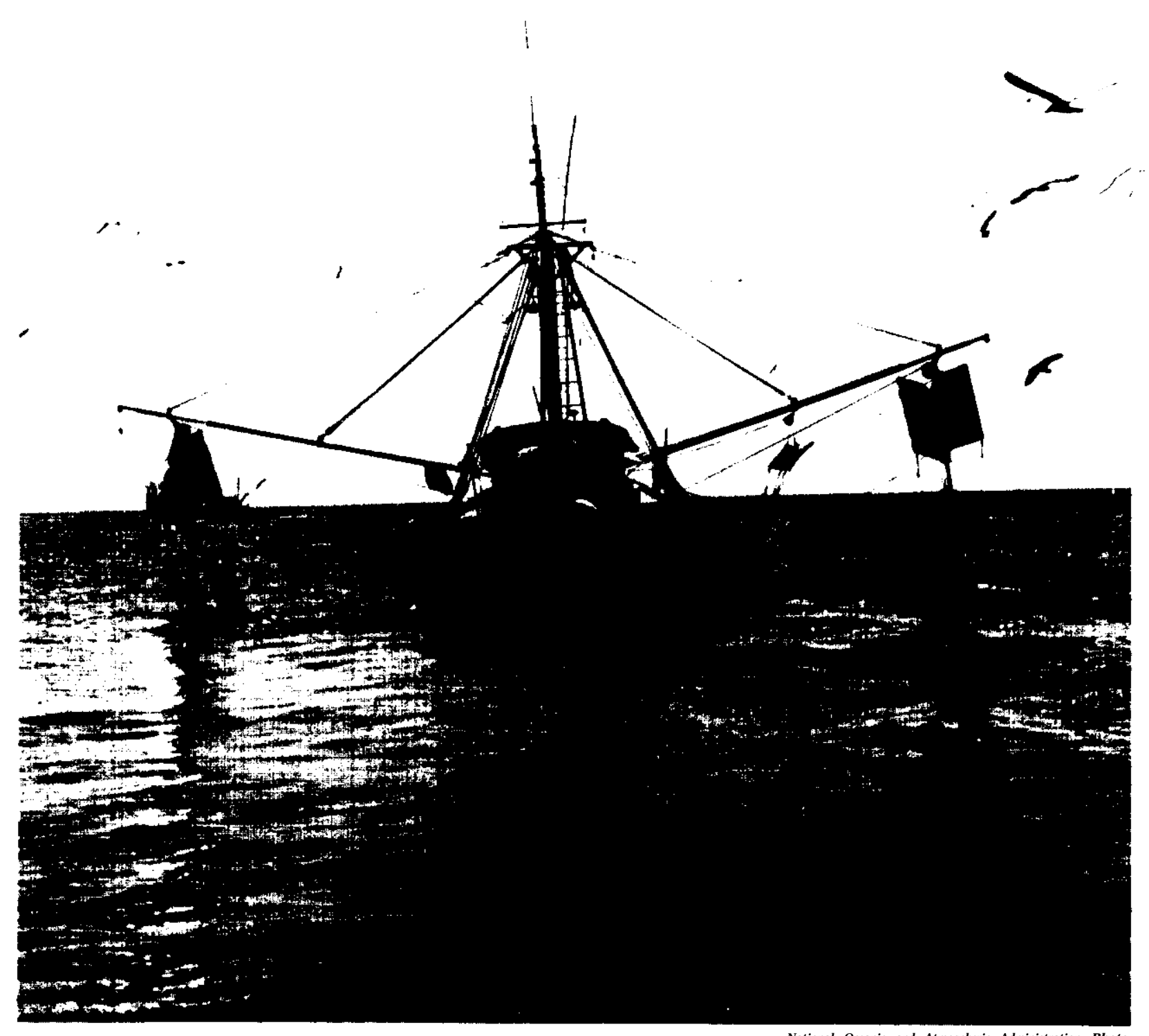

Only about 10 percent of the operators of the west coast trawlers, such as this shrimp boat, consider their gear satisfactory for the job 
9. Fishery Conservation and Management Act of 1976 
Public Law 94-265

94th Congress, H. R. 200

April 13, 1976

\section{An Act}

To provide for the conservation and management of the fisheries, and for other purposes.

Be it ancted by the S'maie and House of Representatives of the United States of A merira in C'ongress assembled, That this Act, with the following table of contents, may le cited as the "Fishery Conservation and Management Act of 1976".

\section{TABIE OF CONTENTS}

Fishery

Conservation and Management Act of 1976.

Sec. 2. Findings, purposes, and policy.

Sec. 3. Definitions.

note.

\section{TITLE I-FISHERY MANAGEMENT AUTHORITY OF THE}

See. 101. Fishery conservation zone.

Sec. 102. Exclusive fishery management authority.

Sec. 103. Highly migratory species.

Sec. 104. Effective date.

TITLE 11-FOREIGN FISHING AND INTERNATIONAL FISHERY

Sec. 201. Foreign fishing.

Sec. 202. International fishery agreements.

Sec. 203. Congressional oversight of governing international fishery agreements. Sec. 204. Permits for foreign fishing.

Sec. 205. Import prohibitions.

\section{TITLE III-NATIONAL FISHERY MANAGEMENT PROGRAM}

Sec. 30 olitional standards for fishery conservation and management.

sec. 302. Regional fishery management councils.

Sec. 303. Contents of fishery management plans.

Sec. 304. Action by the Secretary.

sec.. 305. Implementation of fishery management plans.

sec. 300. State jurisdiction.

sec. 307. Prohibited acts.

sec. 308. Civil penalties.

sec. 309. Criminal offenses.

sec. 310. Civil forfeitures.

See. 312. Effective date of certain provisions.

\section{TITLE IV-MISCELLANEOUS PROVISIONS}

SW'. 401. Effect of law of the sea treaty.

sec. 402. Repeals.

sec. 403. Fishermen's Protective Act amendments

sec. 404. Marine Mammal Protection Act an

mal Protection Act amendment.

sec. 405. Atlantic Tunas Convention Act amendment.

sec. 408. Authorization of appropriations.

SEC. 2. FINDINGS, PURPOSES AND POLICY

(a) FINDINGS.-The Congress finds and declares the following: 16 USC 1801. (1) The fish off the coasts of the United States, the highly migratory species of the high seas, the species which dwell on or in the Continental Shelf appertaining to the United States, and the anadromous species which spawn in United States rivers or estuaries, constitute valuable and renewable natural resources. 
These fishery resources contribute to the food supply, economy, and health of the Nation and provide recreational opportunities. (2) As a consequence of increased fishing pressure and because of the inadequacy of fishery conservation and management practices and controls (A) certain stocks of such fish have been overfished to the point where their survival is threatened? and (B)
other such stocks have been so substantially reduced in number that the could become similarly threatened.

(3) Commercial and recreational fishing constitutes a major source of employment and contributes signifi cantly to the econom of the Nation. Many coastal areas are dependent upon fishing and related activities, and their economies have been badly damaged by the overfishing of fishery resources at an ever-increasing rate over the past decade. The activities of massive foreign fishing fleets in waters adjacent to such coastal areas have contributed to such damage, interfered with domestic fishing efforts, and caused destruction of the fishing gear of United States fishermen (4) International fishery agreements have not been effective in preventing or terminating the overfishing of these valuable fishery resources. There is danger that irreversible effects from overfishing will take place before an effective international agreement on fishery management jurisdiction can be negotiated, signed, rati, and immplemented.

(5) Fishery resources are finite but renewable. If placed under sound management before overfishing has caused irreversible effects, the fisheries can be conserved and maintained so as to provide optimum yields on a continuing basis.

(6) A national program for the conservation and management of the fishery resources of the United States is necessary to pretion, and to realize the full potential of the Nation's fishery tion, and to

(7) A national program for the development of fisheries which are underutilized or not utilized by United States fishermen including bottom fish off Alaska, is necessary to assure that our citizens benefit from the employment, food supply, and revenue which could be generated thereby.

(b) PURPOSES.-It is therefore declared to be the purposes of the Congress in this Act-

(1) to take immediate action to conserve and manage the fishery resources found off the coasts of the United States, and the anadromous species and Continental Shelf fishery resources of the United States, by establishing (A) a fishery conservation zone within which the United States will assume exclusive fishery management authority over all fish, except highly migratory such zone over such anadromous species and Continental Shelf fishery resources;

(2) to support and encourage the implementation and enforcement of international fishery agreements for the conservation and management of highly migratory species, and to encourage the necessary;

(3) to promote domestic commercial and recreational fishing under sound conservation and management principles;

(4) to provide for the preparation and implementation, in accordance with national standards, of fishery management plans

90 STAT- 332 which will achieve and maintain, on a continuing basis, the optimum yield from each fishery;

(5) to establish Regional Fishery Management Councils to prepare, monitor, and revise such plans under circumstances( A) which will enable the States, the fishing industry, consumer and environmental organizations, and other interested persons to participate in, and advise on, the establishment and administration of such plans, and (B) which take into account the social and economic needs of the States; and

(6) to encourage the development of fisheries which are currently underutilized or not utilized by United States fishermen including bottom fish off Alaska.

(c) POLICY.-It is further declared to be the policy of the Congress this Act-

(1) to maintain without change the existing territorial or other ocean jurisdiction of the United States for all purposes othe than tile conservation and management of fishery resources, as provided for in this Act,

(2) to authorize no impediment to, or interference with, recognized legitimate uses of the high seas, except as necessary for the conservation and management of fishery resources, as provide

(3) to assure that the national fishery conservation and managreement program utilizes, and is based upon, the best scientific interested and affected States, and citizens; promotes efficiency, draws upon Federal. State, and academic capabilities in carrying, out research, administration, management, and enforcement; and is workable and effective:

(4) to permit foreign fishing consistent with the provisions of this Act; and

(5) to support and encourage continued active United States efforts to obtain an internationally acceptable treaty. at the Third for effective conservation and management of fishery resources. SEC. 3. DEFINITIONS.

s used in this Act, unless the context otherwise requires-

(1) The term "anadromous species" means species of fish which spaw in fresh or estuarine w (2) The term "conservation.

(2) The term "conservation and management" refers to all (A) which are required to rebuild, rethods, and other measures (A) which a re required to rebuld, restore, or, main other, and which resource and the marine environment; and (B) which are designed to assure that-

(i) a supply of food and other products may be taken. and that recreation benefits maybe obtained, on a continuing basis:

(ii) irreversible or long-term adverse effects on fishery resources and the marine environment are avoided.; and

(iii) there will be a multiplicity of options avail able with respect to future uses of these resources.

(3) The term "Continental Shelf" means the seabed and subsoil of the submarine areas adjacent to the coast, but outside the area of the territorial sea, of the United States to a depth of 200 meters or, beyond that limit, to where the depth of the super-

90 STAT. 333 
Pub. Law 94-265 $\quad-4-\quad$ April 13, 1976 jacent waters admits of the exploitation of the natural resources of such areas.

(4) The term "Continental Shelf fishery resources" means the following:

\section{COLENTERATA}

Bamboo Coral-Acanella spp.;

Black Coral-Antipathes spp.;

Precious Red Coral -Corallium spp.;

Gold Coral-Parazoanthus spp.

\section{Crustacea}

Tanner Crab-Chionoecetes tanneri,

Tanner Crab-Chionoecetes opilio;

Tanner Crab-Chionoecetes angulatus

Tanner Crab-Chionoecetes bairdi;

King Crab-Paralithodes camtschatica;

King Crab-Paralithodes platypus;

King Crab-Paralithodes brevipes;

Labster-Homarus americanus;

Dungeness Crab-Cancer magister;

Cal! forma King Crab-Paralithodes californiensis

California King Crab-Paralithodes rathbuni;

Golden King Crab-Litholdes aequiispinus;

Northern Stone Crab-Litholdes maja

Stone Crab-Menippe mercenaria; and

Deep-sea Red Crab- Geryon quinquedens.

\section{MOLLUSKS}

Red Abalone-Haliotis rufescens;

Pink Abalone-Haliotis corrugata;

apanese Abalone-Haliotis kamtschatkana

Strombus gigas;

sima; and

ocean Quahog-Artica islandica.

\section{SPONGES}

Glove Sponge-Hippiospongia canaliculata; Sheepswool Sponge-Hippiospongia lachne;

Grass Sponge-Spongia graminea; and

Yellow Sponge--Spongia barbera.

Publication in If the Secretary determines, after consultation with the Secretary Federal Regis- of State, that living organisms of any other sedentary species ter.

\section{are at the harvestable stage, either-}

(B) unable to move except in constant physical contact with the seabed or subsoil

of the Continental Shelf which appertains to the United States, and publishes notice of such determination in the Federal Register, such sedentary species shall be considered to be added to the foregoing list and included in such term for purposes of this Act.

(5) The term "Council" means any Regional Fishery Management Council established under section 302.
April 13, 1976

$-5$

Pub. Law 94-265

(6)The term "Fish" means finfish, mollusks, crustaceans, and all other forms of marine animal and plant life other than marine firds, and highly migratory species.

(7) The term "fishery" means-

(A) one or more stocks of fish which can be treated as a unit for purposes of conservation and management and which are identified on the basis of geographical scientific, technical, recreational, and economic characteristics; and

(B) any fishing for such stocks.

(8) The term "fishery conservation zone" means the fishery conservation zone established by section 101 .

(9) The term "fishery resource"' means any fishery, any stock of fish, any species of fish, and any habitat of fish.

(10) The term "fishing" means-

(A) the catching, taking, or harvesting of fish-

(13) the attempted catching, taking, or harvesting of fish

(C) any other activity which can reasonably be expected

to result in the catching, taking, or harvesting of fish; or

$\$ 0$ : any activity described in subparagraphs (A) through

Such term does not inclulde any scientific research activity which is conducted by a scientific research vessel.

(11) The term "fishing vessel" means any vessel, boat, ship or other craft which is used for, equipped to be used for, or of a type which is normally used for-

(A) fishing; or

(B) aiding or assisting one or more vessels at sea in the

performance of any activity relating to fishing, including,

but not limited to, preparation, supply, storage, refrigeration,

transportation, or processing.

(12) The term "foreign fishing"' means fishing by a vessel other than a vessel of the United States.

(13) The term "high seas" means all waters beyond the territorial sea of the United States and beyond any foreign nation's territorial sea, to the extent that such sea is recognized by the United States.

(14) The term "highly migratory species" means species of tuna which, in the course of their life cycle, spawn and migrate over great distances in waters of the ocean.

(15) The term "international fishery agreement" means any bilateral or multilateral treaty, convention. or agreement whic

relates to fishing and to which the United States is a party.

(16) The term "Marine Fisheries Commission" means the Atlantic States Marine Fisheries Commission, the Gulf States Marine Fisheries Commission, or the Pacific Marine Fisherie
Commission.

(17) The term "national standards"' means the national standards for fishery conservation and management set forth in sec.

(18) The term "optimum", with respect to the yield from eans the amount of fish-

(A) which will provide the greatest overall benefit to the nation, with particular reference to food production and recreational opportunities: and

(B) which is prescribed as such on the basis of the maximum sustainable yield from such fishery, as modified by any relevant economic, social, or ecological factor.

90 STAT. 335 
Pub. Law 94-265 $-6-$

(19) The term "person" means any individual (whether or not a citizen or national of the United States), any corporation, partnership, association, or other entity (whether or not organized or existing under the laws of any State), and any Federal, State, (20) The (20) The term or his designee.

(21) The term "State" means each of the several States, the District of Columbia, the Commonwealth of Puerto Rico, American Samoa, the Virgin Islands, Guam, and any other Common(22) The tory, "sossession" the United States. (22) The term "stock of fish" means a species, subspecies, geo-
graphical grouping, or other category of fish capable of manage-

(23) The term "treaty" means any international fishery agreeing of section 2 of article

USC prec. II of the Constitution.
title 1.
(24) The term United States"', when used in a geographical context, means all the States thereof.

(25) The term "vessel of the United States" means any vessel documented under the laws of the United States or registered under the laws of any State.

\section{TITLE I-FISHERY MANAGEMENT AUTHORITY}

\section{OF THE UNITED STATES}

16 USC 1811. SEC. 101 FISHERY CONSERVATION ZONE.

There is established a zone contiguous to the territorial sea of the United States to be known as the fishery conservation zone. The inner boundary of the fishery conservation zone is a line coterminous with the seaward boundary of each of the coastal States, and the oute boundary of such zone is a line drawn in such a manner that each point on it is $\mathbf{2 0 0}$ nautical miles from the baseline from which the territorial sea is measured.

16 USC 1812. SEC. 102. EXCLUSIVE FISHERY MANAGEMENT AUTHORITY

The United States shall exercise exclusive fishery managemen

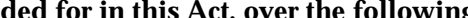

(1) All fish within the fishery conservation zone.

(2) All anadromous species throughout the migratory range of each such species beyond the fishery conservation zone; except that such management authority shall not extend to such species during the time they are found within any foreign nation's territorial sea or fishery conservation zone (or the equivalent), to the extent that such sea or zone is recognized by the United States.

(3) All Continental Shelf fishery resources beyond the fishery conservation zone.

16 USC 1813. SEC. 103. HIGHLY MIGRATORY SPECIES.

The exclusive fishery management authority of the United States shall not include, nor shall it be construed to extend to, highly migratory species of fish.

16 USC 1811 SEC 104. EFFECTIVE DATE

note.
April 13, 1976

Pub. Law 94-265

TITLE II-FOREIGN FISHING AND INTERNATIONAL FISHERY AGREEMENTS

SEC. 201. FOREIGN FISHING

(a) IN GENERAL._After February 28, 1977, no foreign fishing is authorized within the fishery conservation zone, or for anadromous species or Continental Shelf fishery resources beyond the fishery

conservation zone, unless such foreign fishing-

(1) is authorized under subsection (b) or (c)

(2) is not prohibited by subsection (f); and

(3) is conducted under, and in accordance with, a valid and applicable permit issued pursuant to section 204

(b) EXISTING INTERNATIONAL FISHERY AGREEMENTS.-Foreign fishing described in subsection (a) may be conducted pursuant to an international fishery agreement (subject to the provisions of section

(1) was in effect on the date of enactment of this Act; and

(2) has not expired. been renegotiated, or otherwise ceased to be of force and effect with respect to the United States.

(c) Governing INTERNATIONAL FISHERY AGREEMENTS.-Foreign fishing described in subsection (a) may be conducted pursuant to an international fishery agreement (other than a treaty) which meets requirements o this subsection if such agreement becomes effective after application of section 203. . Any such international fishery inreement shall hereafter in this Act be referred to as a "governing internationt shall acknowledge the exclusive fishery man ishery ( nessels,

(1) The foreign nation, and the owner or operator of any fishing vessel fishing pursuant to such agreement, will abic all regulations promulgated by 'the Secretary pursuant to this Act, including any regulations promulgated to implement any applicable fishery

fishing vessel fish nation, and the owner or operator of any requirement that-

(A) any officer authorized to enforce the provisions of this Act (as provided for in section 311) be permitted-

at any time,

(ii) to make arrests and seizures provided for in sect ion 311 (b) whenever such officer has reasonable cause to believe, as a result of such a search or inspection, that any such vessel or any person has committed an act prohibited by section 307 , and

(iii) to examine and make notations on the permit issued pursuant to section 204 for such vessel;

(B) the permit issued for any such vessel pursuant to section 204
such vessel

(C) transponders, or such other appropriate position- fixing and identification equipment as the Secretary of the
department in which the Coast Guard is operating determines
6 USC 1821.

Pos

Post p. 358. 
to be appropriate, be installed and maintained in working order on each such vessel

(D) duly authorized United States observers be permitted on board any such vessel and that the United States be reimbursed for the cost of such observers

(10) he paid

(F) agents be appointed and maintained within the United States who are authorized to receive and respond to any legal process issued in the United States with respect to such owner (G) responsibiti

(G) responsibility be assumed, in accordance with any requirements prescribed by the Secretary, for the reimbursetheir fishing vessels, fishing gear, or catch which is caused by their fishing vessels, fishing gear;

and will abide by any other monitoring, compliance, or enforceand will abide by any of ther nationi which is included in such agreement.

(3) The foreign nation and the owners or operators of all of the fishing vessels of such nation shall not in any sar axl of the fishing vessels of such nation shall not. in any ear, exceed such nation's allocation of the total allowable

(4) The foreign nation will-

(A) apply , pursuant to section 204, for any required permits;

(B) deliver promptly to the owner or operator of the ppropriate fishing vessel any permit which is issued under that section for such vessel: and

C) abide $b$, and take appropriate steps under its own laws to assure that all such owners and operators comply with section 204(a) and the applicable conditions and restrictions established under section 204 (b) (7).

(d) TOTAL ALLOWABLE LEVEL OF FoREIGN FISHING.-The total allowable level of foreign fishing, if any, with respect to any fishery subject to the exclusive fishery management authority of the United States, shall be that portion of the optimum yield of such fishery which will not be harvested by vessels of the United States. as determined in accordance with the provisions of this Act.

(e) ALLOCATION OF ALLOWABLE LEVEL.-Tbe Secretary of State. in cooperation with the Secretary, shall determine the allocation among foreign nations of the total allowable level of foreign fishing which is permitted with respect to any fishery subject to the exclusive fisher management authority of the United States. In making any such determination, the Secretary of State and the Secretary shall consider-

(1) whether, and to what extent, the fishing vessels of such nations have traditionally engaged in fishing in such fishery:

(2) whether such nations have cooperated with the United States in, and made substantial contributions to. fishery research and the identification of fishery resources:

(3) whether such nations have cooperated with the United States in enforcement and with respect to the conservation and management of fishery resources: and

(4) such other matters as the .Secretary of State. in cooperation with the Secretary. deems appropriate.

(f) Reciprocity.-Foreign fishing shall not be authorized for the fishin ${ }_{\mathrm{g}}$ vessels of any foreign nation unless such nation satisfies the
Secretary and the Secretary of State that such nation extends substantially the same fishing privileges to fishing vessels of the United (g) PRELIMINARY FISHERY MANAGEMENT PLANS.-The Secretary, when notified by the Secretary of State that any foreign nation has liminary fishery management plan for any fishery covered by such application if the Secretary determines that no fishery management plan for that fishery will be prepared and implemented, pursuant to title III, before March 1, 1977. To the extent practicable. each such plan-

(1) shall contain a preliminary description of the fishery and a preliminary determination as to the optimum yield from such fishery and the total allowable level of foreign fishing with respect to such fishery;

(2) shall require each foreign fishing vessel engaged or wishing to engage in such fishery to obtain a permit from the Secretary

(3) shall require the submission of pertinent data to the Secretary, with respect to such fishery, as described in section 303(a) (5); and

(4) may, to the extent necessary to prevent irrevesible effects from overfishing, with respect to such fishery, contain conservation and management measures applicable to foreign fishing

(A) are determined to be necessary and appropriate fo the conservation and management of such fishery,

(B) are consistent with the national standards, the other provisions of this Act, and other applicable law, and

(C) are described in section 303(b) (2), (3), (4), (5), and Each preliminary fishery management plan shall be in effect with respect to foreign fishing for which permits have been issued until a fishery management plan is prepare and implemented, pursuant to title 1 , wit respect to such fishery. The Secretary may, in accordance with section 553 of title 5, United States Code, also prepare and promulgate interim regulations with respect to any such preliminary plan. Such regulations shall be in effect until regulations implementing the applicable fishery management plan are promulgated pursuant to section 305

SEC. 202. INTERNATIONAL FISHERY AGREEMENTS

a ) NEGOTIATIONS.-The Secretary of State-

(1) shall renegotiate treaties as provided for in subsection (b) (2) shall negotiate governing international fishery agreements described in section 201 (c);

(3) may negotiate boundary agreements as provided for in subsection $(d)$;

(4) shall, upon the request of and in cooperation with the Secretary, initiate and conduct negotiations for the purpose of entering into international fishery agreements-

(A) which allow fishing vessels of the United States equitable access to fish over which foreign nations assert exclusive fishery management authority, and

(B) which provide for the conservation and management of anadromous species and highly migratory species; and

90 STAT. 33 
Pub. Law 94-265 $-10-$

April 13, 1976

(5) may enter into such other negotiations, not prohibited by subsection (c), as may be necessary and appropriate to further the purposes, policy, and provisions of this Act.

(b) TREATY RENEGOTIATION.-The Secretary of State, in cooperation with the Secretary, shall initiate, promptly after the date of enactment of this Act, the renegotiation of any treaty which pertains to fishing within the fishery conservation zone (or within the area that will constitute such zone after February 28, 1977), or for anador anes species or (Continental She] f fishery resources beyond such zone policy, or provisions of this $\mathrm{Act}$ in order to conform such treaty to puch purposes, policy, and provisions. It is the sense of Congress that

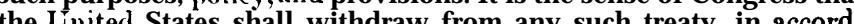
the (nited states shall wif are (c) InTer

(c) INTERNATIONAL FISHERY AGRFEMENTS.-No international fishery agreement (other than a treaty) which pertains to foreign fishing contitute the species or Continental Shel $f$ tishery resources beyond such zone or area-

(1) which is in effect on

(2)med, or amended: or

by the Inited st:at es unless it is in accordance with tile prov isions of section 201 (c).

(d) Bol vd.ary Nfgotiatioxs.-The Secretary of State, in cooperation with the Secretary, may initiate and conduct negotiations with any adjacent or opposite foreign nation to establish the boundaries of the fishery conservation zone of the United States in relation to any such nation.

(e) Nonrecogsitiox.-It is the sense of the Congress that the Cnited States Government shall not recognize the claim of any foreign nation to a fishery conservation zone (or the equivalent) beyond such nation's territorial sea. to the extent that such cea is recognized by the Inited States, if such nation-

(1) fails to consider and take into account traditional fishing activity of fishing vessels of the United States;

(2) fails to recognize and accept that highly migratory species are to be managed by applicable international fishery agreements,

hether or not such nation is a partv to any such agreement;

(3) imposes on fishingressels of the Inited States any condi-

tions or restrictions which are unrelated to fishery conservation and management.

16 USC 1823. SEC. 203. CONGRESSIONAL OVERSIGHT OF GOVERNING INTERNA-

$$
\text { TIONAL FISHERY AGREEMENTS. }
$$

Transmittal to (a) Is Generat.-No governing international fishery agreement shall become effective with respect to the United States before the close of the first 60 calendar days of continuous session of the Congress after the date on which the President transmits to the House of Representatives and to the Senate a document setting forth the text of such governing international fishery agreement. .4 copy of the document shall be delivered to each House of Congress on the same day and shall be delivered to the Clerk of the House of Representatives, if the House is not in session, and to the Secretary of the Senate, if the Senate is not in session.

90 STAT. 340
April 13, 1976

$11-$

Pub. Law 94-265

(b) Referral to Comsittees. - Iny document described in subsection (a) shall be immediately referred in the House of Representatives to the Committee on Merchant Marine and Fisheries, and in the Senate to the Committees on Commerce and Foreign Relations.

(a) - CoMputation OF GO-DAY Period.-For purposes of subsection (1) continuity of session is broken only by an adjournment
of Congress sine die; and

(\$?). the days on which either House is not in session because of in the computation of the 60-clay period.

(d) Congressional, Proced Res.-

(1) RULES UF THE HOCSE OF REPRESENTATIVE AND SENATE.-The provisions of this section are enacted by the Congress-

(A) as an exercise of the rulemaking power of the House of (A) antives and the Senate respectively and they are deemed a part of the rules of each House, respectively, but deemed a part of the rules of each House, respectively, but applicable only with respect to tile procedure to he followed in described in paras case of fishery agreement resolution only to the extent that they are inconsistent therewith; and only to the extent that they are inconsistent therewith; and either House to change the rules (so far as they relate to the procedure of that House) at any time. and in the samemanner and to the same extent as in tile case of any other rule of that House.

(2) Definition.-For purposes of this subsection, the term "fishery agreement resolut ion" refers to a joint resolution of either House of Congress-

(A) the effect of which is to prohibit the entering into force and effect of any governing international fishery agree ment the text of which is $t$ ransmitted to the Congress pursuant to subsection (a) : and

(B) which is reported from tile Committee on Merchant Marine and Fisheries of the House of Representatives or the Committee on Commerce or the Committee on Foreign Relations of the Senate, not later than 45 days after the date on which the document described in subsection (a) relating to that agreement is transmitted to the Congress

(3) Piacemext on calend.sR.- Any fishery agreement resolution upon being reported shall immediately be placed on the appropriate calendar.

Floor cossiberation IX THE IIOCSE.-

(A) $\mathrm{A}$ motion in the House of Representatives to proceed to the consideration of any fishery agreement resolution shall be highly privileged and not debatable. In amendment to the mot ion shall not be in order, nor shall it be in order to move to reconsider the inteby which the motion is agreed to or disagreed to.

(B) Debate in the House of Represertatives on any fishery Debate greement resolution shall he limited to not more than 10 limitation. hours, which shall be divided equally hetween those favoring and those opposing the resolution. A motion firther tolim to recommit any fishery agreement resolution or to to move recon

tion is agreed to or disagreed to.

90 STAT. 341 
(C) Motions to postpone, made in the House of Representatives with respect to tile considerate ion of any fishery agreement resolution, anti motions to proceed to the cons

(D) All appeals from the decisions of the Chair relating to the application of the Rules of the House of Representatives to the procedure relating to any fishery agreement resolution shall be decided without debate.

(E) Except to the extent specifically provided in the preceding provisions of this subsection, considerate ion of any fishery agreement resolution shall be governed by the Rules of the House of Representatives applicable to other bills and resolutions in similar circumstances.

(5) FLOOR CONSIDERATION IN THE SENATE-

(i) A motion in the Senate to proceed to the consideration of any fishery agreement. resolution shall be privileged and not debatable. An amendment to the motion shall not be in order, nor shall it be in order to move to reconsider the vote by which the motion is agreed to or disagreed to.

Debate

(B) Debate in the Senate on any fishery agreement resolution and on all debatable motions and appeals in connection therewith shall be limited to not more than 10 hours. The time shall be equally divided between, and controlled by, the majority leader and the monority leader or their designees.

(C) Debate in the Senate on any debatable motion or appeal in connection with any fishery agreement resolution sha1 be limited to not more than 1 hour. to be equally divided between, and controlled by, the mover of the. mot ion or appea and the manager of the resolution, except that if the manage of the resolution is in favor of any such motion or appeal, the time in opposition thereto shall be controlled by the minority leader or his designee. The majority lender and the minorit leader, or either of them. may allot additional time to any Senator during the consideration of any debatable motion or appeal, from time under their control applicable fishery agreement resolution.

(I)) A motion in the Senate to further limit debate is no debatable. A motion to recommit any fishery agreement resoution is not in order.

C. 204. PERMITS FOR FOREIGN FISHING.

(a) IN GENERAL.-AFTER FEBRUARY 28, 1977, no foreign fishing vessel shall engage in fishing within the fishery conservation zone, or such zone. unless such vessel has on board a valid permit issued under his sect ion for such vessel.

(b) APPLICATIONS AND PERMITS UNDER GOVERNING INTERNAT IONAL FISHERY AGREEMENTS.-

(1) ELIGIBILITY.-Each foreign nation with which the United States has entered into a governing international fishery agreement shall submit an application to the Secretary of State each year for a permit for each of its fishing vessels that wishes to engage in fishing described in subsection (a).

(2) FonMS.- dhe Secretary, in consultation with the Secretary of State and the Secretary of tile department in which the Coas Guard is operating, shall prescribe the forms for permit applications submitted under this subsection and for permits issued pursuant to any such application.
(3) CONTENTS.-Any application made under this subsection shall specify-

(A) the name and official number or other identification of each fishing vessel for which a permit is sought, together with the name and address of tile owner thereof;

(B) the tonnage. capacity, speed, processing equipment type and quantity of fishing gear, and such other pertinen information with respect to characteristics of each such vessel as the Secretary may require;

C) each fishery in which each such vessel wishes to fish

D) the amount of fish or tonnage of catch contemplated

for each such vessel during the time such permit is in force; a $n$ o

(E) the ocean area in which, and the seasc
during which, such fishing will be conducted: which the Secretary may require.

(4) TRANSMITTAL FOR ACTION.-Upon receipt of any application which complies with the requirements of paragraph (3), the Secretary of State shall publish such application in the Federal Register and shall promptly transmit-

(A) such application, together with his comments and recommendations thereon, to the Secretary;

(B) a copy of the application to each appropriate Council and to tile Secretary of the department in which the Coast Guard is operating: and

(C) a copy of such material to the Committee on Merchant

Marine and Fisheries of the House of Representatives and

tot he Committees on Commerce and Foreign Relations of the Senate.

(5) ACTION BY COUNCIL.-.After receipt of an application transmitted under parpgrapph (4) (B), each appropriate Council shall
prepare and submit to the Secretary such written comments on the application as it deems appropriate. Such comments shall be submitted within 45 days after the date on which the application is received by the Council and may include recommendations with respect to approval of the application and, if approval is recommended, with respect to appropriate conditions and restrictions thereon. Any interested person may submit comments to such Coucil with respect to any such application. The Council shall Secretary.

(6) APPROVAL.-After receipt of any application transmitted under paragraph (4) (A), the Secretary. shall consult with the Secretary of the department in which the Coast Guard is operating. The Secretary, after taking into consideration the views and ing. The Sections of such Secretaries and any comments submitted by any Council under paraph (5), may approve the application, if he determines that the fishing described in the application $w$-ill meet the requirements of this Act.

(7) ESTABLISHMENT OF CONDITIONS AND RESTRICTIONS - -ThC Secretary. shall establish conditions and restrictions which shall be included in each permit issued pursuant to any application approved under paragraph $(6)$ and which must be complied with approved under paragraph $(6)$ and which must be complied with by the owner or operator of the fishing vessel for which the the following:

90 STAT. 343
Publication in

\section{Transmittal to} congressional

Written comments.

(1)


Pub. Law 94-265

- 14 -

April 13, 1976

(A) A11 of the requirements of any applicable fishery management plan, or preliminary fishery management plan, and the regulations promulgated to implement any such plan. (B) The requirement that no permit may be used by any vessel other than the fishing vessel for which it is issued. (C) The requirements described in section \$X)1(C) (1), (2), and (3).

(D) Any other condition and restriction related to fishery conservation and namagenent which the Secretary prescribes as necessary and appropriate.

(8) Nonce of IProvin.-The secretar yshall promptly transmit a copy of (ach application approvec under paragraph (6) and the cond it ions and rest rictions est ablished under paragraph

(.1) the Secretary of State for transmittal to the foreign nation involved;

(13) the Secretary of the department in which the Coast iuard is operating;

(C) any Council' which has authority over any fishery spexifiedin such application; and

Transmittal to congressional
committees.

(Disheries of the louse of Representatives and the Conmittees on Commerce and Foreign Relat ions of the Senate.

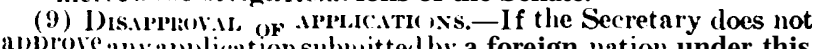
"pip subsert ion. the isatpprowial and his reasons therefore. The secretary of State shall'ros till'refer reasons for din for

(10) F : \}:s.-Reasonahle fees shall be paid to the Secretary by the owner or operator of any foreign fishing vessel for which a permit is issued ]) ursuant to th is subsect ion. The Secretary, in lon a schedule of such fees, which shall apply noudiscriminatoril to each foreiorn nation. In determining the level of such fees, the each form nation. In deterning the provisions of this tet with respect to foreign fishing including but not limited to. the cost of fishery conservation and management, fisheries research, administration, and enforcement.

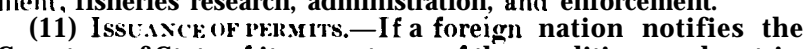
Secretary of State of its acceptance of the conditions and restrictions establishedby the Secretary under paragraph (7), the the Secretary. Ipon payment of the applicable fees established pursuant to paragraph (10), the Secretary shall thereup to such foreign nation, through the Secretary of State, permits for the appropriate fishing ressels of that nation. Each permit shall contain a statement of all conditions and restrictions established under paragraph $(\tau)$ which apply to the fishing vessel for which the permit is issued.

(12) SANCTIONS.-If any foreign fishing vessel for which a permit has been issued pursuant to this subsection has been used tary may, or if any civil penalty imposed under section 308 or any criminal fine imposed under section 309 has not been paid and is overdue the Secretary shall-
April 13, 1976

$-15-$

Pub. Law 94-265

(A) revoke such permit, with or without prejudice to the right of the foreign nation involved to obtain a permit for such vessel in any subsequent year:

(13) suspend such permit for the period of time deemed appropriate: or

(C) impose alditionalconditions and restrictions on the approvedapplication of the foreign nation involved and on any perm it issued under such application.

Any permit which is suspended under this paragraph for nonpayment of a civilpenalty shall be reinstated by the Secretary upon the payment of such civil penalty together with interest thereon at the prevailing rate.

(c) Rrgistr.tion PrRmits.-The Secretary of State, in cooperation with the Secretary, shall issue annually a registration permit fo each fishing vessel of a foreign nat ion winch is a party to an international fishery agreement under which foreign fishing is authorized by section 201 (b) and which wishes to engage in fishing described in subsection (a). Each such permit shall set forth the terms and conditions contained in the agreement, that apply with respect to such fishing, and shall include the additional requirement that the owne or operator of the fishing vessel for which the permit is issued shal prominently display such permit in the wheelhouse of such vessel and show it, upon request, to any officer authorized to enforce the provisions of this Act (as provided for in section 311). The Secretary of depart in which the Coast Guard is operating shall prescribe department in which the Coast Guard is operating, shall prescribe may be made, and the forms of such permits. The Secretary of State may be made, and the forms of such perats. The Stectary of State t ion permits; tion permits; except that the level of, ach coes shater net SEC. 205. IMPORT PROHIBITIONS.

(a) Itetrinin.itions by Sec re:r.iny of State.-If the Secretary of St ate determines that-

(1) he has been unable, within a reasonable period of time, to conclude with any foreign nation an international fishery agreement allowing fishing vessels of the United States equitable access to fisheries over which that nation asserts exclusive fishery management althority, as recognized by the United States, in accordance with traditional fish ing activities of such vessels, if any, and under terms not more restrictive than those established (B) failed to negot iate in good faith:

$(2)$ any foreign nation is not allowin ${ }_{\mathrm{g}}$ fishing vessels of the
failed the net inte in good faith: Inited States to engage in fishing for highly migratory species in arcordance with an applicable international fishery agreement, whether or not such nation is a party thereto;

(3) any foreign nation is not complying with its obligation (3) any foreign nation is not complying with its obligations under any existing international fishery agreement concerning which that nation asserts exclusive fishery management authority

or (4) any fishing ressel of the Ynited States. while fishing in foreign nation-

90 STAT. 345
16 USC 1825. 
(A) in violation of an applicable international fishery agreenlent;

(B) without authorization under an agreement between the TinitedStates and such nat ion.; or

$\left(C^{\prime}\right)$ as a consequence of aclaim of jurisdiction which is not recognized by the Inited States;

he shiall certify such determination to the Secretary of the Treasury. (b) Proulimitioss. - I pon receipt of anv certification from the Secretary of State uncler subsection (a), tile Secretary of the Treasury shallimmediatelytakesuchactionasmav be necessary and appropriate toprohibit the importat ion into the Inited Statw-

(1) of all fish and fish products from the fisheryinvolved, if any; and

(2) upon recommendation of the Secretary of State, such other- fish or fish products. from any fishery of the foreign nation concerned, which the Secret ary of State Grids to be appropriate to earry out the purposes of this section.

(c) RI: sov.u. of Prombiriox.-If the Secretary of State finds that the reasons for the imposition of any import prohibition under this sert ion no longer preva il. the Secretary of State shall notify the Secretary of the Treasury, who shall promptly remove such import prohibition.

(1) Drrivirioxs. - Is used in this swtion-

(1) The term "fish" includes any highly miglatory species.

(2) The term "fish products" meansany article which is pro-

duced from or composed of (in whole orm part) any fish.

\section{TITLE III-NATIONAL FISHERY MANAGEMENT} PROGRAM

\section{USC 18S1. SEC. 301. NATIONAL STANDARDS FOR FISHERY CONSERVATION AND}

(a) Is GENERAL.-.Iny fishery management plan prepared, and any regulat ion promulgated to implement any such plan, pursuant
to this title shall beconsistent with the following nat ional standards for fishery ronservation and $x$, ianagement

1) Conservation and management measures shall prevent over-
fishing while achieving, on a continuing basis, the optimum yield from each fisherl.

(2) Conservation and management $\mathrm{m}$ e a s u re shallbehased 11pont le ?est scientific information available.

(3) To the extent practicable. an individual stock of fish shal be managed IIS a unit throughout its range.and interrelated stocks of fish shall be managed as a unit or in close coordination.

(t) Conservation and management measures shall not discriminite between residents of $d$ ifferent.States. If it becomes neces. sary to allocate or assign fishing privileges among virious (Inite States fishermen, suchallocation shall be ( $\lambda$ ) fair and equitable to all such fishermen; (B) reasonably calculated to promote conservation: and (C) carried out in such manner that no particular individual, corporation, or other entity acquires an excessive share of such privileges.

(5) Conservationandmanagement measures shall, where practicable. promote efficienc in the utilization of fisher-y resources; except that no such measure shall have economic allocation as its sole purpose.
(6) Conservation and management measures shall take into account and allow for variations among, and contingencies in, fisheries, fishery resources, and catches.

(7) Conservation and management measures shall, where practicable, minimize costs and avoid unnecessary deplication.

(b) GUIDELINES.-The Secretary shall establish guidelines, baaed on the national standards, to assist in the development of fishery management plans.

SEC. 302. REGIONAL FISHERY MANAGEMENT COUNCILS

(a) ESTABLISHMENT. - There shall be established, within 120 days Establishment. after the date of the enactment of this Act, eight Regional Fishery

(1) NEW ENGLAND COUNCIL.-The New England Fishery Mangement Council shall consist of the States of Maine, New Hampshire, Massachusetts, Rhode Island, and Connecticut and shall have authority over the fisheries in the Atlantic Ocean seaward of such States. The New England Council shall have 17 voting members, including 11 appointed by the Secretary pursuan (b) (1) (l') (at least one of whom shall be appointed from each such State).

(2) Mid-ATLANTic COUNCIL.-l'he Mid-Atlantic Fishery Management Council shall consist of the States of New York, New Jersey, Delaware, Pennsylvania, Maryland, and Virginia and shall have authority over the fisheries in the Atlantic Ocean seaward of such States. The Mid-Atlantic Council shall have 19 voting members including 12 appointed by the Secretary pursuant voting menbers (b) (1) (C) (at least one of whom shall be appointed fom

(3) SOUTH ATANTIC COUNCIL.-The South Atlantic Fishery Management Council shall consist of the States of North Carolina South Carolina, Georgia, and Florida and shall have authority over the fisheries the Atlantic Ocean seaward of such States. The South Atlantic Council shall have 13 voting members, including 8 appointed by the Secretary pursuant to subsection (b) (1) (C) (at least one of whom shall be appointed from each such State).

(4) CARIBBEAN COUNCIL.-The Caribbean Fishery Management Council shall consist of the Virgin Islands and the Commonwealth of Puerto Rico and shall have authority over the fisheries in the Caribbean Sea and Atlantic Ocean seaward of such States. The Caribbean Council shall have 7 voting members, including 4 appointed by the Secretary pursuant to subsection (b) (1) (C) (at least one of whom shall be appointed from each such State).

(5) GULF COUNCIL.-The Gulf of Mexico Fishery Management Council shall consist of the States of Texas, Louisiana, Mississippi, Alabama, and Florida and shall have authority over the fisheries in the Gulf of Mexico seaward of such States. The Gulf Council shall have 17 voting members, including 11 appointed by the Secretary pursuant to subsection (b) (1) (C) (at least one of whom shall be appointed from each such State) (6) PACIFIC COUNCIL.-The Pacific Fishery Management Council shall consist of the States of California, Oregon, Washington, and Idaho and shall have authority over the fisheries in the Pacific Ocean seaward of such States. The Pacific Council shall have 13 voting members, including 8 appointed by the

90 STAT. 347 
Pub. Law 94-265 $\quad-18-\quad$ April 13, 1976

Secretary pursuant to subsection (b) (1) (C) (at least one of whom shall be appointed from each such State)

(7) NORTH PACIFIC COUNCIL.-The North Pacific Fishery Management Council shall consist of the States of Alaska. Washin the Arctic Ocean, Bering Sea and Pacific Ocean seaward of Alaska. The North Pacific Council shall have 11 voting members including 7 appointed by the Secretary pursuant to subsection (b) (1) (C) 5 of whom shall be appointed from the subsection (b) (1) (C) 7 ap whem Washington n).

(8) WESTERN PACIFIC COUNCIL.-The Western pacific Fishery Management Council shall consist of the State of Hawaii, American Samoa, and Guam and shall have authority over the fisheries in the Pacific Ocean seaward of such States. The Western Pacific Council shall have 11 voting members, including 7 appointed by the Secretary pursuant to subsection (b) ( 1 ) (C) (at least one of whom shall be appointed from each such State).

Each Council shall reflect the expertise and interest of the several constituent States in the ocean area over which such Council is granted authority.

(b) VOTING Members.-(1) The voting members of each Council shall be:

(A) The principal State official with marine fishery management responsibility and expertise in each constituent State, who is designated as such by the Governor of the State, so long as the official continues to hold such position, or the designee of such official.

(B) The regional director of the National Marine Fisheries that if two such directors are within suc Secretary shall designate which of such directors shall be the voting member.

(C) The members required to be appointed by the Secretary shall be appointed by the Secretary from a list of qualified individuals submitted by the Governor of each applicable constituent State. With respect to the initial such appointments. such Governors shall submit such lists to the Secretary as soon as practicable. not later than 45 days after the date of the enactment of this Act. As used in this subparagraph, (i) the term "list of qualified individuals" shall include the names (including pertinent biographical data) of not less than three such individuals for each applicable vacancy, and (ii) the term "qualified individual" means an individual who is knowledgable or experienced with regard to the management, conservation, or recreational or commercial harvest, of the fishery resources of the geographical area concerned.
(2) Each voting member appointed to a Council pursuant to paragraph (1) (C) shall serve for a term of 3 years; except that, with respect to the members initially so appointed, the Secretary shall designate up to one-third thereof to serve for a term of 1 year. up to onethird thereof to serve for a term of 2 years, and the rem

(3) Successorsto the voting members of any Council shall be appointed in the same manner as the original voting members. Any of any term of office shall be appointed for the remainder of that term.

90 STAT. 348
April 13, 1976

$-19$

Pub. Law 94-265

(c) NONVOTING MEMBERS.--(1) The nonvoting members of each Council shall be:

(A) The regional or area director of the United States Fish and Wildlife Service for the geographical area concerned, or his designee.

(B) The commander of the Coast Guard district for the geographical area concerned, or his designee; except that, If two Coast Guard districts a w wh wurpe by the commandant commander designated for such purpose by the commandant of

(C) The executive director of the Marine Fisheries Commission for the geographical area concerned, if any, or his designee.

(D) One representative of the Department of State designated

(2)

(2) The Pacill Councilshall have one additional nonvoting mem-

(d) COMPENSATION AND EXPENSES.-The voting members of each Council, who are not employed by the Federal Government or any for GS-18 of the General Schedule when engaged in the actual per(c) shall be reimbursed for actual expenses incurred in the performance of such duties.

(e) TRANSACTION OF BUSINESS-

(1) A majority of the voting members of any Council shall constitute a quorum, but one or more such members designated by the Council may hold hearings. All decisions of any Council shall be by majority vote of the voting members present and voting.

(2) The voting members of each Council shall select a Chairman for such Council from among the voting members. (3) Each Council shall meet in the geographical area con-
cerned at the call of the Chairman or upon the request of a majority of its voting members.

(4) If any voting member of a Council disagrees with respect to any matter which is transmitted to the Secretary by such Council. such member may submit a statement to the Secretary setting forth the reasons for such disagreement.

(f) STAFF AND ADMINISTRATION.-

(1) Each Council may appoint, and assign duties to, an executive director and such other full- and part-time administrative employees as the Secretary determines are necessary to the performance of its functions.

(2) Upon the request of any Council, and after consultation with the Secretary, the head of any Federal agency is authorized to detail to such Council, on a reimbursable basis, any of the personnel of such agency, to assist such Council in the performance of its functions under this Act.

(3) The Secretary shall provide to each Council such administrative and technical support services as are necessary for the effective functioning of such Council.

(4) The Administrator of General Services shall furnish each Council with such offices, equipment, supplies, and services as he is authorized to furnish to any other agency or instrumentality of the United States.

90 STAT. 349 
(5) Tile Secretary and the Secretary of + State shall furnish each Council with relevant information concerning foreign fishing and international fishery agreements.

(6) Each Council shall determine its organization, and prescribe its practices and procedures for carrying out its functions under this Act, in accordance with such uniform standards as are prescribed by the Secretary. Each Council shall publish and make available to the public a statement of its organization, practices, and procedures.

(A) the compensation and expenses provided for in subsection (d) ;

(B) appropriate compensation to employees appointed under paragraph (1)

(C) the amounts required for reimbursement of other Federal agencies under paragraphs (2) and (4);

(D) the actual expenses of the members of the committees

(E) such other costs as the Secretary determines are nec(g) COmmittees AND PANels.-

(1) Each Council shall establish and maintain, and appoint in the in the development, collection, and evaluation of such statistical, biological, ecom council's and other scientific information as fishery management plan.

(2) Each Council shall establish such other advisory panels as (2) Each Cour or appropriate to assist it in carrying out its functions under this Act.
(h) FUNCTIONS.-Each Council shall, in accordance with the provisions of this Act-
Fishery management plan.

Comments.

Public hearings.

Reports.

Review.
(6) conduct any other activities which are required by, or provided for in, this Act or which are necessary an appropriate

EC. 303. CONTENTS OF FISHERY MANAGEMENT PLANS.

(a) REQUIRED Provisions.-kIY fishery management plan which is prepared by any Council, or by the Secretary, with respect to any fishery, shall-

(1) contain the conservation and management measures, applicable to foreign fishing and fishing by vessels of the United States, which are-

(A) necessary and appropriate for the conservation and management of the fishery;

(B) described in this subsection or subsection (b), or

(C) consistent with the national standards, the other provisions oft his Act, and any other applicable law;

(2) contain a description of the fishery, including, but not limited to, the number of vessels involved, the type and quantity of fishing gear used, the species of fish involved and their location the cost likely to be incurred in management, actual and potential revenues from the fishery, any recreational interests in the fishery, and the nature and extent, of foreign fishing and Indian treaty fishing rights, if any;

(3) assess and specify the present and probable future condition of, and the maximum sustainable yield and optimum yield from, the fishery, and include a summary of the information uti(4) in making such specification

(A) and specify-

(A) the capacity and the extent to which fishing vessels of the United States, on an annual basis, will harvest the. optih (3), and

(B) the portion of such optimum yield which, on an annual

basis, will not be harvested by fishing vessels of the United (5) specify can be made available for foreign fishing; and authority and, from time to time, such amendments to each such plan as are necessary:

(2) prepare comments on any application for foreign fishing transmitted to it under section 204(b) (4) (B), and any fishery management plan or amendment transmitted to it under section
$304(C)$ (2) : (3) conduct public hearings, at appropriate times and in appro-
priate locations in the geographical area concerned, so as to allow all interested persons an opportunity to be heard in the development of fishery management plans and amendments to such plans. and with respect to the administration and implementation of the provisions of this Act:

(4) submit to the Serretarv-

(.4) a report. before February 1 of each year, on the Coun-

cil's activities (during the immediately preceding calendar year, (B) such periodic reports as the Council deems appropriate,
and

(C) any other relevant report which may be requested by the Secretary:

(5) review on a continuing basis, and revise as appropriate, the assessments and specifications made pursuant to section 303(a) (3) and (4) with respect to the optimum yield from, and the total allowable level of foreign fishing in, each fishery within its geographical area of authority; and
16 USC 18.53. Secretary with respect to the fishery, including, but not limited to information regarding the type and quantity of fishing gear used catch by species in numbers of fish or weight thereof, areas in hauls.

(b) DISCRETIONARY PROVISIONS.-hy fishery management plan which is prepared by any Council, or by the Secretary, with respect to any fishery, may-

(1) require a permit to be obtained from, and fees to be paid to the Secretary with respect to any fishing vessel of the United States fishing or wishing to fish in the fishery conservation zone or for anadromous species or Continental Shelf fishery resources beyond such zone:

(2) designate zones where, and periods when. fishing shall be limited, or shall not be permitted, or shall be permitted only by specified types of fishing vessels or with specified types and quantities of fishing gear

(3) establish specified limitations on the catch of fish (based on area, species, sire, number, weight, sex, incidental catch, total biomass, or other factors), which are necessary and appropriate for the conservation and management of the fishery;

90 STAT. 351 

coastal States nearest to the fishery;

(6) establish a system for limiting access to the fishery in order to achieve optimum yield if, in developing such system, the Council and the Secretary take into account.-

(A) resent participation in the fishery, fishery,

(C) the economics of the fishery.

(D) the capability of fishing vessels used in the fishery to engage in other fisheries,

(E) the cultural and social framework relevant to the fishery, and

(F) any other relevant considerations: and

(7) prescribe such other measures, requirements, or conditions and restrictions as are determined to be necessary and appropriate for the conservation and management of the fishery.

(c) PROPOSED REGULATIONS.-Any Council may prepare any proposed regulations which it deems necessary and appropriate to carry out any fishery management plan, or any amendment to any fishery management plan, which is prepared by it. Such proposed regulation shall be submitted to the Secretary, together with such plan or amendment, for action by the Secretar pursuant to sections 304 and 305.

(d) CONFIDENTIALITY OF STATISTICS.-Any statistics submitted to the Secretary by any person in compliance with any requirement unde subsection (a) (5) shall be confidential and shall not be disclosed except when required under court order. The Secretary shall, by regulation. prescribe such procedures as may be necessary to preserve such confidential ity., except that the Secretary may release or make public any such statistics in any aggregate or summary form which does no directly or indirectly disclose the identity or business of any person who submits such statistics.

16 USC 1854. SEC. 304. ACTION BY THE SECRETARY.

(a) ACTION BY THE SECRETARY AFTER RECEIPT OF PLAN.-Within 60 days after the Secretary receives any fishery management plan, any amendment to any such plan, which is prepared by any Council, the Secretary shall-

(1) review such plan or amendment pursuant to subsection (b)

(2) notify such Council in writing of his approval, disapproval, or partial disapproval of such plan or amendment.

In the case of disapproval or partial disapproval, the Secretary shall include in such notification a statement and explanation of the Secretary's objections and the reasons therefor, suggestions for improvement. a request to such council to change such plan or amendment to satisfy the objections, and a request to resubmit the plan or amend ment, as so modified, to the Secretary within $\mathbf{4 5}$ days after the date on which the Council receives such notification.

(b) REVIEW BY THE SECRETARY.-The Secretary shall review any fishery management plan, and any amendment to $a_{y}$ such plan, prepared by any Council and submitted to him to determin ${ }_{e}$ whether

it is consistent with the national standards, the other provisions of this Act, and any other applicable law. In carrying out such review,

(1) the Secretary of State with respect to foreign fishing;

(2) the Secretary of the department in which the Coast Guard is operating with respect to enforcement at sea.

(c) PREPARATION BY THE SECRETARY.-(l) The Secretary may prepare a fishery management, plan, with respect to any fishery, or an ards, the other provisions of this Act, and any other applicable law, if--

(i) the appropriate Council fails to develop and submit to the Secretary, after a reasonable period of time, a fishery managea plan, if such fishery requires conservation and management

or

(B) the Secretary disapproves or partially disapproves any such plan or amendment, and the Council involved fads to change under subsection (a) (2)

In preparing any such plan or amendment, the Secretary shall consult with the Secretary of State with respect, to foreign fishing and with the Secretary of the department in which the Coast Guard is operating with respect to enforcement at sea.

(2) Whenever, pursuant to paragraph (1) the Secretary prepares a fishery management plan or amendment, the Secretary shall promptly transmit such plan or amendment to the appropriate Council for consideration and comment. Within 45 days after the date of receipt of such plan or amendment, the appropriate Council may recommend, to the Secretary, changes in such plan or amendment, consistent with
the national standards, the other provisions of this Act, and any other applicable law. After the expiration of such 45-day period, the Secretary may implement such plan or amendment pursuant to section 305 . (3) Notwithstanding paragraph (I), the Secretary may not include in any fishery management plan, or any amendment to any such plan prepared by him, a provision establishing a limited access system described in section 303(b) (6), unless such system is first approved by a majority of the voting members, present and voting, of each appropriate Council.

(d) ESTABLISHMENT OF FEES.-The Secretary shall by regulation Regulations. establish the level of any fees which are authorized to be charged pursuant to section 303(b) (1). Such level shall not exceed the administrative costs incurred by the Secretary in issuing such permits.

(e) FISHERIES RESEARCH-The Secretary shall initiate and maintain a comprehensive program of fishery research to carry out and further the purposes, policy, and provisions of this Act. Such program shall be designed to acquire knowledge and information, including statistics, on fishery conservation and management, including, but not limited to, biological research concerning the interdependence of fishcries or stocks of fish, the impact of pollution on fish, the impact of wetland and estuarine degradation, and other matters bearing upon the abundance and availability of fish.

f) MISCELLANEOUS DUTIES.-(1) If any fishery extends beyond the geographical area of authority of any one Council, the Secretary may.-

(A) designate which Council shall prepare the fishery management plan for such fishery and any amendment to such plan; or 

(B) may require that the plan and amendment be prepared
jointly by the councils concerned.

No jointly prepared plan or amendment may be submitted to the Secretary unless it is approved by a majorityf the voting members, present and voting, of each Council concernel

(2) The Secretary shall establish the boundaries between the geographical areas of authority of adjacent Councils.

16 USC 1855. SEC. 305. IMPLE.MENTATION OF FISHERY MANAGEMENT PLANS.

Publication in (a) INGENERAL. $-A s$ soon as practicable after the Secretary-

(1) approves, pursuant to section

(2) repares, pursuant to section $30-\mathrm{i}(\mathrm{c})$, any fishery management pran or amendment :

the Secretary shall publish in the Federal Register (A) such plan or umendment, and (II) any regulations which he proposes to promuloate toimplement such plan or amendment. Interested persons shall be afforded a period of not less than 45 days after such publication within which to submit in writing data, views, or comments on the plan or amendment, and on the proposed regulat ions.

(b) He.IRING.-The Secretary may schedule a hearing, in accordance With sect ionir. B of title 5. . mited States (ode. on any fishery management plan, any amendment to any such plan, and any regulat ions to implement any such plan or amendment. If any such hearing is sherluled, the Secretary may, pending its outcome-

(A) postpone the effective date of the regulations proposed to

implement such plan or amendment: or

(B)take such other action as he deems appropriate to preserve the rights or status of any person.

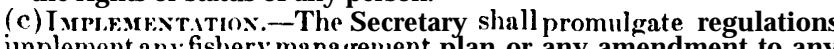
to implement any fishery management plan or any amendment to any unch plan-

(1) after consideration of all relevant matters-

(A) presented to him during the 45-day period referred in subsection (a) and

(B) produced in any hearing held under subsection (b);

(2) if he finds that the plan or amendment is consistent with the national standards, the other provisions of this Act, and any other applicable law.

To the extent practicable, such regulations shall be put into effect in a manner which does not disrupt the regular fishing season for any fishery.

(d).Jupicin Rrvirw.-Regulations promulgated by the Secretary under this Act shall be subject to judicial review to the extent authorized by. and in accordance with, chapter 7 of title 5 . United States Code if a petition for such review is filed within $30 \mathrm{dy}$ after the date on whel the rogulations are romulgated: except that (1) date on which the regulations are romulgated: except that (1) section ias of such title is not applicatle, and (2) the appropriate court $706(\mathrm{P})(\mathrm{A}),(\mathrm{B}),(\mathrm{C})$. or (D) of such title

(e) EMERcescy. Actows. If the Secretary finds that an emergency involvingany fishery resources exists, he may-

(1) promulgate emergency regulations, without regard to subsections (a) and (c), to implement any fishery management plan if such emergency so requires: or

(2) romulgate emergency regulations to amend any regulation $w$ ich implements any existing fishery management plan, to the extent required by such emergency.
Any emergency regulation which changes any existing fishery management plan shall he treated as an amendment to such plan for the period in which such regulation is in effect. Any emergency reguation promulgated under this subsection (A) shall be published in the Federal Register together with the reasons therefor; (B) shall remain in effect for not more than 45 days after the date of such publication. except that any such regulation may be repromulgated for one additional period of not more than 45 days; and (C) may be terminated by the Secretary at any earlier date by publication in the Federal Register of a notice of termination.

(f) ANNunL RePorT.-The Secretary shall report to the Congress and the President. not later than March 1 of each year, on all activities of the Councils and the Secretary with respect to fishery management plans, regulations to implement such plans, and all other activities that were undertaken under this $A$ ct during the preceding calendar year.

(g) RFSPONSIBIIITY of THE SFicRETARY.-The Secretary shall have genera] responsibility to carry out any fishery management plan or amendment approved or prepared by him, in accordance with the provisions of this Act. The Secretary may promulgate such regulaas may be necessary to discharge such responsibility or to carry out any other provision of this Act.

\section{SEC. 308. STATE J URISDICTION.}

(a) In General.-Except as provided in subsection (b), nothing in this Act shall be construed as extending or diminishing the jurisdiction or authority of any State within its boundaries. No State may directly or indirectly:egulate any fishing which is engaged in by any fishin ${ }_{g}$ vessel outsi arits houndaries, unless such vessel is registered under the laws of such State.

(b) E X EM O N.-(1) If the Secretary finds, after notice and an Notice, hearing. opportunity for a hearing in accordance with section $\mathbf{5 5 4}$ of title 5 , United States Code, that -

(A) the fishing in a fishery, which is covered by a fishery management plan implemented under this Act, is engaged in predominately within the fishery conservation zone and beyond such zone; and

(B) any State has taken any action, or omitted to take any

action, the results of which will substantially and adversely affect the carrying out of such fishery maria gement plan;

the Secretary shall promptly notify such state and the appropriate Council of such finding and of his intention to regulate the applicable fishery within the boundaries of such State (other than its internal waters), pursuant to such fishery management plan and the regulations promulgated to implement suchplan.

(2) If the Secretary, pursuant to this subsien, assumes responsibility for the regulation of any fisherv, the State involved mav at any time thereafter apply to the Secretary for reinstatement of its authority over such fishery. If the Secretaryfinds that the reason for which he assumed such regulation no onger prevail, he shall

\section{SEC. 307. PROHIBITED ACTS.}

It is unlawful-

(1) for any person-

(A) to violate any provision of this Act or any regulation or permit issued pursuant to this Act;

90 STAT. $35 S$

Publication in

ublication in Federal RegisReport to Congress and

Regulations.

16 USC 1856.

Notice 
Pub. Law 94-265 - $26 \quad-\quad$ April 13, 1976

(B) to use any fishing vessel to engage in fishing after the revocation, or during the period of suspension, of an applicable permit issued pursuant to this Act;

(C) to violate any provision of, or regulation under an applicable governing international fishery agreement entered into pursuant. to section 201 (c)

(D) to refuse to permit any officer authorized to enforce the provisions of this Act (as provided for in section 311) to board a fishing vessel subject to such person's control for purposes of conducting any search or inspection in connection with the enforcement of this Act or any regulation permit, or agreement referred to in subparagraph (A) or

(E) to forcibly assault, resist, oppose, impede. intimidate, or interfere with any such authorized officer in the conduct of any search or inspection described in subparagraph (D) (F) to resist a lawful arrest for any act prohibited by this
section;

(G) to ship. transport. offer for sale, sell, purchase, import. export, or have custody, control. or possession of. any fish permit, or agreement referred to in subparagraph (A) or (C) : or

(H) to interfere with. delay, or prevent, by any means, the apprehension or arrest of another person, knowing that the apprehension or arrest of another person, knowing that
such other person has committed any act prohibited by this sect ion: and

(2) for any vessel other than a vessel of the Inited States. and for the owner or operator of any vessel other than a ressel of the Cnited States, to engage in fishing-

(A) within the boundaries of any State: or (B) within the fishery ronseriation zone. or for any anadromous species or Cent inentalsheif fishery resource heyond such zone, unless such fishing is anthorized by, and issued pursuant to section 204 (b) or (c).

\section{USC 1858. SEC 308. CIVIL PENALTIES.}

(a) Issrssinext of Prondr.-Any person who is found by the Secret arv, after notice and añ opportunity for a hearing in accordance with sert ion 5.54 of title5. T nited States Core. to hare committed an

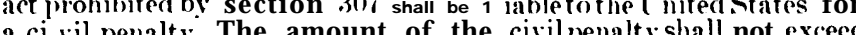
a ci ril penalty
$\$ 95,000$ for each violat ion. Each day of a continuing violation shall constitute a separate offense. The amount of such civil penalt $y$ shall he assessed by the Secretary, or his designee, by written notice. In determining the amount of such penalty, the secretary slall take into account the nature ci rcumstances. extent. and graity of the into accomit the nature eircunstances. extent. and graviog of the degree of culpability, any history of prior offenses, ahil it y to pay. and such other matters as justice rim?- requi re

(b) Rrvirw of Civit. Provitr.-1 n\}' person against whom a civil (b) Rlty is assessed under sulseet ion (a) may obtain review thereof in the appropriate court of the Ynitedstates by filing a notice of appeal in sucheourt $w$-it $h i n 30$ days from the date of suchorder and by simultaneously sending a copy of such notice bycertified mail to the Secretary. The Secretary shall promptly file in such court a
cert i ficd copy of the record upon which such violation was found
April 13, $1976 \quad-27-\quad$ Pub. Law 94-265

or such penalty imposed, as provided in section 2112 of title 28 United States Code. The findings and order of the Secretary shall be set aside by such court if they are not found to be supported by substantial evidence, as provided in section 706(2) of title 5, United States Ode.

(c) Action Lox Failcte To Pay Assessanent-If any person fails to pay an assessment of a civil penalty after it has become a fina and unappealable order, or after the appropriate court has entered final judgment in favor of the secretary, the Secretary shall refer the matter to the Attorney General of the United States, who shall recover the amount assessed in any appropriate district court of the United order imposing the civil penalty. shall not be subject to review.
oritate

(d) Com PRomise or OTIER X (TiON by SECRETaRY.-The secretary may compromise, modify, or remit, with or without conditions, an "ill penaltywhich is st

SEC. 309. CRIMINAL OFFENSES

(a) Orrzsses.- I person is guilty of an offense if he commits any act prohibited by-

$$
\begin{aligned}
& \text { (1) section 307(1) (D), (E), (F), or (H) ; or } \\
& \text { (2) section } 307(2) \text {. }
\end{aligned}
$$

(b) Prismmext-Any offense described in subsection (a) (1) is punishable by a fine of not more than $\$ 50.000$. or imprisonment for not more than 6 months, or both; except that if in the commission of any such offense the person uses a dangerous weapon, engages in conduct that causes bodily injury to any officer authorized to enforce the provisions of this Act (as provided for in section 311), or places any such officer in fear of imminent bodily injury, the offense is punishable by a fine of not more than $\$ \mathbf{1 0 0 . 0 0 0}$, or imprisonment for not more than 10) years, or both. Any offense described in subsection (a) (2) is punishable by a fine of not more than $\$ 100,000$, or imprisonment for not more than 1 year, or both.

(c) Jurispictiox.-There is Federal jurisdiction over any offense described in this section.

\section{SEC. 310. CIVIL FORFEITURES.}

(a) IN (ikNFral.-Any fishing vessel (including its fishing gear, furniture. appurtenances. stores. and cargo) used. and any fish taken or retained, in any manner. in connection with or as a result of the commission of any act prohibited by section 307 (other than any act for which the issuance of a citation under section 311 (c) is sufficient Ull or part of such vessel may. and all such fish shall. be forfeited to the nited States pursuant to a civil proceeding under this section.

(b) Jirisdictiox of Cocres. - Iny district court of the United States which has jurisdiction under section 311 (d) shall have jurisdiction. upon t-application by the Attorney General on behalf of the United States, to order any forfeiture authorized under subsection (a) and any action provided for under subsection (d)

(c) J IDGMExT. - If a judgment is entered for the United States in a civil forfeiture proceeding under this section. the Attorney General may seize any property or other interest declared forfeited to the Cnited States. which has not previously been seized pursuant to this Act or for which security has not previously been obtained under subsection (d). The provisions of the customs laws relating to(1) the disposition of forfeited property,

(2) the proceeds from the sale of forfeited property, 
(:) the remission or mitigation of forfeitures, and (4) the compromise of claims,

shall apply to any forfeiture ordered, and to any case in which forfeiture is alleged to be authorized, under this section, unless such provisions are inconsistent with the purposes, policy, and provisions of this $\Lambda$ ct. The duties and powers imposed upon the Commissioner of Customs or other persons under such provisions shall, with respect to this Act, be performed by officers or other persons designated for such purposeby the Secretary.

(d) ProcFinc Rr.- - (1) Any officer authorized to serve any process in em which is issued by a court having jurisdiction under section 311 d) shall-

(A) stay the execution of such process; or

(B) discharge any fish seized pursuant to such process;

upon the receipt or a satisfactory bond or other security from any person claiming such property. Such bond or other security shall be appropriate court upon order thereof, without any impairment of appropriate court uponorder (hereof, without any impainent of its to an order of such court. Jud tar or other security against both the principal and any sureties in erent that any condition thereof is breaced, as determined by such

(2) Any fish seized pursuant to this Act may be sold. subject to the fair market ralue thereof, The proceeds of anv such sale shall be deposited with stich court pending the disposition of the matter involved.

(e) Rerittrabia Presumption,-For purposes of this section, it shall be a rebuttable presumpt ion that all fish found on board a fishing ressel which is seized in connect ion with an act prohibited by section 307 were taken or retained in violation of this . Act.

16 USC 1861. SEC. 311. ENFORCEMENT.

(a) RrsponsiniLITY.-The provisions of this $A$ ct shall be enforced Ci huard is operating such Secretaries may by agrement, on reimburalue basis or otherwise, utilize tI IF personie servics, oquip ment (including aircraft and ressels), and facilities of any other Federalagemer inclucling all elements of the Department of Defense. and of any secretaries shall report semianumally to each committee of tile Congress listed in section $203(b)$ and to the Councils, on the degree and extent of known and est i mated Compliance with the provisions of this Art.

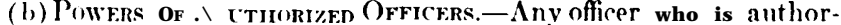
ized (bythe Secretary, the Secretary of the department in which the Const Guard is operiting. or the head of any Federal or State agency which has entered into an agreement with such Secretaries under subsect ion (a ) ) toen force the provisions of th is Act n]ay-

(1) withor without a warrant or other process-

(.1) arrestany person, if he has reasonable cause to believe 307

(B) board, and search or inspect, any fishing vesselwhich is subject to the provisions of this . Iet: (C) seize any fishing ressel (together with its fishing gear.
furniture, appurtenances. stores, and cargo) used or employed

90 STAT. 358 in, or with respwet to which it reasonably appears that such vessel was used or employed in, the violation of any provi(D) seize any

(D) seize any fish (wherever found) taken or retained in iolat ion of any provision of this Act; and

(E) seize any other evidence related to any violation of anverovision of this Ict;

(2) execess issued by any court (3) exercise any. othe

(c) Issiance of CITATIONs.-If any officer authorized to enforce the provisions of this. Ict (as provided for in this section) finds that a fishing vessel is operating or has been operated in violation of any provision of this Ict, such officer may, in accordance with regulations issued jointly bythe Secretary and the Secretary of the department in which the ('east ('iuard is operating, issue a citation to the owner or operator of such ressel in lieu of proceeding under subsection (b). If a permit has been issued pursuant to this Act for such vessel, such officer shall note the issuance of any citation under this subsection incer shall note the issuance of any citation under this subsection, Secretary shall maint ain a record of all citations issued pursuant to this subsection.

(d) J J risdiction of Cotros.-The district courts of the United States shall have exclusice jurisdiction over any case or controversy arising under the provisions of this $\mathbf{A c t}$. In the case of Guam, and any (Commonwealth, territory, or possession of the InitedStates in the Pacific Ocean, the appropriate court is the United States District Court for the District of Guam, except that in the case of American Simoa, the appropriate court is the United States District Court for the I istrict of Hawaii. Any such court may, at any time-

(1) enter restraining orders or prohibitions;

(2) issue warrants, process in rem, or other process; and

(4) take such other actions as are in the interest of justice.

(e) I) EFinition.-For purposes of this section-

(1) The term "provisions of this Act" includes (A) any regulation or permit issued pursuant to this Act, and (B) any provision of, or regulation issued pursuant to, any international fishery agreement under which foreign fishing is authorized by section 201 (b) or (c), with respect to fishing subject to the exclusive fishery management authority of the Inited States.

(2) The term "violation of any provision of this Act" includes (A) the commission of any act prohibited by section 307 , and $(B)$ the violation of any regulation, permit, or agreement referred to in paragraph (1).

SEC. 312. EFFECTIVE DATE OF CERTAIN PROVISIONS.

16 USC 1857

Sections 307, 308,309, 310, and 311 shall take effect March 1, 1977. note.

TITLE IV-MISCELLANEOUS PROVISIONS

\section{SEC. 401. EFFECT ON LAW OF THE SEA TREATY.}

If the Inited States ratifies a comprehensive treaty, which includes provisions with respect to fishery conservation and management jurisdiction, result ing from any Inited Nations Conference on the Law of the Sea, the Secretary. after consultation with the Secretary of State may promulgate any amendment to the regulations promulgated under this Act if such amendment is necessary and appropriate to

90 STAT. 359 
Pub. Law 94-265 $\quad-30-\quad$ April 13, 1976

conform such regulations to the provisions of such trenty, in antic $\dot{p}_{2}$ tion of the date when such treaty shall come into force and effectfor, or otherwise be applicable to, theU nited States.

SEC. 402. REPEALS.

(a) The Act of October 14,1966 (16 U.S.C. 1091-1094), is repealed as of March 1, 1977

as of March 1, 1977 .

SEC. 403. FISHERMEN'S PROTECTIVE ACT AMENDMENTS.

(a).\& MENDMENTs.-The I c't of August 27, 1954 (22 II.S.C. 1972), is amen(led-

(1) bumending section 2 thereof to read as follows: "Src. 2. If -

“(1) any vessel of the Inited States is seized by a foreign country on the basis of claims in territorial waters or the $h \stackrel{a}{a}$ seas which are not recognized by the 1 nited States: or

"(2) any general claim of any foreign countrv to exclusive fishery management aut hority is recognized by the United States, and any ressel of the 'nited States is seized by such foreign country on the lasis of conditions and restrictions under such

$*(A)$ are unrelated to fishery conservation and manage-

"(i) fail to consider and take into account trarlitional fishing practices of vessels of theUnited States,

"(C) are greater or more onerous than the conditions and restrictions which the I"nited States applies to foreign fishing vessels subject to the exclusive fishery management authority of the nited.states (as established $m$ titlel of the ishery (onservarion and $M$ anagement $\Lambda$ ct of 1976 ). Or

"( I)) fail to allow fishing ressels of the Inited States fishery management authority; and there is nodispute as to the material facts with respect to the Secret ary of State shall immediately take such steps aze necessary- - - for the protection of such vessel and for the health "(i) for the protection

and wel fare of its crew: "(iii) to determine the amount of anv fine. license. fee. reoist ration fee, or other direct charge rein] ursable under section $3(\mathrm{n})$ of this ict. ": and muse 1973. $\begin{array}{r}(2) \text { bramending section } 3(a) \text { thereof by inserting immediately } \\ \text { before tile last sentence thereof the following new sentence: " } F \text { or }\end{array}$ purposes of this section, the term 'other direct charee means any pry.however characterized or computed (including. hut not limited to. any computation based on the value of a ressel or the value of fish or other proper-t $y$ on hoard a vessel). which is imposed in addition to any fine. license fee, or registration fee."

22 USC 1972 (b) FFFr'TIriI D.ITF.-The amendment made by subsection (a) (1) $\begin{array}{ll}\text { note } & \text { shall take effect March } 1.1977 \text {. The ameniment made by subsect ion } \\ 22 & \text { (a) (2) shall apply with respect to seizures of vessels of the Tnited }\end{array}$ note. States occurring on or a ftcr Decemlier 31.1974.

\section{SEC. 404. MARINE MAMMAL PROTECTION ACT AMENDMENT.}

(a) Ampondrant.-Section 3(15) (I3) of the Marine Mammal Protection Act of 1972 (16 U.S.C. 1362(15) (B) ) is amended by striking

90 STAT. 360
April 13, 1976
- 31 -
Pub. Law 94-265

out the fisheries zone establishedpursuant to the $\mathrm{Act}$ of October 14 1966." and inserting in lieu thereof "-the waters included within a zone, contiguous to the territorial sea of the Cnited states, of which the inner boundary is a line colderminous with the seaward boundary of each coastal state, and tile outer boundary is a line dra wn in such a manner that eachpoint on it is $2(10$ nautical iniles from the baseli ne from which the territorial seat is measured.".

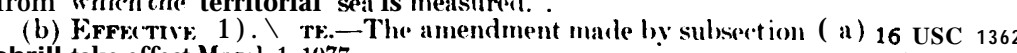
shrill take effect March 1, 1977

ACT AMENDMENT.

(a) AMENDMENT.-Section 2(4) of the Atlantic Tunas ('on \}. ention Act of 1975 (16 U. S.( (.971 (4)) is amended by striking out "the fisheries zone established pursuant to the Act of October 14, 1966 ( 80 Stat. 908; 16 U.S.C. $1091-1094), "$ and inserting in lieu thereof "the waters included within a zone, contiguous to the territorial sea of the United States, of which the inner boundary is a line coterminous with the seaward boundar of each coastal State, and the outer boundary is a line drawn in such a manner that each point on it is 200 nautical miles from the baseline from which the territorial sea is measured." (b) EFFECTIVE 1).I r.-The amendment marle by subsection ( $\boldsymbol{x}$ ) shall take effect March 1,1977.

SEC. 406. AUTHORIZATION OF APPROPRIATIONS.

There are authorized to be appropriated to the Secretary].. for purposes of carrying out the provisions of this Act. not to exceed the followingsums:

(1) $\$ 5,000+) 00$ for the fiscal year ending J une 30,1976 .
(2) $\$ 5,000,000$ for the transitional fiscal quarter ending September 30,1976 .

(3) \$25,000,000 for the fiscal year ending September 30, 1977

(4) $\$ 30,000,000$ for the fiscal year ending September 30,1978.

Approved April 13, 1976.

LEGISLATIVE HISTORY

HOUSE REPORTS: No. 94445 (Comm. on Merchant Marine and Fisheries)

SENATE REPORTS: No. 94-416 (Comm. on Commerce), No. 94-4S9

(Comm. on Foreign Relations) and No. 94-515

(Comm. on Armed Services) all a c companyin

CONGRESSIONAL RECORD:

Dec. 19, S, 961 considered in Senate.

Vol. 122 (1976) Jan. 19-22, 27, S. \%1 considered in Senate.

Jan. 28 , considered and passed Senate, amended,
in lieu of $S . \% 1$.

Mar. 29, Senate agreed to conference report.

WEEKLY COMPILATION OF PRESIDENTIAL DOCUMENTS

Vol. 12, No. 16 (1976) Apr. 13, Presidential statement.

90 STAT. 361

note. 971 